\title{
'How to describe the functional health status of children with otitis media'
}

Citation for published version (APA):

Timmerman, A. A. (2008). 'How to describe the functional health status of children with otitis media'. [Doctoral Thesis, Maastricht University]. Datawyse / Universitaire Pers Maastricht. https://doi.org/10.26481/dis.20080118at

Document status and date:

Published: 01/01/2008

DOI:

10.26481/dis.20080118at

Document Version:

Publisher's PDF, also known as Version of record

\section{Please check the document version of this publication:}

- A submitted manuscript is the version of the article upon submission and before peer-review. There can be important differences between the submitted version and the official published version of record.

People interested in the research are advised to contact the author for the final version of the publication, or visit the DOI to the publisher's website.

- The final author version and the galley proof are versions of the publication after peer review.

- The final published version features the final layout of the paper including the volume, issue and page numbers.

Link to publication

\footnotetext{
General rights rights.

- You may freely distribute the URL identifying the publication in the public portal. please follow below link for the End User Agreement:

www.umlib.nl/taverne-license

Take down policy

If you believe that this document breaches copyright please contact us at:

repository@maastrichtuniversity.nl

providing details and we will investigate your claim.
}

Copyright and moral rights for the publications made accessible in the public portal are retained by the authors and/or other copyright owners and it is a condition of accessing publications that users recognise and abide by the legal requirements associated with these

- Users may download and print one copy of any publication from the public portal for the purpose of private study or research.

- You may not further distribute the material or use it for any profit-making activity or commercial gain

If the publication is distributed under the terms of Article $25 \mathrm{fa}$ of the Dutch Copyright Act, indicated by the "Taverne" license above, 
'How to describe the functional health status of children with otitis media' 
ISBN 978-90-5278-674-2

(C) Copyright AA Timmerman, Maastricht 2008 


\title{
'How to describe the functional health status of children with otitis media'
}

\author{
PROEFSCHRIFT
}

Ter verkrijging van de graad van doctor aan de Universiteit Maastricht, op gezag van de Rector Magnificus, Prof. mr. G.P.M.F. Mols

volgens het besluit van het College van Decanen,

in het openbaar te verdedigen op

vrijdag 18 januari 2008 om 12 uur

door

Angelique Antonius Timmerman

$\underbrace{(101}_{\substack{\text { UNIVERSITAIRE } \\ \text { PERS MASTRICHT }}}$ 


\section{Promotor}

Prof. dr. J.J. Manni

\section{Co-promotoren}

Dr. L.J.C. Anteunis

Dr. C.M.G. Meesters

\section{Beoordelingscommissie}

Prof. dr. B. Kremer (voorzitter)

Prof. dr. G.J. Dinant

Mw. dr. A.T.M. van Zeben - van der Aa

Prof.dr. L. Zimmerman

The Heinsius Houbolt Foundation and the Maastricht ENT Research Foundation financially supported the studies described in this thesis. Publication and distribution of this thesis was financially supported by the Stichting Atze Spoor Fonds. 
Wanneer je een schip wilt gaan bouwen, breng dan geen mensen bijeen om timmerhout te sjouwen of te tekenen alleen. Voorkom dat ze taken ontvangen, deel evenmin plannen mee maar laat eerst de mensen verlangen naar de eindeloze zee.

Antoine de Saint Exupéry

Aan hen op wie ik heb mogen 'leunen' bij het hervinden van inspiratie... 



\section{Contents}

Chapter 2 Psychometric qualities of questionnaires for the assessment of functional health status in otitis media

Timmerman AA, Anteunis $L C$, Speyer $R$, Meesters $C M G$.

Clinical Otolaryngology. 2007;32, 1-11.

Chapter 3 The initial development of an instrument for the description of 'otitis media with effusion specific behavior' in young children

Timmerman AA, Anteunis $U C$, Meesters CMG.

International Journal of Behavioral Medicine. 1999;6:255-267.

Chapter 4 First psychometric evaluation of a disease-specific questionnaire for children's behaviour related to otitis media with effusion

Timmerman AA, Anteunis $U C$, Meesters CMG.

Psychological Reports. 2005;97:819-831.

Chapter 5 Response-shift bias and parent-reported quality of life in children with otitis media Timmerman AA, Anteunis $\amalg C$, Meesters CMG.

Archives of Otolaryngology—Head \& Neck Surgery. 2003;129:987-991.

Chapter 6 Psychometric evaluation of the OM8-30 questionnaire in Dutch children with otitis media

Timmerman AA, Anteunis LC Chenault MN, Meesters CMG, Haggard MP. European Archives of Oto-Rhino-Laryngology and Head \& Neck Surgery: in review process.

Chapter 7 The level of psychosocial adaptation of young school children with otitis media

Timmerman AA, Meesters CMG, Anteunis, LC, Chenault MN. International Journal of Pediatric Otorhinolaryngology: in press. 
Chapter 8 General discussion and conclusions

$\begin{array}{ll}\text { Summary } & 131\end{array}$

$\begin{array}{lr}\text { Samenvatting } & 139\end{array}$

$\begin{array}{ll}\text { Dankwoord } & 147\end{array}$

$\begin{array}{ll}\text { Publication list } & 153\end{array}$

$\begin{array}{ll}\text { Questionnaires } & 157\end{array}$

$\begin{array}{lr}\text { Curriculum vitae } & 159\end{array}$ 


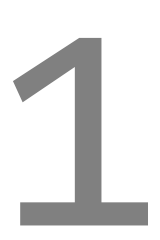

General introduction and outline 



\section{Background}

\section{Epidemiology of otitis media}

Otitis media (OM) is a worldwide paediatric health care problem and nearly all children have experienced at least one episode of middle ear effusion (MEE) by the age of three. ${ }^{1,2} \mathrm{MEE}$ is present in both acute $\mathrm{OM}$ and chronic $\mathrm{OM}$. Acute $\mathrm{OM}$ is a condition that combines the presence of MEE with the rapid onset of acute symptoms of inflammation of the middle ear, while chronic $\mathrm{OM}$ is characterized as an asymptomatic condition causing a mild and conductive hearing loss due to MEE present in the middle ear behind an intact tympanic membrane. ${ }^{3}$ Chronic OM may result from an episode of acute $\mathrm{OM}$ or may be described as newly diagnosed chronic OM of unknown duration resulting from poor Eustachian tube function often persisting for weeks or months. ${ }^{4} \mathrm{OM}$ is defined as a self-limiting condition with high rates of spontaneous resolution, although in chronic OM this likelihood depends on the OM type present. In cases of chronic OM persisting after acute $\mathrm{OM}$, the resolution rates by ear are reported to be high with $75 \%$ after 3 months and 90\% after 6 months, while for chronic OM with unknown onset and duration bilateral resolution rates have been found to be $30 \%$ and $40 \%$, respectively. Chronic OM lasting 3 months or longer shows bilateral resolution rates of only $25 \%$ after 6 months. ${ }^{5}$ It seems that children with chronic OM fall into two categories: most children get better within a few months without any medical intervention but a subgroup does not, due to the persistent and recurrent nature of the disease. ${ }^{6}$ This subgroup will continue to suffer a conductive hearing loss over time, which can be classified as mild to moderate, with a mean loss of approximately $27 \mathrm{~dB} \mathrm{HL}(\mathrm{SD}=13 \mathrm{~dB})$ as measured by pure tone audiometry $(0.5,1,2,4 \mathrm{KHz})$ across childhood. ${ }^{7,8}$ It is comparable with putting plugs in the ears, causing a risk of softer speech sounds and voiceless consonants to be missed. ${ }^{9}$

\section{Developmental effects of otitis media}

For more than 30 years research has been conducted examining whether the persistence of $O M$ affects child development, starting with the early speculations that very young children with chronic OM were likely to experience prolonged periods of intermittent hearing loss that might affect language development. ${ }^{10,11}$ In the Global Language Model hearing loss is a causal variable that may affect early language acquisition due to the assumption that there is a 'critical period' during which normal hearing is necessary. In these first two or three years of speech and language development, the incidence of OM and prevalence of MEE 
are the highest. ${ }^{12}$ Several initial retrospective studies, using language performance tests and school achievement measures, have found that children with a history of chronic OM compared with children without such a history in early childhood have language and academic problems later in childhood. ${ }^{13,14}$ These studies, however, suffered from methodological shortcomings, due to using parent report and medical records for the assessment of OM presence and the lack of reliable hearing data in young children. Hearing loss is intermittent between and within episodes and varies between children, which makes it a construct difficult to assess over time. ${ }^{15}$ Although it did not become clear how long the hearing loss has to persist before development is affected, these first studies using the Global Language Model have been an important precursor for further research of developmental effects of chronic $O M$.

More recent models stress the influence of multiple factors in conjunction with the OM experience during early development. The Contextual Transactional Model developed by Roberts ${ }^{12,16}$ and the Interactive Language and Attention Model of Feagans ${ }^{15,17}$ are quite similar and consider hearing loss as the causal mediating variable in $\mathrm{OM}$ impact and attempt to counter the shortcomings of the Global Language Model in three ways. ${ }^{15}$ First, the early and later developmental effects are considered separate for two reasons. It is hypothesized that language functions will recover later in childhood because of their strong biological basis. ${ }^{18}$ Also, children older than 6 years may experience improvement of their hearing, due to the bimodal peaks in age distribution at 2 and 5 years ${ }^{19,20}$ which implies that any long-terms effects of OM may not be directly related to language development. Children with chronic OM in early childhood may have developed a coping style through which they have learned to attend to the less auditory parts of the environment, resulting in problems with sustained attention to oral language. This may imply negative effects on complex speech processes, i.e., comprehension of extended discourse in conversation or story telling. Also the use of pragmatics, which is knowing how to use certain language forms and nonverbal communication, may be less developed. The second feature of the models stress the bidirectional character of effects, as children with chronic OM may influence the patterns of interaction with peers and adults by avoiding situations with many children talking or with background noise, resulting in a less responsive home environment early in life. Third, the models include several risk or protective factors under which conditions $O M$ could result in negative developmental outcomes (i.e., quality of day-care, caregiver sensitivity, child temperament/IO and ambient noise). These may serve as moderating variables interacting with chronic $\mathrm{OM}$ and representing conditions under which negative outcomes can occur. For instance, children with chronic OM suffering from hearing loss, could 
be buffered against negative effects by more one-to-one interactions and a caregiver sensitive to the child's reduced hearing.

Some consistent effects of chronic OM have been reported on pragmatics ${ }^{21-24}$ and attention-related behaviours, ${ }^{25-27}$ both in early childhood and at school age, resulting in more limited use and quality of verbal language compared to other children. Although these studies both seem to support the abovementioned models, considerable controversy exists due to methodological differences between studies. In a review on this topic, Roberts et al. ${ }^{16}$ described some issues that need to be addressed in future studies: (1) statistical control for cumulative risk factors related to OM and developmental effects, as quality of day care and responsiveness of the home environment were found to be moderate in study outcomes, and (2) longitudinal studies, incorporating measures that not only assess developmental outcomes at different ages, but also document the duration and amount of hearing loss over time, assessing possible threshold effects.

It is therefore necessary to identify the children most at risk, considering $\mathrm{OM}$ and concomitant hearing loss as continuous variables. This could prevent that children suffering from short or recurrent OM mask the presence of any developmental effects resulting from persistent hearing loss.

\section{Clinical management issues in otitis media}

The most common treatment for chronic $O M$ is the insertion of tympanostomy tubes, with the goal of restoring normal hearing, reducing MEE prevalence and OM recurrence rates. ${ }^{3}$ Surgery rates seem to reflect the evolution in the field of research related to the effects of chronic OM on child development. In most western countries, surgery for chronic OM had become the most common reason for surgery in children around 1980, due to concern about adverse developmental effects. ${ }^{28,29}$ The appropriateness of these high surgery rates was increasingly questioned between 1985 and $1990^{30}$ for several reasons, among which the most important was that rates of spontaneous recovery were high for chronic $\mathrm{OM}$ and no evidence was found for adverse consequences of no treatment. ${ }^{20,32}$ After 1990 several randomised controlled trials (RCTs) were conducted, including treatment (i.e., tympanostomy tubes alone or combined with adenoidectomy) versus watchful waiting conditions. ${ }^{32,33}$ In an individual patient meta-analysis of 7 RCTs only short term improvements on hearing were reported, with no differences at 12 and 18 months follow-up, while language development showed no differences between 6-9 and 12-18 months follow up. ${ }^{3}$ One of the limitations of these studies is that in most trials children with relatively asymptomatic MEE were included, often recruited from the general population by screening programs. ${ }^{20,34}$ Also, in 
several RCTs children (11\%-85\%) in the watchful waiting condition received surgery during the trial due to ethical concerns. ${ }^{3}$

It is recognised that RCTs included mostly children with uncomplicated episodes of $\mathrm{OM}$, with low co-morbidity and high rates of spontaneous resolution, which is not the group of children that may benefit the most from surgery. 2,35 Attention has been given to individual treatment decisions by using terms such as the 'otitis-prone child' or 'child at risk' and Rosenfeld ${ }^{35}$ states: 'optimal surgical outcomes are most likely to occur if the right child has the right surgery' (p. 317). Selecting 'the right child' is difficult because the OM history prior to diagnosis is often unknown because associated symptoms may have been absent or minimal, which may explain the lack of consensus on treatment. ${ }^{36}$ The clinical guideline states that for hearing levels between 21 and $39 \mathrm{~dB}$, the range of mild hearing loss present in chronic $\mathrm{OM}$, individualised management is necessary, depending on effusion duration, severity of hearing loss and caregiver preference. It is also recommended that several aspects are considered in auditory assessment: (1) Degree of hearing loss, (2) Temporal pattern of hearing loss, and (3) Impact of hearing loss on everyday child functioning (e.g., speech in noise perception). ${ }^{35,37}$ In the diagnostic process of children with chronic OM the last aspect may be important because the impact of hearing loss not only gives an indication of the morbidity, it can also deliver information about present compromised developmental outcomes. At least, it could support the decision whether a child with chronic OM needs intervention or that the recommended watchful waiting period of 3 months is appropriate. ${ }^{38}$ In clinical practice this information is usually delivered by informal caregiver questioning of the presence of signs or symptoms. ${ }^{39}$

\section{Assessment of otitis media impact}

The information reported by caregivers during clinical assessment has the advantage of being integrated over time. ${ }^{40}$ In chronic $\mathrm{OM}$ it is the overall persistence and severity that is important in both the diagnostic process and the evaluation of treatment effects. Questionnaires are outcome measures that seem most appropriate for this purpose, due to efficiency in time and costs. However, these measures are subjective in nature and need to be validated before any systematic use.

The first pilot study describing the 'chronic OM illness experience' was conducted by Facione in $1991^{41}$, who acknowledged that only using objective measures of physical health status may underestimate OM-related morbidity and impact. That study has been a precursor for a new area of research developed over the past 10 years: attempts have been made to describe the impact of chronic OM on the daily functioning of the parent and child, in order to identify children most at 
risk for adverse developmental outcomes. It started with the emphasis on the assessment of physical symptoms and concrete behavioural signs related to developmental domains. ${ }^{42,43}$ The increasing popularity of the science of quality of life for the assessment of subjective well being in chronic diseases, ${ }^{44,45}$ has later been translated to $\mathrm{OM}$ impact assessment ${ }^{40}$ and is conceptualised as HealthRelated Quality of Life (HROoL). ${ }^{46,47}$ It is often used synonymously with functional health status (FHS) due to the restriction of the definition ${ }^{48}$ to those aspects of Ool influenced by the impairments, functional states, perceptions and social opportunities influenced by health or disease. FHS in chronic OM is assessed by concrete behavioural signs and symptoms, reflecting the physical, psychological and social functioning of the child. ${ }^{49}$

\section{Objective and outline of the thesis}

The main objective of the present thesis is to describe the impact of chronic OM and associated mild hearing loss during childhood, in order to support the identification of children at risk for adverse developmental outcomes.

Specific research objectives are:

(1) Identification and psychometric evaluation of questionnaires developed to assess the impact of chronic OM in children.

In a systematic review, a literature search will be conducted to identify questionnaires developed to describe chronic OM impact, conceptualised as functional health status (FHS) in chronic OM. Psychometric evaluation of the questionnaires will be performed according to predefined quality criteria for measurement properties in questionnaires. (Chapter 2)

(2) Development and psychometric validation of questionnaires to describe specific behavioural characteristics related to chronic OM during childhood.

Two age-specific questionnaires developed for behaviour related to chronic OM in infants (12-48 months) will be described and preliminary analyses conducted to give an indication of the statistical fit of the items in the formulated developmental domains. (Chapter 3)

Subsequently, the psychometric validation of the questionnaires will be carried out in terms of construct validity, reliability (i.e., internal consistency and reproducibility) and responsiveness to clinical change. (Chapter 4) 
The OM8-30 $0^{50}$ questionnaire developed to describe chronic OM impact at school age (3-8 years) will be will be psychometrically validated to confirm the factor structure of the domains in the original English version. The discriminatory ability of the developmental domains of the OM8-30 will be evaluated by means of the correlation pattern with the internalising and externalising behaviour dimensions of the Strengths and Difficulties Questionnaire (SDQ). (Chapter 6)

The ultra short-form OM-6 $6^{47}$ questionnaire, evaluating HROOL in children between 6 months and 12 years, will be psychometrically validated for a Dutch population. (Chapter 5)

(3) Assessment of the effect of a sudden change (i.e., the resolution of $O M$ ) in health status on parental perception of HRQoL.

The presence of response shift bias in parental report, also called scale recalibration, will be evaluated by a retrospective pre-test with the OM- 6 questionnaire after tympanostomy tubes surgery. (Chapter 5)

(4) Describing the level of psychosocial adaptation of school age children with a history of chronic OM.

Assessment of the presence of behavioural deficits at school age with the SDQ ${ }^{51}$, as hypothesized in the Interactive Language and Attention Model, ${ }^{15}$ due to sustained inattention to language during early childhood. (Chapter 7)

This thesis will be concluded with a general discussion, describing implications of the results and recommendations for further research using questionnaires for the assessment of FHS in chronic OM. (Chapter 8) 


\section{References}

1. Casselbrant ML, Mandel EM. Epidemiology. In: Rosenfeld RM, Bluestone CD, eds. Evidence-Based Otitis Media. Hamilton, Canada: BC Decker Inc.; 1999:147-162.

2. Rovers MM, Schilder AGM, Zielhuis GA, Rosenfeld RM. Otitis media. The Lancet. 2004;363:465473.

3. Rovers MM, Black N, Browning GG, Maw R, Zielhuis GA, Haggard MP. Grommets in otitis media with effusion: an individual patient data meta-analysis. Archives of Diseases in Childhood. 2005;90:480-485.

4. Rosenfeld RM, Kay D. Natural history of untreated otitis media. The Laryngoscope. 2003;113:1645-1657.

5. Rosenfeld RM. Natural history of untreated otitis media. In: Rosenfeld RM, Bluestone CD, eds. Evidence-Based Otitis Media. Hamilton, Canada: BC Decker Inc.; 1999:157-177.

6. Rosenfeld RM. Amusing parents while nature cures otitis media with effusion. International Journal of Pediatric Otorhinolaryngology. 1998;43:189-192.

7. Gravel JS. Hearing and auditory function. In: Rosenfeld RM, Bluestone CD, eds. Evidence-Based Otitis Media. Hamilton, Canada: BC Decker Inc.; 1999:342-359.

8. Haggard RS, Primus MA. Parental perceptions of hearing loss classification in children. American Journal of Audiology. 1999;8:83-92.

9. Klein JO. The burden of otitis media. Vaccine. 2001;19:S2-S8.

10. Menyuk P. Effect of persistent otitis media on language development. Annals of Otology Rhinology \& Laryngology. 1980;89:257-263.

11. Northern JL, Downs MP. Hearing in children. $2^{\text {nd }}$ ed. Baltimore (MD), 1978.

12. Vernon-Feagans L, Miccio AW, Yont KM. Speech, language, pragmatics and attention. In: Rosenfeld RM, Bluestone CD, eds. Evidence-Based Otitis Media. Hamilton, Canada: BC Decker Inc.; 2003:360-382.

13. Lehmann MD, Charron K, Kummer A, Keith RW. The effects of chronic middle ear effusion on speech and language development-A descriptive study. International Journal of Pediatric Otorhinolaryngology. 1979;1:137-144.

14. Zinkus PW, Gottlieb MI. Patterns of perceptual and academic deficits related to early chronic otitis media. Pediatrics. 1980;66:246-253.

15. Vernon-Feagans L. Impact of otitis media on speech, language, cognition and behaviour. In: Rosenfeld RM, Bluestone CD, eds. Evidence-Based Otitis Media. Hamilton, Canada: BC Decker Inc.; 1999:353-374.

16. Roberts J, Hunter L, Gravel J, Rosenfeld R, Berman S, Haggard M. et al. Otitis media, hearing loss an language learning: controversies and current research. Developmental \& Behavioral Pediatrics. 2004;25:110-122.

17. Feagans LV, Kipp EK, Blood I. The effects of otitis media on the language and attention skills of day-care attending toddlers. Developmental Psychology. 1994;30:701-708.

18. Ruben RJ. An inquiry into the minimal amount of auditory deprivation which results in a cognitive effect in man. Acta Otolaryngologica. 1981;414:157-164.

19. Engel JAM, Anteunis UC. Treatment with ventilation tubes in the Netherlands: incidence in children from birth to 12 years of age, 1990-1994. Nederlands Tijdschrift voor Geneeskunde. 1999;143:902-905.

20. Zielhuis GA, Rach GH, van den Broek P. Screening for otitis media with effusion in preschool children. The Lancet. 1989;11:311-314. 
21. Feagans L, Sanyal M, Henderson F, Collier A, Appelbaum M. Relationship of middle ear disease in early childhood to later narrative and attention skills. Journal of Pediatric Psychology. 1987;12:581-594.

22. Creps CL, Vernon-Feagans L. Preschoolers social behavior in day care: links with entering day care in the first year. Journal of Applied Developmental Psychology. 1999;20:461-479.

23. Yont KM, Snow CE, Vernon-Feagans L. Early communicative intents in 12-month-old children with and without chronic otitis media. First Language. 2001;16:265-288.

24. Vernon-Feagans L, Hurley MM, Yont KM. The effect of otitis media and day-care quality on mother/child book reading and language use at 48 months. Applied Developmental Psychology. 2002;23:113-133.

25. Roberts JE, Burchinal MR, Koch MA, Footo MM, Henderson FW. Otitis media in early childhood and its relationship to later phonological development. Journal of Speech and Hearing Disorders. 1988;53:416-424.

26. Vernon-Feagans L, Manlove EE, Volling BL. Otitis media and the social behavior of day-careattending children. Child Development. 1996;67:1528-1539.

27. Bennet KE, Haggard MP, Silva PA, Stewart IA. Behaviour and developmental effects of otitis media with effusion into the teens. Archives of Diseases in Childhood. 2001;85:91-95.

28. Padgham N, Mills R, Christmas $\mathrm{H}$. Has the increasing use of grommets influenced the frequency of surgery for cholesteatoma? Journal of Laryngology and Otology. 1989;103:1034-1035.

29. Rob MI, Westbrook JI, Taylor R, Rushworth RL. Increased rates of ENT surgery among young children: have clinical guidelines made a difference? Journal of Pediatrics and Child Health. 2004;40:627-632.

30. Black N. Glue ear: the new dyslexia? British Medical Journal. 1985;290:1963-1965.

31. Casselbrant ML, Brostoff LM, Cantekin El, Flaherty MR, Doyle WJ, Bluestone, CD, et al. Otitis media with effusion in preschool children. Laryngoscope. 1985;95:428-436.

32. Maw R, Wilks J, Harvey I, Peters TJ, Golding J. Early surgery compared with watchful waiting for glue ear and effect on language development in preschool children: a randomised trial. Lancet. 1999;353:960-963.

33. Paradise JL, Feldman HM, Campbell TF, Dollaghan, CA, Colborn, DK, Bernard, BS. et al. Effect of early or delayed insertion of tympanostomy tubes for persistent otitis media on developmental outcomes at the age of three years. New England Journal of Medicine. 2001;344:1179-1187.

34. Rovers MM, Straatman H, Ingels K, van der Wilt GJ, van den Broek P, Zielhuis GA. The effect of short-term ventilation tubes versus watchful waiting on hearing in young children with persistent otitis media with effusion: a randomized trial. Ear and Hearing. 2001;22:191-199.

35. Rosenfeld RM, Bluestone CD. Clinical pathways for otitis media with effusion. In: Rosenfeld RM, Bluestone CD, eds. Evidence-Based Otitis Media. Hamilton, Canada: BC Decker Inc.; 2003:303324.

36. Chopra R. 'Glue ear' in perspective. The Journal of the Royal Society for the Promotion of Health. 2000;120:90-93.

37. Rosenfeld RM, Culpepper L, Doyle KJ, Grundfast, KM, Hoberman, A, Kenna, MA et al. Clinical practice guideline: Otitis media with effusion. Otolaryngology-Head \& Neck Surgery. 2004;130:S95-S118.

38. Richards M, Giannoni C. Quality-of-life outcomes after surgical intervention for otitis media. Archives of Otolaryngology-Head \& Neck Surgery. 2002;128:776-782.

39. Greenhalgh J, Meadows K. The effectiveness of the use of patient-based measures of health in routine practice in improving the process and outcomes of patient care: a literature review. Journal of Evaluation in Clinical Practice. 1999;5:401-416. 


\section{General introduction}

40. Haggard MP, Smith SC. Impact of otitis media on child quality of life. In: Rosenfeld RM, Bluestone CD, eds. Evidence-Based Otitis Media. Hamilton, Canada: BC Decker Inc.; 1999:375-398.

41. Facione N. Quality of life issues in chronic otitis media with effusion: parameters for future study. International Journal of Pediatric Otorhinolaryngology. 1991;22:167-179.

42. Alsarraf $\mathrm{R}$, Jung $\mathrm{CH}$, Perkins J, Crowley $\mathrm{C}$, Gates GA. Otitis media health status evaluation: a pilot study for the investigation of cost-effective outcomes of recurrent acute otitis media treatment. Annals of Otology, Rhinology \& Laryngology. 1998;107:120-128.

43. Timmerman AA, Anteunis LC, Meesters CMG. The initial development of an instrument for the description of 'Otitis Media with Effusion Specific Behavior' in young children. International Journal of Behavioral Medicine. 1999;6:255-267.

44. Katz S. The science of quality of life. Journal of Chronic Diseases. 1987;40:459-463.

45. Guyatt GH, Feeny DH, Patrick DL. Measuring health-related quality of life. Annals of Internal Medicine. 1993;118:622-629.

46. Mui S, Rasgon BM, Hilsinger RL, Lewis B, Lactao G. Tympanostomy tubes for otitis media: qualityof-life improvement for children and parents. Ear, Nose \& Throat Journal. 2005;84:418,420422,424 .

47. Rosenfeld RM, Goldsmith AJ, Tetlus L, Balzano A. Quality of life for children with otitis media. Archives of Otolaryngology-Head \& Neck Surgery. 1997;123:1049-1054.

48. Patrick DL, Deyo RA. Generic and disease-specific measures in assessing health status and quality of life. Medical Care. 1989;27:S217-S232.

49. Brouwer CNM, Maille AR, Rovers MM, Grobbee DE, Sanders EAM, Schilder AGM. Health-related quality of life in children with otitis media. International Journal of Pediatric Otorhinolaryngology. 2005;69:1031-1041.

50. Haggard $M$, Spencer $H$, Gregori $M$. Internationally standardised clinical description: can it be achieved in ENT? ENT News. 2007;16:69-72.

51. Goodman R. The Strengths and Difficulties Questionnaire: a research note. Journal of Child Psychology and Psychiatry. 1997;38:581-586. 



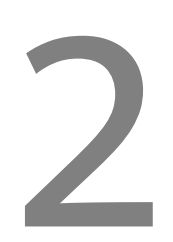

\section{Psychometric qualities of questionnaires for the assessment of functional health status in otitis media}

Angelique A. Timmerman Cor M.G. Meesters Renée Speyer Lucien J.C. Anteunis 


\section{Abstract}

- Assessment of questionnaires developed for the description of functional health status (FHS) in children with chronic otitis media (OM) and evaluation of psychometric qualities.

- The included 15 questionnaires were developed for children with recurrent or persistent OM by using a target population from an ENT department and the age range for the questionnaires differed within a continuum from 0-18 years.

- The OM8-30, OMO-22 and OM-6 adequately reflect the multidimensional aspects of FHS.

- The OMO-22 and OM8-30 have been found to be most adequate for discrimination between in terms of impact severity between children and the OM- 6 showed the best psychometric qualities for the evaluation of clinical change.

- The evaluation of psychometric qualities was limited by a lack of information for several questionnaires, to be addressed in future research.

- Clinical applicability is crucial for the assessment of FHS in chronic OM, but it requires a trade-off with necessary psychometric qualities. 


\section{Introduction}

It is increasingly recognised that both the assessment of impact and evaluation of treatment effects in chronic otitis media (OM) need to be broader than just examining the presence of middle ear effusion or hearing loss. Outcomes, such as speech and language problems, resulting from hearing loss need to be included in evaluations of the impact of chronic OM. ${ }^{1}$ Several studies describing the experiences of children and their families were conducted in order to heighten the awareness of the burden and stress chronic OM may cause, resulting in a compromised quality of life. ${ }^{2,3}$ In the past years several studies used proxy (i.e., usually parent) completed questionnaires to objectify this illness experience. ${ }^{4,5}$

The concept of health related quality of life (HROOL) was introduced in the field of $\mathrm{OM}$ and used for the evaluation of those aspects of quality of life directly affected by the physical health condition. ${ }^{1}$ There is a difficulty in using HROOL for the assessment of chronic OM impact, as it is an expression of the subjective perception and reaction to health status over time which cannot be adequately assessed by proxy report, especially in young children. ${ }^{6,7}$ However, it is possible to ask proxies to describe the impact of chronic $O M$ in terms of the functional health status (FHS) of the child. FHS is considered multidimensional in nature and contains several concepts: symptoms, functional (physical, psychological, social) wellbeing, general health perceptions, while also including overall quality of Life (QoL). ${ }^{8}$

For the standardisation of the assessment of chronic OM impact, structured reviews are an important prerequisite for effective application of questionnaires. ${ }^{9}$ Several reviews have already been conducted on this topic. First, Haggard et al. ${ }^{10}$ in the process of describing measurement issues related to HROoL assessment in children, reviewed a number of questionnaires. Brouwer ${ }^{11}$ focused on the effects of OM on both HROLL and FHS, while assessing the applicability of questionnaires used, also including children with acute $O M$. The current systematic review was conducted to focus on the impact in children with chronic $\mathrm{OM}$, in order to describe the persistence (or recurrence) and severity over time and justify treatment in these cases. For an adequate interpretation of results, it is important to assess the psychometric qualities of questionnaires used and give an update of the literature. The present study attempts to assess which questionnaires have been developed to describe FHS in chronic OM, evaluate their psychometric qualities and which questionnaires can be adequately used for discriminative and evaluative purposes in research and clinical practice. 


\section{Methods}

\section{Search strategy}

A systematic literature search was performed using PubMed (1966-January 2007) and EMBASE (1989-January 2007). The search was limited to English, French, German, Spanish and Dutch language publications. In both databases the Medical Subject Heading (MeSH) otitis media was exploded to include several subcategories indicating the nature of the condition: effusion (PubMed), suppurative (PubMed, EMBASE), secretory (EMBASE), chronic (EMBASE) or serous (EMBASE). This MeSH term was combined with questionnaires or health surveys for PubMed, while for EMBASE instrument, measurement or questionnaire were added. For PubMed there was a possibility of including infant or child preschool or child and human, in order to exclude studies on adults. The search was supplemented by using free text words to identify the most recent publications after January 2005. The following keywords were included to qualify the nature of otitis media in PubMed and EMBASE: secretory, chronic, serous, acute or mucoid. Otitis media was combined with survey or questionnaire.

\section{Data extraction and quality assessment}

In both databases 1374 references were found, 887 from EMBASE and 487 from PubMed. Reference tracking delivered four additional studies ${ }^{10,12-14}$, while one study still had to be published. ${ }^{15}$ Only studies containing children (<18 years) suffering from chronic (i.e., persistent or recurrent) OM and using proxy completed disease-specific questionnaires were included. Editorials, case reports, review articles, studies with sample sizes $<25$ and those containing tests or generic questionnaires were excluded in this sequence. The included 28 articles can be subdivided into 17 studies describing the psychometric development of (a) questionnaire(s) for FHS in chronic OM, while the remaining 11 studies described several applications.

For psychometric evaluation, the checklist of 'quality criteria for measurement properties of health status questionnaires' developed by Terwee ${ }^{16}$ was used, based on the comprehensive criteria developed by the Scientific Advisory Committee (SAC) of the American Medical Outcomes Trust. ${ }^{17}$ These quality criteria have been described in Table 1 and contain descriptors of validity, reliability, responsiveness, floor- and ceiling effects and interpretability. Indeterminate ratings for any of the psychometric qualities were discussed and resolved by two authors, both psychologists (AT, CM), in a consensus meeting. 


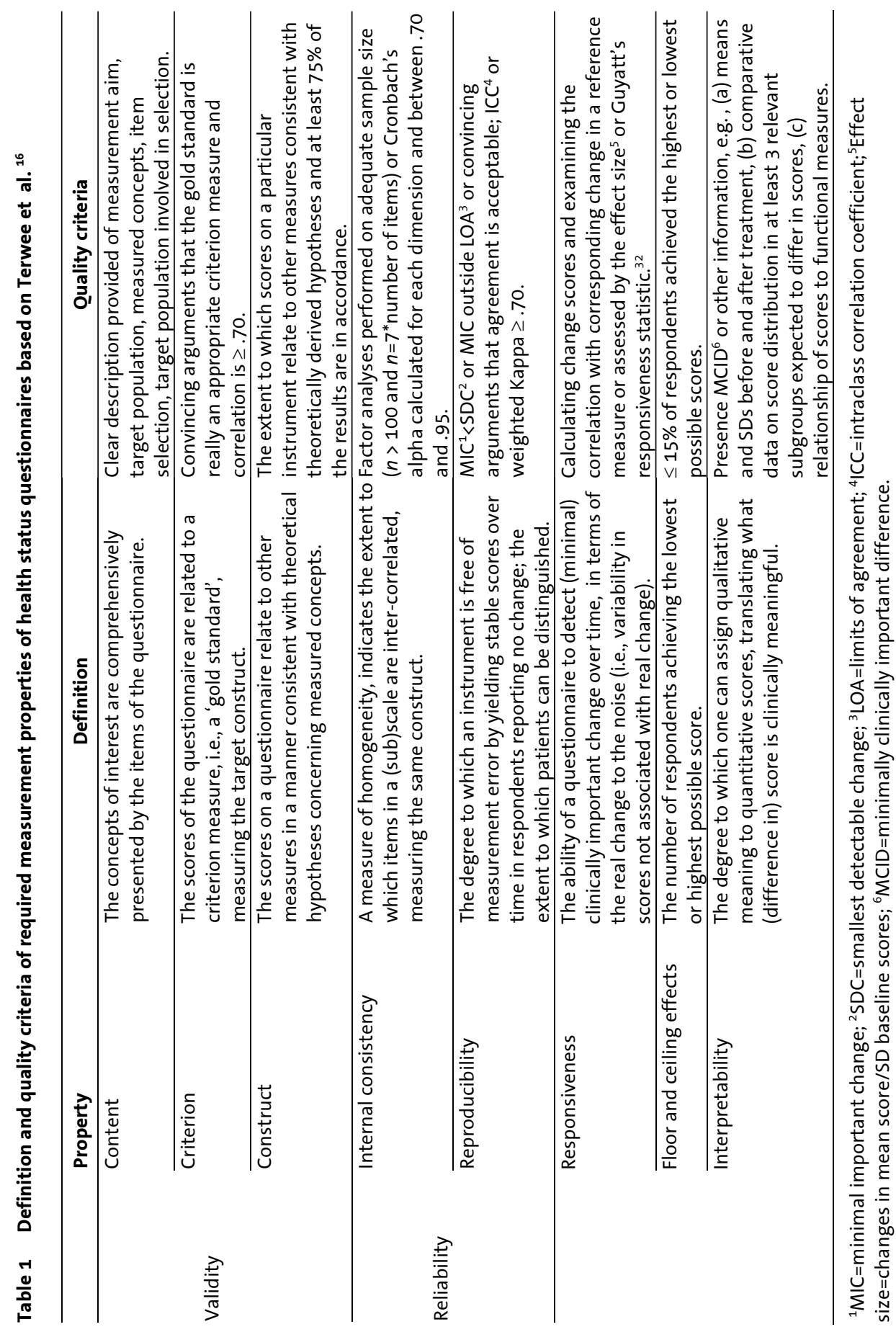




\section{Results}

\section{Evaluation of questionnaires for the assessment of chronic OM impact}

The following issues were addressed: description of the included questionnaires and conducted validation studies, assessment of the measurement characteristics and an evaluation of the psychometric qualities.

\section{Description of the questionnaires and validation studies}

A description of the 15 questionnaires for the assessment of FHS in chronic OM can be found in Table 2. All questionnaires are intended for children suffering from chronic OM, while the OMO-22 and the OM- 6 are also used in case of recurrent acute $O M$.

The age range differs, some questionnaires were developed for infants younger than 3 years (OM-CSI, OM-FSO, OMD, ENT-questionnaire, OME-SBO 12-24 and OME-SBO 25-48), while others are specifically for school children ranging from 3 to 11 years (OM survey, SCQ and OM8-30). Several questionnaires have an even broader range somewhere between 6 months and 12 years (COIEO, GIC-PPS, OMO-22 and OM-6) and one is applicable for children between 0 to 18 years (OoL-tubes).

The study designs for validation differed, cross-sectional studies were conducted for the $\mathrm{EIS}^{13}$, OM survey ${ }^{18}, \mathrm{COIEQ}^{4}, \mathrm{SCQ}^{19,20}$, OoL tubes ${ }^{21}$ and the OM8-30 ${ }^{15}$. Although some of these studies were called 'retrospective', two time frames were used, e.g., past disease and current language development in the OM survey and both 12 months before and after tubes surgery in the COIEQ and OoL-tubes. For the GIC-PPS ${ }^{22}$, OMO-22 ${ }^{23}$, OM-65 ${ }^{5}$, OME-SBO 12-24 and OME-SBO 25-48 24 prospective intervention studies were conducted, with measurements before and after tympanostomy tubes insertion. Studies were longitudinal for the EIS ${ }^{25}$ and ENT questionnaire ${ }^{12}$, while the OM-CSI, OM-FSO and OMD ${ }^{26}$ were evaluated in a patient-control design. Only the OM8-30 was validated within a randomised controlled trial (RCT). ${ }^{10}$

Most of the questionnaires were validated by using the target population from an ENT department, except for the OM survey and the ENT questionnaire, which contained a sample of school children and full-term versus pre-term born infants, respectively. The SCO was developed by using parent samples recruited in primary care and via the newspaper/magazine, besides the ENT sample. 


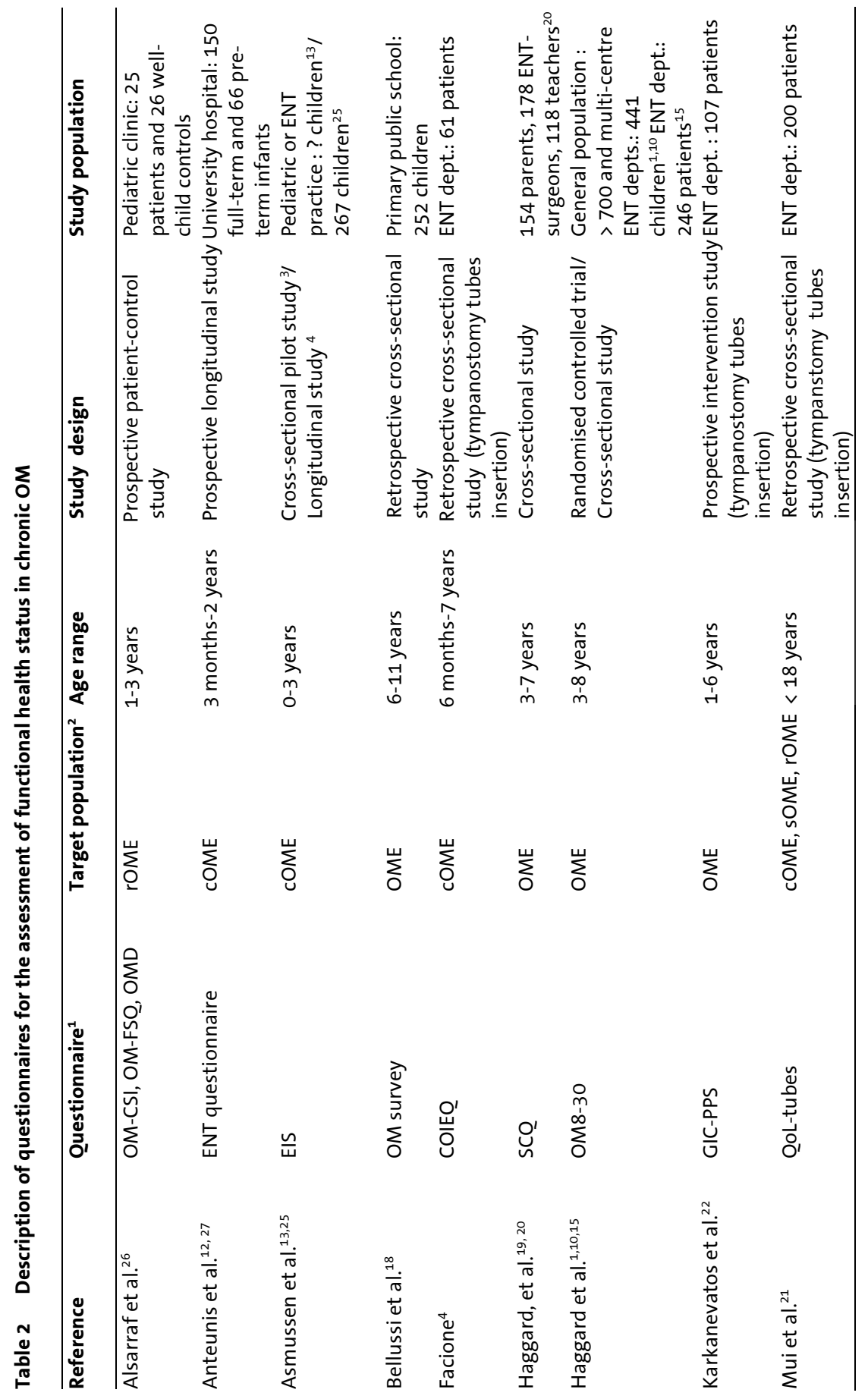




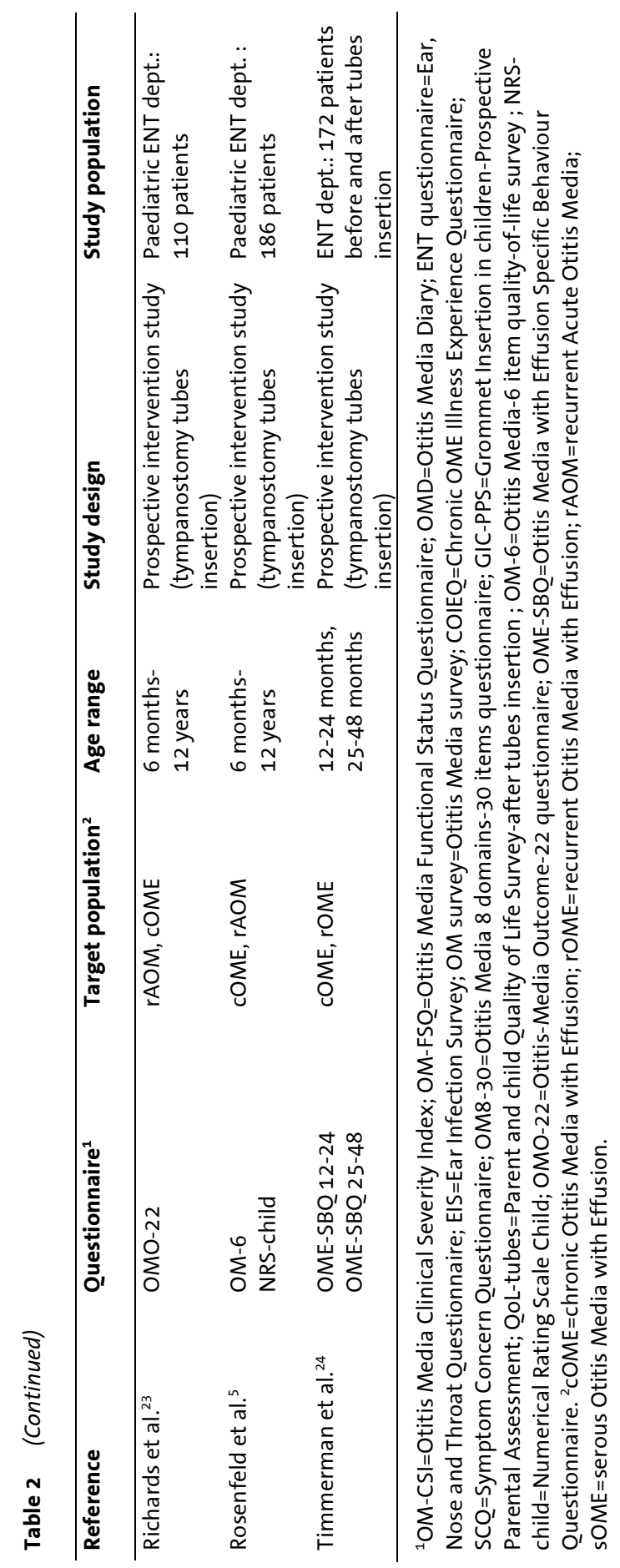




\section{Keypoints}

- FHS is described in children suffering from chronic OM in 15 included questionnaires, 2 questionnaires also evaluate the effect of tympanostomy tubes insertion.

- The intended age range shows a continuum between 0 and 18 years, some of the questionnaires were developed for infants (0-3 years) or school age children (3-11 years).

- Study designs for validation differed between cross-sectional, longitudinal and prospective intervention studies, one questionnaire was validated in a RCT.

- $\quad$ The target population for validation consisted of an ENT sample for 13 questionnaires.

\section{Measurement characteristics of the questionnaires}

The questionnaires address the FHS of children with chronic OM, except for the NRS-child, which is usually combined with the OM-6 and describes the child health-related quality of life (HROLL). The Ool-tubes also contains two questions assessing the overall OoL of child and parent.

Both the OM-CSI and the OM-survey have two sections, one for the parent and the other for completion by the physician (OM-CSI) while the (OM-survey) has one for the parent and another for the teacher. For the SCO several versions with different wordings are adopted, as for the parent the specific child has to be the referent while for professionals (i.e., teachers and ENT surgeons) the typical children as encountered in their work setting. ${ }^{20}$

The domains covered in the questionnaires, as depicted in Table 3, can be roughly summarised into six impact areas: (1) Physical symptoms (13 questionnaires), (2) Child development (8 questionnaires), (3) Educational performance (4 questionnaires), (4) Emotional burden (2 questionnaires) and Practical burden (3 questionnaires) for child and/or parent, (5) General health status ( 2 questionnaires)/ HROoL (3 questionnaires) and, (6) Effect of tympanostomy tubes insertion (2 questionnaires).

The number of scales present range from 1 (OMD, NRS-child, ENT questionnaire) to 8 for the OM8-30, while no domains were formulated for the COIEO supposed to describe 'the chronic OME illness experience'. For several questionnaires evaluating effect of tympanostomy tubes insertion (COIEQ, GIC-PPS) more scales are present in the version to be completed after intervention. Item numbers range from 1 for the NRS-child to 33 for the OME-SBO 25-48, respectively. In 12 questionnaires an ordinal Likert type scoring format is present although the number of response options range from 3 to 9. The OM-CSI, OM survey, OM8-30 
Chapter 2

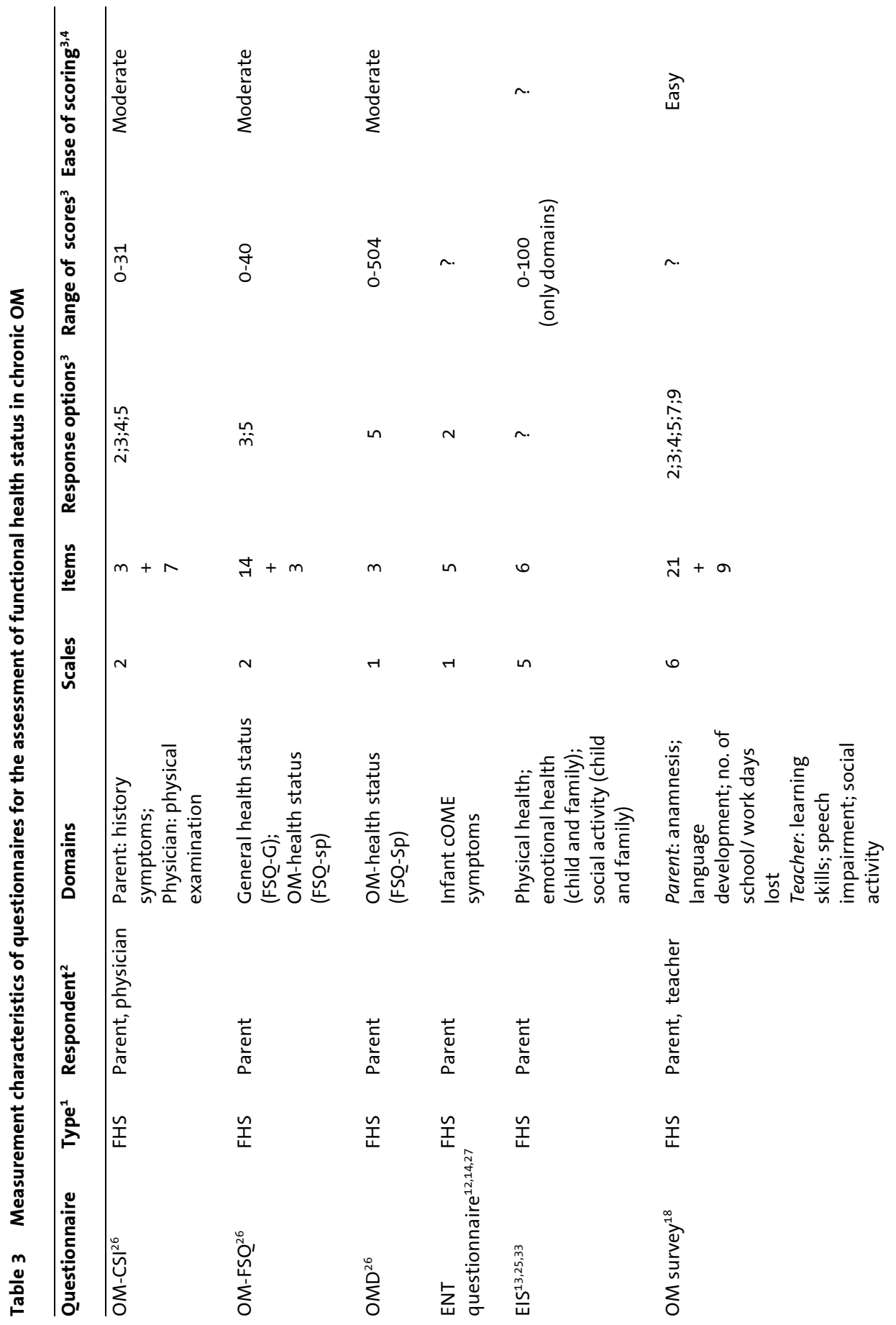


Otitis media and questionnaires

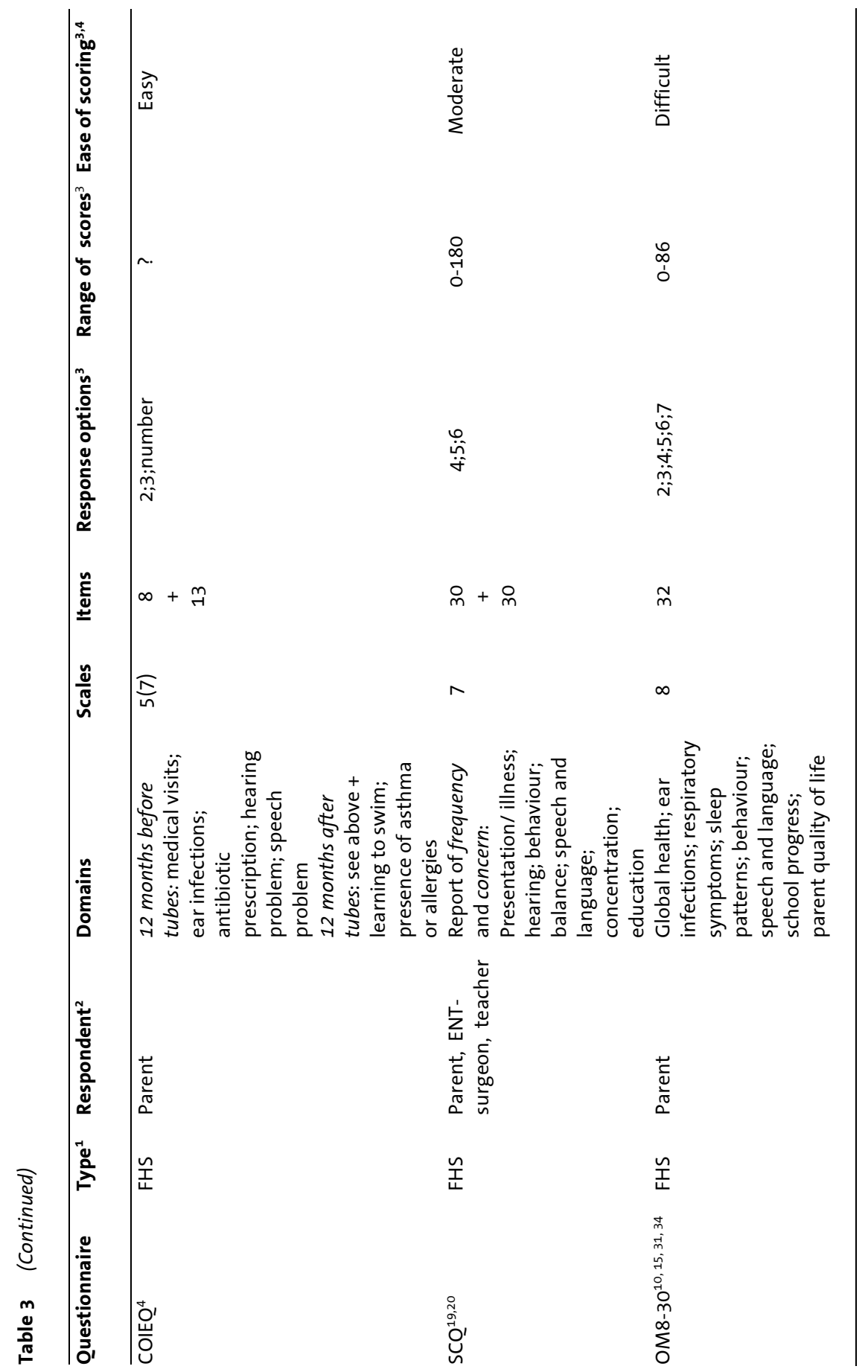


Chapter 2

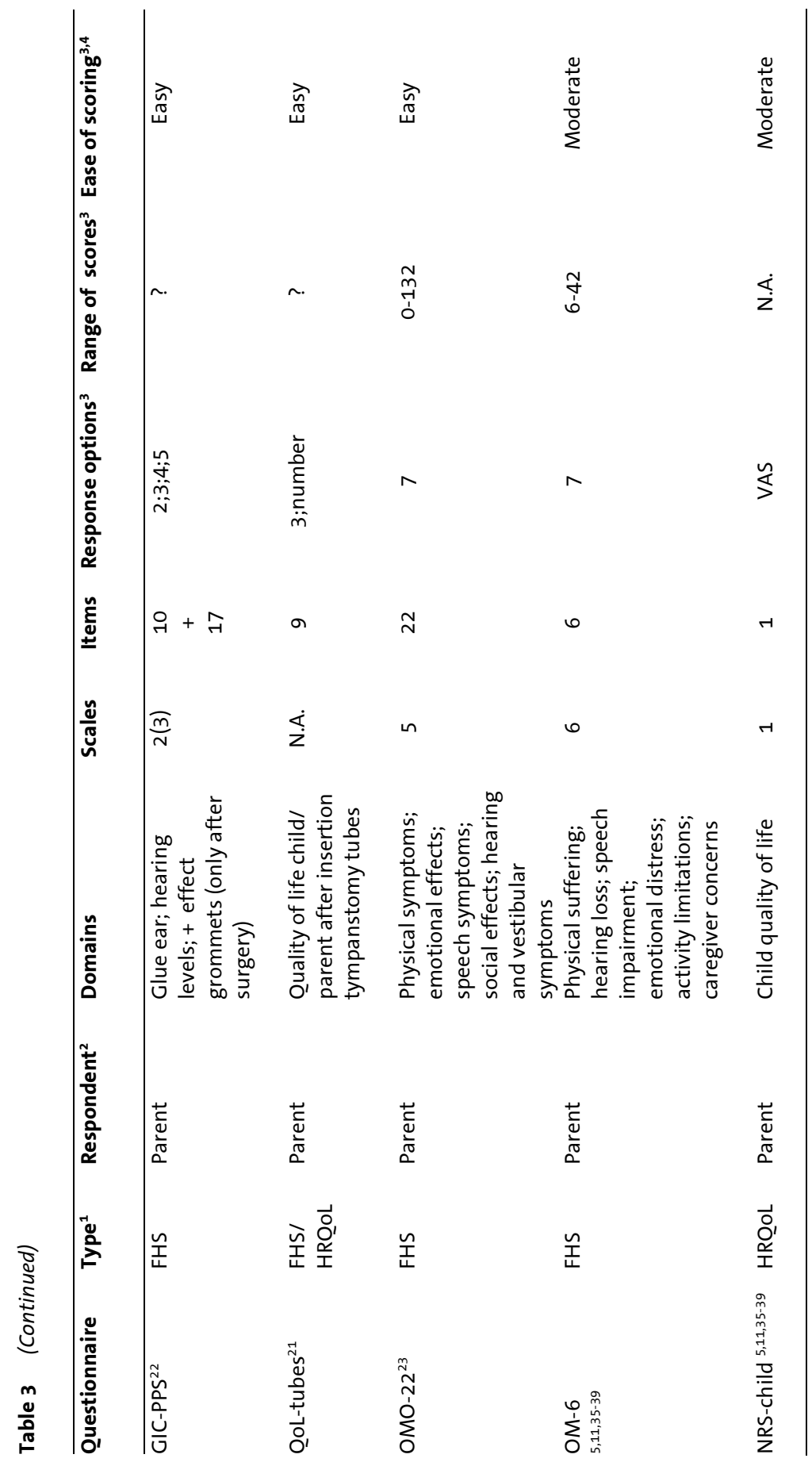


Otitis media and questionnaires

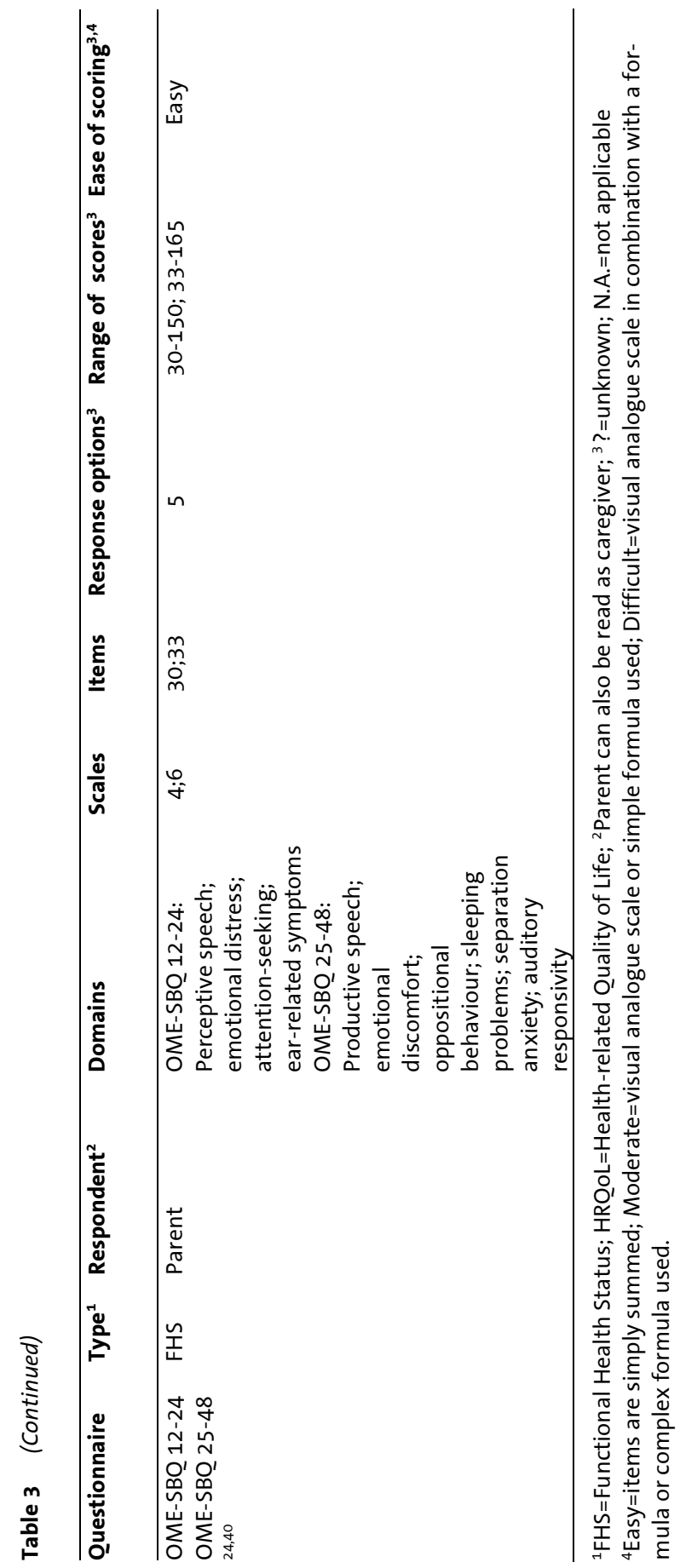


and GIC-PSS also contain a dichotomous ('yes/no') scoring format, which is the only format in the ENT questionnaire and COIEO. The NRS-child is rated by a visual analogue scale (VAS). The smallest score range was found for the OM-CSI (0$31)$, the widest for the OMD (0-504). A combined 'impact score' is derived from the frequency and concern scale values of the SCO. No information on scoring range was present for the OM survey, ENT questionnaire, COIEQ, GIC-PPS and OoL-tubes.

The ease of scoring was classified as either 'easy' by summing the items (8 questionnaires) or 'moderate' by using a simple formula or visual analogue scale (6 questionnaires). Only the OM8-30 uses a complex formula, which resulted in a rating of 'difficult to score'.

\section{Keypoints}

- For all questionnaires caregivers are the respondents, 3 questionnaires (OMCSI, OM survey, SCO) also have sections for completion by the physician or teacher.

- The questionnaires cover roughly six impact domains and physical symptoms is present the most (13 questionnaires).

- Scales present range from 1 (OMD, ENT-questionnaire) to 8 (OM8-30), 12 questionnaires use a Likert type scoring format.

- The scoring is classified mainly as easy or moderate, only the OM8-30 uses a complex formula.

\section{Psychometric qualities of the questionnaires}

The results of the psychometric questionnaire evaluation, using the quality criteria of Terwee ${ }^{16}$ are presented in Table 4 . Content validity was found to be positive for 11 out of 15 questionnaires, with indeterminate ratings for the OM survey, COIEO, GIC-PPS and OoL-tubes due to the lack of information related to item selection, while none of the questionnaires received a negative rating. Only two questionnaires were found to be related to a criterion measure (i.e., 'gold standard'): the OM-CSI with clinical severity $(r=.97)$ and OM8-30 with the full 83 item pool $(r>.93) .{ }^{10}$ The ENT questionnaire predicted the presence of severe, but not mild, chronic OM $(p s<.05)^{27}$, while for the OM-6 only data related to criterion validity were found for three out of six domains. ${ }^{5}$ Construct validity has been assessed by correlating the total scores for measures used, which was the case for the OM-CSI, OM-FSO and OMD (ps<.001). For the SCQ (ps<.05) and OME-SBO 12-24 and 25-48 ( $p s<.05$ and/or $p s<.01$ ) correlations were described between the scales of the questionnaires. ${ }^{20,24}$ Only the expected developmental domains of the OM8-30 were satisfactorily correlated with the scales of the Strengths and Diffi- 
culties Questionnaire (SDO) assessing psychosocial adjustment in children ( $p<<.002) .^{15,28}$ A substantial correlation $(r=-.64, p<.001)$ has been found between the OM- 6 and NRS-child, as HROoL incorporates aspects of FHS.

Internal consistency, as a measure of reliability, was found to be positive (>.70) for the OM-CSI, OM-FSO, OMD, SCO, OM8-30 and OMO-22, indicating construct homogeneity. Indeterminate ratings were found for the OME-SBO 12-24 and 2548 , with some of the correlations $<.70$. Reproducibility was evaluated by several methods. Test-retest correlations were assessed within a period ranging from 7 days (OM-6) to 3 months (OM8-30) and were >.70. For the OME-SBO 12-24 $(p=.01), \mathrm{OME}-\mathrm{SBO} 25-48(p=.007)$ a paired-sample $t$ test was conducted, which was also the case for the OMO-22 (p=.41). For the OM-CSI, OM-FSO and OMD mean data were presented for several visits without statistical analyses for stability over time.

Responsiveness was found to be very large $(S R M>.80)$ for all scales of the OM-6, while for the OME-SBO 12-24 and 25-48 it ranged from small (SRM $\leq .20)$ to large (SRM $\geq 80$ ). ANOVA tests of trend were conducted for the OM-CSI, OM-FSO and OMD, with correlation coefficients between .59 (OMD) and .74 (OM-CSI) for children recovering from OM after 6 and 12 weeks $(p<.0001)$. Doubtful statistical methods were used for the EIS, GIC-PPS, OMO-22 and OoL-tubes because no correction was conducted for measurement error due to between-subject variability or change within stable subjects. The cross-sectional study design applied resulted in a 'not applicable' rating for the OM survey, COIEQ and SCQ.

Floor effects were present in all OM-6 scale scores, except for caregiver concern and total score. For the SCO floor effects were reported for behaviour and balance scales, indicating that more than $15 \%$ of scores were in the lowest or highest response category. ${ }^{19}$

Interpretability was rated positive for 12 questionnaires, according to (1) Means and SDs before and after treatment (GIC-PPS, OoL tubes, OM-6, OME-SBO 12-24 and 25-48), (2) Comparative data on score distribution in at least 3 relevant subgroups expected to differ in scores (SCO), (3) Relationship of scores to clinical diagnosis (OM-CSI, OM-FSO, OMD, OM survey, ENT questionnaire). No information was found on this for the OM8-30 and only part of the necessary data was presented for the EIS and COIEQ, respectively. 


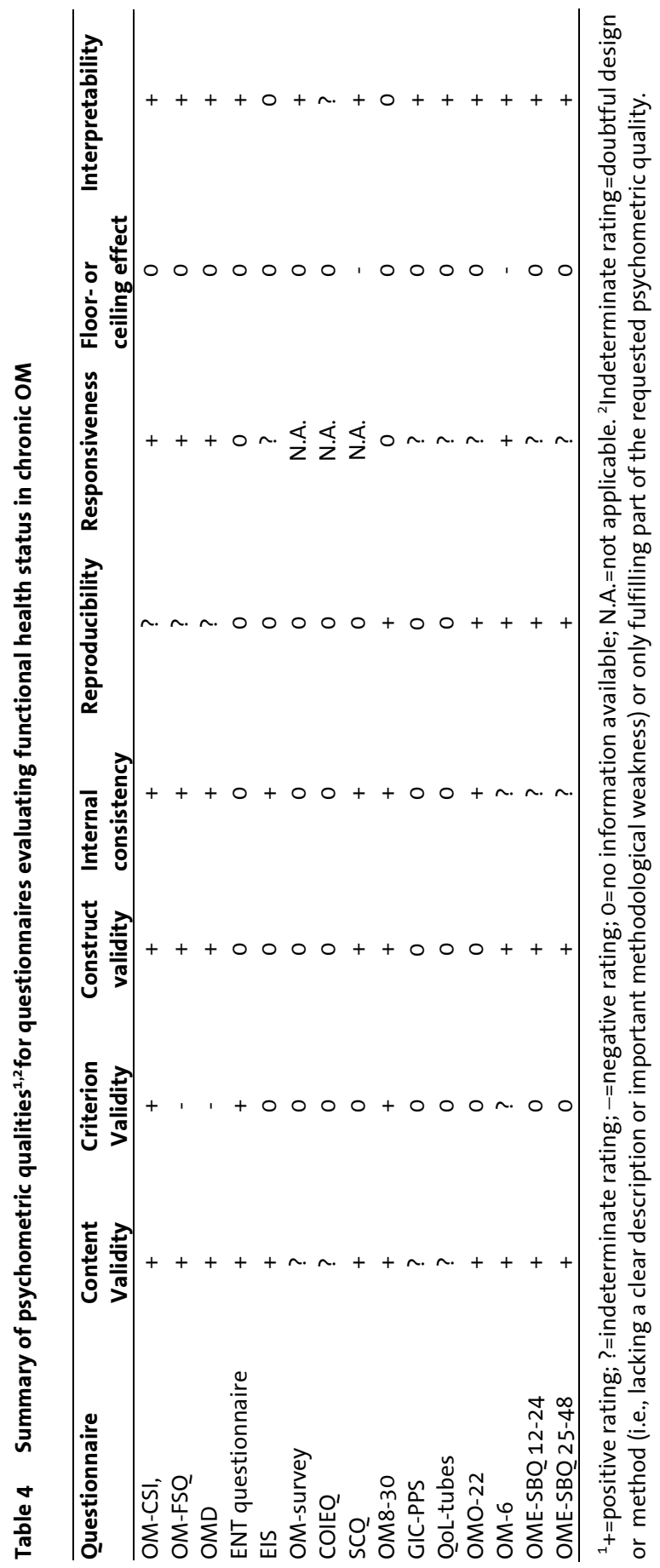




\section{Keypoints}

- Content validity was rated positive for 11 questionnaires, while 2 questionnaires (OM-CSI, OM8-30) showed satisfying criterion validity and for 8 questionnaires received a positive rating for construct validity (OM-CSI, OM-FSO, OMD, SCO, OME-SBQ 12-24 and 25-48, OM8-30, OM-6).

- Reliability assessed by both internal consistency, was found to be satisfying for 6 questionnaires (OM-CSI, OM-FSO, OMD, SCO, OM8-30, OMO-22), and reproducibility with positive ratings for 5 questionnaires (OM-6, OM8-30, OME-SBO 12-24 and 25-48, OMO-22).

- $\quad$ SRM after surgery was found to be large for the OM- 6 and small to large for both the OME-SBO 12-24 and 25-48, the OM-CSI, OM-FSO and OMD received a positive change rating after $\mathrm{OM}$ resolution.

- Interpretability is crucial for clinical applicability and was rated positive for 12 questionnaires.

\section{Discussion}

In the present study 15 disease-specific questionnaires were identified for the assessment of chronic OM impact. None of the questionnaires showed positive ratings on all quality criteria. The OM8-30 showed the best psychometric qualities, but the clinical applicability could not be judged. For the assessment of clinical impact, the OM-6 and OMO-22 seem to be appropriate instruments, but not all psychometric qualities have been evaluated satisfactorily. Although the OMCSI seems to reconcile both aspects, the sample size used was quite small and it assessed only physical impact in terms of clinical severity.

In general, the content validity was found to be adequate for most questionnaires, which is a prerequisite for choosing a questionnaire. There are several issues involved in the application of a questionnaire for chronic OM impact, besides the particular purpose and age range. ${ }^{1}$ First, there is the measurement aim, it has to be clear whether a questionnaire is going to be used for discriminative or evaluative purposes. If the goal is to differentiate in terms of impact severity between children with $O M$ and describe which children will benefit from surgical intervention, internal consistency and reproducibility are important qualities. The OM8-30 and OMO-22 seem the most appropriate questionnaires in this respect. For the evaluation of treatment effects in the physical domain, the OM-CSI can be used. The OM- 6 adequately evaluates clinically relevant change for FHS, but it was complicated by the presence of floor effects at baseline, which may result in missed intervention effects in the lower score ranges. The COIEO, OoL-tubes and GIC-PPS were designed for this purpose, but so far no data regarding responsive- 
ness were presented for these questionnaires. ${ }^{4,21,22}$ A second issue involves the target population, which depends on disease severity. According to clinical practice guidelines ${ }^{29,30}$ only 'high risk' children with chronic bilateral $O M$ for more than 9 months and a hearing loss of $25 \mathrm{~dB}$ for at least 3 months in the best ear need to be considered, due to high rates of spontaneous resolution. For the included questionnaires, except for the OM survey, children visiting secondary care formed the target population, which is probably most adequate for the assessment of FHS in chronic OM. ${ }^{18}$ The multidimensional aspects of FHS have been adequately represented in the broad impact measures OM8-30, OMO-22 and OM-6.

The last issue involved in the choice of a questionnaire, besides its' psychometric qualities, is the interpretability which has been rated as present for all questionnaires. For the use of questionnaires in routine practice, the applicability is an important issue. Adequate psychometric qualities and practical burden in terms of questionnaire length, ease of administration and scoring method have to be balanced. The OM8-30 is quite long and difficult to score. A shorter version (OM213) containing separate physical and developmental impact domain measures is under construction. ${ }^{31}$ The OM- 6 has tried to reconcile these issues by using a small number of items including a list of signs or symptoms with a risk of bias, in terms of less precision. ${ }^{10}$ The OMO-22, an extended version of the OM-6, solves this problem by expanding the sings or symptoms into individual variables. However, the information about the psychometric qualities of the OMO-22 was limited, making the interpretation of results questionable.

Rating questionnaires for psychometric qualities depends on the availability of information and the quality of reporting. As Terwee et al. ${ }^{16}$ state: '... poorly reported validation studies will lead to low ratings for questionnaires that are not necessarily poor in design or performance' (p. 340). This necessitates further psychometric evaluation of the questionnaires, as the number of negative ratings was found to be very low compared to 'no information available' ratings (Table 4). It is difficult to state which questionnaire shows the best psychometric qualities for the assessment of FHS in chronic OM at this stage, as it has to be balanced against discriminative and evaluative purposes, practical burden and the needed breadth of FHS assessment, but the OM-CSI, OM-6, OMO-22 and OM8-30 all seem promising. 


\section{References}

1. Haggard MP, Smith SC. Impact of otitis media on child quality of life. In: Rosenfeld RM, Bluestone CD. eds. Evidence-Based Otitis Media. $2^{\text {nd }}$ ed. Hamilton, Canada: BC Decker Inc.; 1999:375-398.

2. Wuest J, Stern PN. Childhood otitis media: the family's endless quest for relief. Issues in Comprehensive Pediatric Nursing. 1990;13:25-39.

3. Asmussen L, Olson LM, Sullivan SA. 'You have to live it to understand it...' Family experiences with chronic otitis media in children. Ambulatory Child Health. 1999;5:303-312.

4. Facione N. Quality of life issues in chronic otitis media with effusion: parameters for future study. International Journal of Pediatric Otorhinolaryngology. 1991;22:167-179.

5. Rosenfeld RM, Goldsmith AJ, Tetlus L, Balzano A. Quality of life for children with otitis media. Archives of Otolaryngology-Head \& Neck Surgery, 1997;123:1049-1054.

6. Gill TM, Feinstein AR. A critical appraisal of the quality of quality-of-life measurements. JAMA. 1994;272:619-626.

7. Matza LS, Swensen AR, Flood EM, Secnik K, Kline Leidy N. Assessment of health-related quality of life in children: a review of conceptual, methodological and regulatory issues. Value in health. 2004;7:79-92.

8. Ferrans CE, Zerwic JJ, Wilbur JE, Larson JL. Conceptual model of health-related quality of life. Journal of Nursing Scholarship. 2005;37:336-342.

9. Garratt A, Schmidt L, Mackintosh A, Fitzpatrick R. Quality of life measurement: bibliographic study of patient assessed health outcome measures. British Medical Journal. 2002;324:14171422.

10. Haggard MP, Smith SC, Nicholls EE. Quality of Life and Child Behavior. In: Rosenfeld RM, Bluestone CD, eds. Evidence-Based Otitis Media. $2^{\text {nd }}$ ed. Hamilton, Canada: BC Decker Inc.; 2003:401429.

11. Brouwer CNM, Rovers MM, Maille AR, Veenhoven RH, Grobbee DE, Sanders EAM. et al. The impact of recurrent acute otitis media on the quality of life of children and their caregivers. Clinical Otolaryngology. 2005;30:258-265.

12. Anteunis $\sqcup$, Engel JA, Hendriks JJ, Manni JJ. A longitudinal study of the validity of parental reporting in the detection of otitis media and related hearing impairment in infancy. Audiology. 1999;38:75-82.

13. Gupta K, Asmussen L, Olson L. The Ear Infection Survey (EIS): Psychometric testing of a functional health status measure for young children with otitis media. Abstract Book Association for Health Services Research. 1999;16:346-347.

14. Engel J, Anteunis L, Volovics A, Hendriks J, Marres E. Predictive value of parent-reported symptoms in the assessment of otitis media with effusion during infancy. Scandinavian Journal of Primary Health Care. 2000;18:25-29.

15. Timmerman AA, Anteunis LC, Meesters CMG, Haggard MP. The psychometric evaluation of the OM8-30 questionnaire in Dutch children with otitis media, submitted.

16. Terwee CB, Bot SDM, de Boer MR, van der Windt DAWM, Knol DL, Dekker J. et al. Quality criteria were proposed for measurement properties of health status questionnaires. Journal of Clinical Epidemiology. 2007;60:34-42.

17. Lohr KN, Aaronson NK, Alonso J, Burnam MA, Patrick DL, Perrin EB. et al. Evaluating quality-of-life and health status instruments: development of scientific review criteria. Clinical Therapeutics. 1996;18:979-992. 
18. Bellussi L, Mandala FM, Passali GC, Lauriello M, Passali D. Quality of life and psycho-social development in children with otitis media with effusion. Acta Otorhinolaryngologica Italica. 2005;25:359-364.

19. Haggard MP, Birkin JA, Browning GG, Gatehouse S, Lewis S. Behavior problems in otitis media. The Pediatric Infectious Disease Journal. 1994;13:S43-S50.

20. Higson J, Haggard M. Parent versus professional views of the developmental impact of a multifaceted condition at school age: otitis media with effusion ('glue ear'). British Journal of Educational Psychology. 2005;75:623-643.

21. Mui S, Rasgon BM, Hilsinger RL, Lewis B, Lactao G. Tympanostomy tubes for otitis media: qualityof-life improvement for children and parents. Ear, Nose \& Throat Journal. 2005;84:418, 420-422, 424.

22. Karkanevatos A, Lesser THJ. Grommet insertion in children: a survey of parental perceptions. The Journal of Laryngology and Otology. 1998;112:732-741.

23. Richards M, Giannoni C. Quality-of-life outcomes after surgical intervention for otitis media. Archives of Otolaryngology-Head \& Neck Surgery. 2002;128:776-782.

24. Timmerman A, Anteunis L, Meesters C. First psychometric evaluation of a disease-specific questionnaire for children's behavior related to otitis media with effusion. Psychological Reports. 2005;97:819-831.

25. Asmussen L, Olson L, Siegel R, Bien J. The Ear Infection Survey: Is it responsive to change in health over time? Pediatric Academic Societies' Annual Meeting. 2000 (Abstract).

26. Alsarraf R, Jung $\mathrm{CH}$, Perkins J, Crowley C, Gates GA. Otitis media health status evaluation: a pilot study for the investigation of cost-effective outcomes of recurrent acute otitis media treatment. Annals of Otology, Rhinology \& Laryngology. 1998;107:120-128.

27. Engel JAM, Anteunis UC, Volovics A, Hendriks JJT, Manni JJ. Chronic otitis media with effusion during infancy, have parent-reported symptoms prognostic value? A prospective longitudinal study form 0 to 2 years of age. Clinical Otolaryngology. 1999;24:417-423.

28. Goodman R. Psychometric properties of the strengths and difficulties questionnaire. Journal of the American Academy of Child and Adolescent Psychiatry. 2001;40:1337-1345.

29. Boomsma $\sqcup$, van Balen FAM, Rovers MM, Wiersma T, Goudswaard AN. Summary of the practice guideline 'otitis media with effusion' (second revision) from the Dutch College of General Practitioners. Nederlands Tijdschrift voor Geneeskunde. 2006;150:2028-2032.

30. Rosenfeld RM, Culpepper L, Doyle KJ, Grundfast KM, Hoberman A, Kenna MA. et al. Clinical practice guideline: otitis media with effusion. Otolaryngology-Head \& Neck Surgery. 2004;130:595S118.

31. Haggard $M$, Spencer $H$, Gregori $M$. Internationally standardised clinical description: can it be achieved in ENT? ENT News. 2007;16:69-72.

32. Deyo RA, Diehr P, Patrick DL. Reproducibility and responsiveness of health status measuresStatistics and strategies for evaluation. Controlled Clinical Trials. 1991;12:142S-158S.

33. Asmussen L, Sullivan SA, Olson LM, Fleming GV. The 'Ear Infection Survey': a condition-specific functional outcomes measure for families of children with chronic otitis media. AHSR FHSR Annual Meeting Abstract Book. 1996;13:14.

34. Haggard $M$, Spencer $\mathrm{H}$, Gregori M. Overcoming international differences for clinical comparisons and research. ENT News. 2007;16:68-71.

35. Rosenfeld RM, Bhaya MH, Bower CM, Brookhouser PE, Casselbrant ML, Chan KH. et al. Impact of tympanostomy tubes on child quality of life. Archives of Otolaryngology-Head \& Neck Surgery. 2000;126:585-592. 


\section{Otitis media and questionnaires}

36. Timmerman AA, Anteunis LC, Meesters CMG. Response-shift bias and parent-reported quality of life in children with otitis media. Archives of Otolaryngology-Head \& Neck Surgery. 2003;129:987-991.

37. Kubba H, Swan IRC, Gatehouse S. How appropriate is the OM- 6 as a discriminative instrument in children with otitis media? Archives of Otolaryngology-Head \& Neck Surgery. 2004;130:705-709.

38. Witsell DL, Stewart MG, Monsell EM, Hadley JA, Terrell JE, Yueh B. et al. The Cooperative Outcomes Group for ENT: a multicenter prospective cohort study on the outcomes of tympanostomy tubes for children with otitis media. Otolaryngology-Head \& Neck Surgery. 2005;132:180-188.

39. Lee J, Witsell DL, Dolor RJ, Stinnett S, Hannley M. Quality of life of patients with otitis media and caregivers: a multicenter study. The Laryngoscope. 2005;116:1798-1804.

40. Timmerman AA, Anteunis LC, Meesters CMG. The initial development of an instrument for the description of 'Otitis Media with Effusion Specific Behavior' in young children. International Journal of Behavioral Medicine. 1999;6:255-267. 



\section{The initial development of an instrument for the description of 'otitis media with effusion specific behaviour' in young children}

Angelique A. Timmerman Lucien J.C. Anteunis Cor M.G. Meesters 


\section{Abstract}

Objective: The preliminary evaluation of a newly developed questionnaire concerning behaviour of young children with recurrent otitis media with effusion (OME) and documenting behavioural change after tympanostomy tube insertion. Method: A sample of 95 parent-child pairs were interviewed using an age-specific questionnaire: after diagnosing OME and scheduling for surgery, at the day care theatre a few weeks later and 6 weeks after the intervention.

Results: The levels of internal consistency were varying from still insufficient to fairly good for the different subscales of the construct 'OME-specific behaviour' and these levels were comparable for both age-specific questionnaires. As expected, parental report proved to be stable during time, but behavioural changes were reported after tympanostomy tubes insertion.

Conclusions: The questionnaires seem to assess a decline in behaviour expected to be specific for OME. Implications for future research are discussed, while considering the influence of parental concerns on behavioural reports. 


\section{Introduction}

Otitis media with effusion (OME) is one of the most common diseases in childhood. It is suggested that at least $90-95 \%$ of all children suffer at least one episode of middle ear disease up to 10 years of age, with the highest risk in the first three years of life. ${ }^{1-3}$ This condition is also called 'glue ear', which means that fluid has accumulated in the middle ear(s), causing a mild and fluctuating hearing loss, ${ }^{2,3}$ often in the absence of clinical symptoms or inflammation., ${ }^{4,5}$

In the past decades there have been reports concerning negative developmental outcomes of chronic OME in the short and long term ${ }^{6,7}$ especially in the area of speech- and language development, in which the 'auditory deprivation' seems to be an important mediating variable. ${ }^{4,5,8}$ In a broader perspective there has been research focusing on behavioural and social difficulties, (e.g., distractibility, overactivity and poor social skills at school age) as a hypothesized result of the frequent and prolonged exposure to OME in the first years of life. ${ }^{8-10}$ This kind of research is usually retrospective in nature, a questionable methodology to report both the presence and absence of OME in a certain time frame, given not only the self-resolving nature of the disease, but also the limited validity of parental recall. Another issue is the impossibility to control retrospectively for other factors that might influence the presence of behaviour problems. Despite this plea for prospective research into possible behavioural consequences of the early presence of chronic $O M E$, this is a relatively undiscovered area: only a few longitudinal studies have emerged until now. ${ }^{9,10}$

This prospective study underlines the importance of correctly identifying recurrent OME at a young age, which might be essential for normal development throughout childhood. ${ }^{11}$ This statement is supported through research analyzing the relationship between OME and language learning, in which hearing over time is assumed to be a mediating variable. Both receptive and expressive language at 18 and 24 months seem to be related to average hearing from 6-18 months, better language development being associated with better average hearing levels. ${ }^{12}$ It is quite difficult, however, to detect OME in the first years of life, except for continuous universal screening, because the speech- and language development of children is only rudimentary at that time. The search for other possible indicators of chronic OME in young children leads then to the idea that they need to use other nonverbal means of expressing themselves. ${ }^{13,14}$ Their behaviour is an important means of communication at this age, in which the parent-child interaction is of vital importance. It is the child's behaviour, or change in behaviour, that makes the parents decide to visit the General Practitioners' (GP) office with complaints about the child's health. In the case of the individual child, these 'rea- 
sons for concern' are important for the choice of treatment strategy concerning $\mathrm{OME}$, besides the history and clinical presentation. ${ }^{15}$

It is expected that behaviour, which might be specific to the presence of OME, can be described in a valid manner based on parental report. ${ }^{15,19}$ In this context, it is hypothesized that the behaviour of the child remains stable in time, given a chronic OME status. Alternatively, behavioural changes due to the resolution of OME are expected within a matter of weeks. The main purpose of the present study was to develop a questionnaire for the description of 'OME-specific behaviour' in children aged 12-48 months, besides the presentation of the first clinical test results, hoping that such an instrument could serve as a future supplement to objective diagnostic measures for OME, both in research and clinical context.

\section{Methods}

\section{Participants}

At the time of study entry, the 95 participating children had a mean age of 22.9 months, $(S D=7.6$, range $=12.0-47.2$ months). All participants were attending the Otolaryngology Department of the university hospital Maastricht, the Netherlands. This hospital also serves a regional function for the most southern part of the Dutch country, the surroundings of Maastricht. Inclusion criteria for this study were: (1) aged between 12 and 48 months; (2) OME present in one or both ears for a minimum of 3 months as diagnosed through otoscopy by an otolaryngologist and confirmed by tympanometry; (3) average hearing loss as a consequence of OME of at least $20 \mathrm{~dB}$ in the best ear, as confirmed by audiometry; (4) scheduled for tympanostomy tubes insertion in the day care theatre within 2 to 4 weeks.

Children and their parents were referred to the department of otolaryngology by either the GP, paediatrician or a doctor of the Well Baby Clinic. Prior to participation, parents were informed about the purpose and procedure of this study and an informed consent, which had been approved by the university hospital Medical Ethics Committee, was obtained.

\section{Procedure}

The caregivers, nearly always the mother, of the children enrolled in this prospective study were asked to complete a recently developed questionnaire for 'OME specific behaviour' at three consecutive times. In research literature this design has been called a pretest posttest design ${ }^{16}$, because two measurements were 
planned before tympanostomy tube insertion and one after surgery. The first questionnaire was administered a few days after scheduling of the intervention. A second measurement was planned just before surgery, at about 2 to 4 weeks after entering the study. Six weeks after surgery, parent(s) and child revisited the hospital for both the completion of the questionnaire once more during an interview session and a check up (i.e., tympanometry) on the middle ear status.

\section{Questionnaire development}

Item generation For the generation of items describing the construct 'OMEspecific behaviour', two sources of information were available. First, otolaryngologists $(n=9)$ were requested to describe behaviours, which they assumed to be characteristic to the presence of both OME and otitis media with acute symptoms in children at different ages, ranging from 0-5 years. The second source contained research reports about behaviour related to OME, as well as the effects of hearing loss in young children. ${ }^{17,18}$

Literature concerning the normal development of infants and its milestones at certain ages was used. ${ }^{18,19}$ At this time, the idea emerged to develop two separate questionnaires for children aged 12-24 and 25-48 months with similar and different items, as there seems to be a tremendous variation in skill development during children's early years, sometimes within a matter of weeks. ${ }^{20}$ Different behavioural scales related to hearing were identified for both instruments and the items were constructed on the basis of content validity. The final versions of both age-specific questionnaires were revised by an audiologist (Lucien J.C. Anteunis) and developmental psychologist (Cor M.G. Meesters).

Item scaling The questionnaires for children aged 12-24 months (Group A) and 25-48 months (group B) consist of three scales questioning child behaviours representing developmental domains:

1. Speech- and language behaviour: 19 (group A,B) items.

2. Emotional behaviour: 27 (group A), 28 (group B) items.

3. Physical and motor behaviour: 10 (group A), 12 (group B) items.

Because items related to the use of language and social interaction are expected to be connected to OME, a higher number of items in these domains can be explained this way. The scales ought to be age-specific for children aged 12 to 48 months. ${ }^{18}$

The 56 (group A) and 59 (group B) items in each questionnaire were formulated as statements, containing the phrase 'mijn kind ... (my child ... )'. The following example represents an item from the domain 'speech and language behaviour', for children aged 12-24 months only: 'Mijn kind is zeer geïnteresseerd in nieuwe, vreemde geluiden in zijn omgeving en reageert daar snel op' ('My child is very 
interested in new, strange sounds in the environment and responds to these in a quick fashion'). This statement was formulated in a negative fashion, which means that the presented behaviour is not expected to be indicating the presence of OME. The different scales also contain positive items expected to be specific for the presence of OME: mijn kind maakt vaak een ongelukkige indruk, zonder dat er een duidelijke reden voor is' ('my child often strikes me as unhappy, although there seems no obvious reason present'), which is an example from the domain emotional behaviour. This is one of the statements that is not expected to be age-specific and is for this reason present in both instruments. The prevention of an 'acquiescence tendency' explains the use of positive and negative formulated items. Each item had the same scoring format, a 5-point Likert scale, ranging from 1='do not agree at all', to $5=$ 'do totally agree', with the midpoint $3=$ 'do not disagree, do not agree'. The statements were given equal weighting and scoring was reversed for negative items, resulting in comparable scores in the direction of possible 'OME-specific behaviour'. In the introduction of both questionnaires parents were instructed to answer the statements from their own point of view, concerning the possible presence of the behaviours in their child at that specific time.

\section{Statistical analyses}

Reliability analysis (Cronbach's $\alpha$ ) was carried out at this point to determine the internal consistency of the scales, with the purpose of giving an indication concerning the statistical fit of different items in each of the subscales, which were constructed on the basis of content fit. The significance of differences in calculated mean group scores between measurements was assessed with a paired samples $t$ test, which also delivers information concerning the test-retest reliability for each scale. The Bonferroni correction was used to minimize significant results due to a great number of $t$ tests ( 3 scales $\times 3$ administering times $=9$ statistical tests for Q1 and Q2 separately). Therefore, $\alpha$ was set at $.05 / 18=.003$ for these tests. The statistical analyses were performed separately for each age group.

\section{Results}

\section{Descriptive features of the sample}

The sample consisted of two age groups: (a) 56 children aged 12-24 months, 31 boys and 25 girls, mean age $=17.6$ months, $\mathrm{SD}=3.2$, range $=12.0-23.8$ months and 
(b) 39 children aged $25-48$ months, 28 boys and 11 girls, mean age $=30.6$ months, $\mathrm{SD}=4.7$, age range $=24.8$ months to 47.2 months. These numbers are descriptive for the first measurement (T1), after scheduling for intervention at the day care theatre.

\section{Drop-outs during the study}

Less data are available in both age-groups at the time of surgery (T2: $n=51$ for group A, $n=37$ for group B) and 6 weeks after the placement of tympanostomy tubes (T3: $n=44$ for group A, $n=35$ for group B). There were several reasons for dropping out the study: still incomplete data (T2: $n=2$ for group $\mathrm{A} ; \mathrm{T} 3: n=7$ in group A, $n=1$ in group B), surgery within one week (T2 and T3: $n=1$ in group A, $n=1$ in group $\mathrm{B}$ ), refusal (T2 and T3: $n=1$ in group A), moving to another area (T3: $n=1$ in group $\mathrm{A}$ ), family problems (T3: $n=1$ in group $\mathrm{B}$ ), lost data (T2: $n=1$ in group $\mathrm{A}$ and group $\mathrm{B} ; \mathrm{T} 3: n=2$ in group $\mathrm{A}, n=1$ in group $\mathrm{B})$.

\section{Internal consistency}

The homogeneity of the subscale structures, supposed to measure behaviours specific to OME, appears to be comparable for both age specific questionnaires $\left(\mathrm{Q}_{1}, \mathrm{Q} 2\right)$ in general. The highest internal consistency (Cronbach's $\alpha$ ) was found for the emotional behaviour scale (Q2: $\alpha=.85$ ) and the lowest for the physical and motor behaviour scale (Q1: $\alpha=.46)$. For the language and speech behaviour scale, results are intermediate. This tendency is depicted in Table 1 , which also indicates that the internal consistency for emotional behaviour is the highest at T2 for both surveys, in comparison to T1 and T3. There is no distinctive pattern between measurements when comparing Q1 and Q2 for the language and speech and physical and motor behaviour scales, although the absolute and relative score ranges appear to be comparable for these subscales.

It can be stated that the homogeneity of the subscales for Q1 and Q2 is insufficient ( $\alpha=.46$ to $\alpha=.60$ ) for physical and motor behaviour, above sufficient for speech and language behaviour ( $\alpha=.60$ to $\alpha=.75$ ) and fairly good for emotional behaviour ( $\alpha=.68$ to $\alpha=.85$ ). 
Table 1 Reliability coefficients (Cronbach's $\alpha$ ) for scales related to 'OME-specific behaviour' indicating the amount of statistical fit of different Items, at study entry (T1), at the day care theatre (T2) and six weeks after surgery (T3)

\begin{tabular}{|c|c|c|c|c|c|}
\hline \multirow[b]{3}{*}{ Scale } & \multirow[b]{3}{*}{ Time } & \multicolumn{4}{|c|}{ Age-specific questionnaire } \\
\hline & & \multicolumn{2}{|c|}{ 12-24 months (Q1) } & \multicolumn{2}{|c|}{ 25-48 months (Q2) } \\
\hline & & Cronbach's $\alpha$ & $n$ & Cronbach's $\alpha$ & $n$ \\
\hline \multirow[t]{3}{*}{ Language and speech behaviour } & T1 & .70 & 56 & .72 & 39 \\
\hline & $\mathrm{T} 2$ & .62 & 50 & .75 & 36 \\
\hline & T3 & .60 & 44 & .64 & 35 \\
\hline \multirow[t]{3}{*}{ Emotional behaviour } & T1 & .76 & 56 & .82 & 39 \\
\hline & T2 & .80 & 50 & .85 & 37 \\
\hline & T3 & .78 & 44 & .68 & 35 \\
\hline \multirow[t]{3}{*}{ Physical and motor behaviour } & $\mathrm{T} 1$ & .53 & 56 & .60 & 39 \\
\hline & T2 & .46 & 50 & .59 & 37 \\
\hline & T3 & .52 & 44 & .53 & 35 \\
\hline
\end{tabular}

\section{Stability of parental report}

The test-retest stability of T1 and T2 contains the short documented period of 2 to 4 weeks before surgery, the most optimal time frame for assessment of the stability in what is expected to be 'OME-specific behaviour'. ${ }^{25}$ The highest stability was found for the speech and language behaviour scales in both Q1 and Q2 and physical and motor behaviour in Q2, as reflected by the non-significant differences in parental report ( $p>.003)$. The results of the paired samples $t$ tests are shown in Table 2. The same, less pronounced, tendency is observed for the emotional behaviour in Q1 and Q2: the amount of (mean) change between T1 and T2 is non significant, although comparable to that after the intervention. 
Table 2 Mean change scores and paired samples $t$ tests for scales, related to 'OME-specific behaviour', at study entry (T1), at the day care theatre (T2) and 6 weeks after surgery (T3)

\section{Age-specific questionnaire}

12-24 months (Q1)

25-48 months (Q2)

\begin{tabular}{|c|c|c|c|c|c|c|c|c|c|c|c|c|c|c|}
\hline Scale & $\begin{array}{l}\text { Time } \\
\text { Span }\end{array}$ & $\begin{array}{c}M \\
\text { values }\end{array}$ & $\begin{array}{c}\text { M } \\
\text { change }\end{array}$ & $T$ & $p$ & Sign. & $n$ & $\begin{array}{l}\text { Time } \\
\text { span }\end{array}$ & $\begin{array}{c}M \\
\text { values }\end{array}$ & $\begin{array}{c}M \\
\text { change }\end{array}$ & $t$ & $p$ & Sign. & $n$ \\
\hline Language and & T1-T2 & $47.3-47.1$ & -.20 & .15 & $.882^{1}$ & ns & 51 & T1-T2 & $50.2-49.2$ & -1.0 & .73 & $.472^{1}$ & ns & 37 \\
\hline speech & T2-T3 & $47.1-37.9$ & -9.2 & 5.66 & $.000^{2}$ & s & 43 & T2-T3 & $48.9-42.1$ & -6.8 & 3.99 & $.000^{2}$ & s & 35 \\
\hline Behaviour & T1-T3 & $46.9-37.8$ & -9.1 & 6.27 & $.000^{2}$ & s & 44 & T1-T3 & $49.6-42.1$ & -7.5 & 4.23 & $.000^{2}$ & s & 35 \\
\hline Emotional & $\mathrm{T} 1-\mathrm{T} 2$ & $61.0-65.1$ & +4.1 & -2.35 & $.023^{1}$ & ns & 51 & $\mathrm{~T} 1-\mathrm{T} 2$ & $70.4-66.6$ & -3.8 & 1.85 & $.073^{1}$ & ns & 37 \\
\hline \multirow[t]{2}{*}{ behaviour } & $\mathrm{T} 2-\mathrm{T} 3$ & 65.1-58.6 & -6.5 & 3.43 & $.001^{2}$ & $s$ & 43 & T2-T3 & $66.2-62.3$ & -3.9 & 1.37 & $.090^{2}$ & ns & 35 \\
\hline & T1-T3 & $61.7-58.6$ & -3.1 & 1.67 & $.051^{2}$ & ns & 44 & T1-T3 & 69.1-62.3 & -6.8 & 3.23 & $.002^{2}$ & s & 35 \\
\hline \multirow{3}{*}{$\begin{array}{l}\text { Physical and } \\
\text { motor } \\
\text { Behaviour }\end{array}$} & $\mathrm{T} 1-\mathrm{T} 2$ & $27.1-25.7$ & -1.4 & 2.10 & $.041^{1}$ & ns & 51 & $\mathrm{~T} 1-\mathrm{T} 2$ & $30.6-29.7$ & -.90 & .72 & $.474^{1}$ & ns & 37 \\
\hline & $\mathrm{T} 2-\mathrm{T} 3$ & $25.6-20.9$ & -4.7 & 5.31 & $.000^{2}$ & $s$ & 43 & T2-T3 & $29.9-25.0$ & -4.9 & 3.72 & $.001^{2}$ & $s$ & 35 \\
\hline & T1-T3 & $26.9-20.8$ & -6.1 & 6.09 & $.000^{2}$ & $\mathrm{~s}$ & 44 & T1-T3 & $31.0-25.0$ & -6.0 & 4.30 & $.000^{2}$ & $\mathrm{~s}$ & 35 \\
\hline
\end{tabular}

$\alpha=0.003$; negative mean change=decline in 'OME-specific behaviour'; positive mean change=rise in 'OME-specific behaviour'; $n s=$ not significant; $s=$ significant; ${ }^{1}$ Two-sided. ${ }^{2}$ One-sided.

\section{Behavioural changes after surgery}

Paired samples $t$ tests (Table 2) also revealed significant behavioural change at group level: for both Q1 and Q2, there appears to be a decline in the presence of behaviour expected to be OME-specific for the language and speech behaviour and physical and motor behaviour scales 6 weeks after the intervention (T3), in comparison with either T1 or T2 $(p<.06)$. There seems to be variability in the direction of change concerning the emotional behaviour scale for both questionnaires. For Q1, the mean change between $\mathrm{T} 2$ and $\mathrm{T} 3 \mathrm{~h}$ has been significant, which is not the case for the amount of alteration concerning T1 versus T3. This pattern is reversed for Q2 because no actual change is present between T2 and T3, yet approaching significance when comparing $\mathrm{T} 1$ and $\mathrm{T} 3$, indicating behavioural changes over time.

\section{Discussion}

The assumption that behaviour specifically related to OME could be described has been at the basis of this study. This resulted in the development and first psychometric evaluation of two age specific questionnaires describing the expected 'OME-specific behaviours' for children aged 12-48 months. It seems possi- 
ble to measure some aspects of this construct: the different subscales show variable degrees of internal consistency for both age specific questionnaires, whereas behavioural report remains stable before surgery and shows significant change after the resolution of OME. The emotional behaviour subscale is a striking exception in the last respect: although the scale shows a high amount of homogeneity for both questionnaires, the pattern of behavioural change after surgery is less consistent during this study.

This result touches at some fundamental theoretical and methodological issues in research concerning young children, which might also offer explanations at the same time. The questionnaires are based on statements that could not only be indicative of the presence or absence of OME, but also signify developmental milestones in young children.

For both the physical and motor and speech and language behaviour scales the expected milestones can be quite easily assessed and interpreted by parents, because developmental progression (e.g., walking, uttering new words) in these domains is expected to be quite visible and consistent. This is more difficult in the case of the emotional behaviour scale, not only because it is quite difficult to grasp what the concept really contains, due to the value laden nature of items referring to personality and social interaction. ${ }^{21}$ The relationship between parent and child is a mediating factor in this respect, which means that parental report of emotional behaviour in the child is not only a product of the beliefs and expectations of the parent, but also of the quality of the interaction between parent and child. ${ }^{18}$ The last point could be more explicitly stated by arguing that mutual emotional involvement is present, which could bias parental report concerning behaviour of the child. Although these arguments seem to apply to the language and speech and physical and motor behaviour scales as well, there is a difference in the fact that language and speech behaviour probably will be more directly related, through hearing, to the presence of OME in real life than parental expectation. Ascertaining the possible presence of a relation to OME seems quite easy for the physical and motor behaviour scale. The low amount of items in this category in both questionnaires, however, as mentioned in the Questionnaire development section, might be a repressing factor in reliability analysis.

It seems that parents become concerned by lack of (sufficient) progression in areas like language and physical development. If there is too much divergence according to parental expectations of normal development, usually a physician (i.e., GP) will be consulted. In this respect an important question according to Levy ${ }^{22}$ is: are these concerns valid or are they based on parental perceptions of their child as 'vulnerable'? How accurate are these appraisals of 'abnormality' made by parents? To date, little scientific knowledge seems to exist referring to 
the accuracy of parental judgment concerning the health status of the child. In this context, Rosenfeld ${ }^{14}$ argued:

'Although this degree of hearing impairment (i.e., between 15 and $27 \mathrm{~dB}$ ) was detected easily by an audiologist, caregivers' estimates of their child's hearing levels did not correlate with actual hearing levels, except for children with extreme hearing problems versus all others'. (p.1054)

It does not seem possible for parents to recognize subtle hearing losses, taking the self-resolving nature of the disease into consideration. The recognition of chronic OME cases might be important to avoid possible negative developmental consequences in the long term. These are the cases that need referral for treatment. ${ }^{19}$ It has been found that active questioning by health personnel increases the number of referrals in children with hearing disorders, especially those younger than 12 months, also resulting in the correct identification of more children at this young age. ${ }^{15}$ This seems an important argument in considering the clinical use of a short and easy-to-administer questionnaire for 'OME-specific behaviour'.

In medical practice, behavioural description could serve two goals: (1) to support the suspicion of OME and referral by a GP, and (2) as a check for the otolaryngologist after surgery to confirm the resolution of OME-related complaints. Because parents seem to have an important mediating role at this point, it is necessary to question the supposed 'uniformity' of parents and their children with OME: parental report of hearing disorders seems to be more prevalent in higher socioeconomic groups, whereas the objective evidence indicates a higher prevalence of OME in the lower socioeconomic groups. ${ }^{19}$

This statement raises new questions, calling for two directions in future research: (1) validation of the questionnaire(s) supposed to measure the construct 'OMEspecific behaviour', in which factor analysis on a number of 100 or more children might play a crucial role, resulting in a shorter and more easy-to-administer survey, because the current version of the questionnaire is usable in the context of research, but not in clinical practice (e.g., by the GP for the detection of OME). In this context, a control sample of children without OME is an important remaining factor in the construct validation of both questionnaires. In clinical practice this seems a though job, taking the earlier mentioned high prevalence rates of OME into consideration.

(2) Investigation of the underlying concerns of parents: how serious is OME relative to other diseases that can occur during childhood? How is the child's quality of life influenced by the presence of OME, according to parental perception of their child's health status? This investigation might not only explain what causes 
differences in parental reports of hearing problems through their frame of reference, but also gain important insights into the validity of parental report concerning OME. An important issue seems to be raised here, because many guidelines for medical practice include hearing impairment as a criterion for detection and management of OME. In this context, it is stated that: 'in the absence of audiologic assessment, the best judgment as to the adequacy of hearing or history of hearing impairment should be sought, trusting on parental report'. ${ }^{23,24}$ There is usually no hearing test available in the practice of GPs, despite their important role in the detection and referral of children suspected to suffer from OME.

However, the last argument underlines the importance of this line of research, not only for the development of a valid questionnaire to ascertain behaviours expected to be OME-specific in young children in terms of research purposes, but in the long run through the construction of a survey with a good positive predictive value. From a clinical perspective, it might be important in the identification of the 'otitis-prone' condition that needs observation to enable the most optimal form of disease management. ${ }^{25}$ In supporting the basic goal of detecting chronic OME as early as possible, the child's development is expected to be served in a constructive fashion, considering high and often silent prevalence rates in young children. 


\section{References}

1. Black N. Glue ear: the new dyslexia? British Medical Journal. 1985;290:1963-1965.

2. Hindley P. Psychiatric aspects of hearing impairments. Journal of Child Psychology and Psychiatry. 1997;38:101-117.

3. Webster A, Bamford JM, Thyer NJ, Ayles R. The psychological, educational and auditory sequelae of early, persistent, secretory otitis media. Journal of Child Psychology \& Psychiatry. 1989;30:529-546.

4. Paradise JL. Otitis media during early life: how hazardous to development? A critical review of the evidence. Pediatrics. 1981;68:869-873.

5. Vernon-Feagans L, Manlove EE, Volling BL. Otitis media and the social behaviour of day-careattending children. Child Development. 1996;67:1528-1539.

6. Casselbrant ML, Brostoff LM, Cantekin El, Flaherty MR, Doyle WJ, Bluestone, CD, et al. Otitis media with effusion in preschool children. Laryngoscope. 1985;95:428-436.

7. Paradise JL. Does early-life otitis media result in lasting developmental impairment? Why the question persists and a proposed plan for addressing it. Advances in Pediatrics. 1992;39:157-165.

8. Riley LCM, Timmerman AA, Meesters CMG, Anteunis UC. In search of 'Otitis Media with EffusionSpecific Behaviour'. Dutch Journal for Ear- Nose- and Throat Surgery. 1997;3:173.

9. Silva PA, Kirkland C, Simpson A, Stewart IA, Williams SM. Some developmental and behavioural problems associated with bilateral otitis media with effusion. Journal of Learning Disabilities. 1982;15:417-421.

10. Feagans L, Sanyal M, Henderson F, Collier A, Appelbaum M. Relationship of middle ear disease in early childhood to later narrative and attention skills. Journal of Pediatric Psychology. 1987;12:581-594.

11. Forgays DK, Wasserman RC. Recurrent otitis media and parenting stress in mothers of two-yearold children. Developmental \& Behavioural Pediatrics. 1992;13:321-325.

12. Zinkus PW, Gottlieb MI. Patterns of perceptual and academic deficits related to early chronic otitis media. Pediatrics. 1980;66:246-253.

13. Roberts JE, Burchinal MR, Koch MA, Footo MM, Henderson FW. Otitis media in early childhood and its relationship to later phonological development. Journal of Speech and Hearing Disorders. 1988;53:416-424.

14. Rosenfeld RM, Goldsmith AJ, Tetlus L, Balzano A. Quality of life for children with otitis media. Archives of Otolaryngology—Head \& Neck Surgery. 1997;123:1049-1054.

15. Hitchings V, Haggard MP. Incorporation of parental suspicions in screening infants' hearing. British Journal of Audiology. 1983;17:71-75.

16. Friel-Patti S, Finitzo T. Language learning in a prospective study of otitis media with effusion in the first two years of life. Journal of Speech and Hearing Research. 1990;33:188-194.

17. Chen D. Parent-infant communication: early intervention for very young children with visual impairment or hearing loss. Infants and Young Children. 1996;9:1-12.

18. Goldfarb CE, Roberts W. Developmental monitoring in primary care. Canadian Family Physician. 1996;42:1527-1536.

19. Haggard MP, Birkin JA, Browning GG, Gatehouse S, Lewis S. Behaviour problems in otitis media. The Pediatric Infectious Disease Journal. 1994;13:S43-S50.

20. Campbell DT, Stanley JC. Experimental and quasi-experimental designs for research. Chicago: Rand McNally, 1963.

21. Northern JL, Downs MP. Hearing in children. Baltimore (MD): Waverley Press, 1978. 
22. Sweitzer RS. Audiologic evaluation of the infant and young child. In: Jaffe, BF. ed. Hearing loss in children: a comprehensive text. Baltimore: University Park Press, 1977:101-131.

23. Halberstadt-Freud HC. Psychological research with children and adolescents. Lisse: Swets \& Zeitlinger, 1989.

24. McCloskey G. Selecting and using early childhood rating scales. Topics in Early Childhood Special Education. 1990;19:39-64.

25. Veerman JW. Backgrounds and uses of behaviour questionnaires. In: Kievit Th, de Wit J, Groenendaal JHA, Tak JA. eds. Manual for psychological research serving the treatment of children. Amersfoort, the Netherlands: Academische Uitgeverij, 1992:224-242.

26. Pachter LM, Dworkin PH. Maternal expectations about normal child development in 4 cultural groups. Archives of Pediatric \& Adolescence Medicine. 1997;151:1144-1150.

27. Levy JC. Vulnerable children: Parents' perspectives and the use of medical care. Pediatrics. 1980;65:956-963.

28. van de Lisdonk EH, Appelman CLM, Bossen PC, de Melker RA, Dunk JHM, van Weert H. Dutch College of General Practitioners-Practice Guideline Otitis Media with Effusion. Huisarts en Wetenschap. 1991;34:426-429.

29. Stool SE, Berg AO, Berman S, Carney CJ, Cooley JR, Culpepper L. et al. Managing otitis media with effusion in young children. Quick reference guide for clinicians. (AHCPR Publication No. 94-0623). Rockville (MD): Agency for Health Care Policy and Research, Public Health Service, U.S. Department of Health and Human Services, 1994.

30. Linder TE. Management of 'otitis-prone' children: a diagnostic and therapeutic challenge. Otorhinolaryngologia Nova. 1998;8:148-153. 


\section{4}

\section{First psychometric evaluation of a disease-specific questionnaire for children's behaviour related to otitis media with effusion}

Angelique A. Timmerman Lucien J.C. Anteunis Cor M.G. Meesters 


\section{Abstract}

Objective: The major goal of the present study is a psychometric analysis of two age-specific questionnaires for the assessment of 'Otitis Media with Effusionspecific behaviour' in young children, intended for use in case-finding.

Methods: In total, 172 children aged 12 to 24 months and 121 children aged 25 to 48 months were available initially. Caregivers completed the questionnaires on two occasions before tympanostomy tube insertion and once 6 weeks later.

Results: Factor analysis of a matrix for 30 items yielded four factors for the younger age group and six factors for a 33-item matrix for the older age group, showing more differentiation of factors in terms of developmental specificity for behaviour related to OME. The total internal consistency was .82 and each of factor measured different aspects of the disease-specific behaviour $(\alpha \leq 0.25)$ in both questionnaires. Sensitivity to change seemed promising and was significant for the age-group 12-24 months.

Conclusions: Research with revised questionnaires is recommended, in an ongoing validation process, to create the optimal developmental conditions for children with chronic or persistent OME. 


\section{Introduction}

In research related to otitis media with effusion (OME) much attention has been paid to the possible negative consequences for the development of the young child, especially in speech and language. OME is also called glue ear because fluid is present in the middle ear cavity behind an intact tympanic membrane, in the absence of clinical symptoms of an acute infection and is usually accompanied by a hearing loss in a continuum between 20 and $30 \mathrm{~dB} .{ }^{1}$ This condition has become known as a self-limiting disease: the rate of spontaneous recovery is about $50 \%$ within 3 months. However, a small group of children between 25 and 48 months was reported to show persistent and recurrent episodes, with a probability of a first, second and third recurrence of $37 \%, 13 \%$ and $3 \%$, respectively. ${ }^{2}$ These children run a potential risk of adverse developmental sequelae, given the chronicity of OME. ${ }^{3}$ It is this small subgroup of children with chronic OME that require referral for further treatment at an Ear, Nose and Throat (ENT) department, as recommended by the clinical practice guideline for Otitis Media with Effusion. ${ }^{1,4}$ In clinical practice, the caregiver's concern about the child's condition usually leads to medical consultation. In the first years of life, caregivers must voice their suspicions about the child's condition, given the still rudimentary language development of the child. As the expression of children is assumed to be nonverbal at this stage, their behaviour is expected to be the most important means of communication. Reasons for caregiver concern could be either child development at a different rate than expected or concerns about the seriousness and duration of hearing-related symptoms, as expressed through a change in behavior. ${ }^{5}$ The otolaryngologist needs to objectify these parental concerns, which have been one of the indicators for the choice of treatment regimen in children with OME. ${ }^{6,7}$ To support this process of finding possible indicators of chronic OME in young children, as the clinical practice guideline does not provide information on how to assess which children are most in need for referral or medical intervention, two age-specific questionnaires have been developed, one for the age group of 12 to 24 months and one for the age group of 25 to 48 months. Both questionnaires are supposed to measure the presence of the so-called construct of 'OME-specific behaviour' and are intended for use in identification of the small subgroup of children suffering from chronic OME. The main question of an initial descriptive study was whether behaviours as reported by parents could be assumed to be specifically related to OME. ${ }^{8}$ Analysis indicated that the construct seemed promising and warranted further psychometric analysis. The main findings of the first study can be summarized as follows: (1) subscales showed varying degrees of internal consistency for the construct 'OME specific-behaviour' in both questionnaires, ranging from insufficient for the subscale 'physical and motor behaviour', 
moderate for 'speech and language behaviour' and fairly good for 'emotional behaviour'; (2) parental report was stable over time between two pretests, and (3) significant behavioural change appeared after tympanostomy tube insertion on the three scales for both age groups. ${ }^{8}$ Exploratory assessment of the factor structure of both questionnaires seems warranted.

The present study was guided by two hypotheses. First, the scales of the questionnaires, developed on theoretical grounds, should show a good statistical fit by assessment of factor structure, reliability and correlation pattern. Second, 'OME-specific behaviour', assumed to be measured by these scales, would show sensitivity to change after an intervention to resolve the symptoms.

\section{Methods}

\section{Description of study}

This study is part of a larger research project entitled 'The Maastricht Otitis Media with Effusion Study' and is aimed at assessment of developmental parameters related to OME as well as supporting evidence-based management.

\section{Questionnaire development}

During the first phase of questionnaire development, items were generated by means of different sources of information: (1) ENT surgeons, audiologists and speech and language experts were consulted and from their clinical expertise they described the behavioural expression of parent-reported symptoms often noticed in children suffering from chronic or recurrent $\mathrm{OME}$, and (2) scientific literature about child development yielded useful information about normal developmental stages, which was used to formulate aged-specific items and to assess deviations expressed in (auditory) behaviour. ${ }^{9-12}$

The questionnaire for infants aged 12 to 24 months contained 56 items (form A) and that for 25 to 48 months 59 items (form B). The questionnaires were supposed to tap the most important developmental domains: 'speech and language behaviour' (forms A and B: 19 items), 'emotional behaviour' (form A: 27 items, form B: 28 items), 'physical and motor behaviour' (form A: 10 items, form B: 12 items). The items were formulated as statements, either positive items expected to be specific for the presence of OME, i.e., 'my child touches or picks his ears regularly' or negative items, meaning that the presented behaviour is not expected to indicate the presence of OME, i.e., 'my child is very interested in new strange sounds'. This was done to reduce a tendency toward acquiescence. Each 
item had the same scoring format, a 5 -point Likert scale anchored by $1=$ 'do not agree at all' and $5=$ 'totally agree', with the midpoint of $3=$ 'do not agree, do not disagree'. Negative items not indicative of the presence of behaviour problems were reverse coded, which yielded unidirectional scores representing the 'OMEspecific behaviour'.

\section{Procedure}

The questionnaire was completed by the proxy (i.e., a parent or other caregiver of the child) at three points in time during this study, following the course of diagnosis and treatment at the ENT department. The first measurement (pre-test 1=T1) was planned before surgery, after the diagnosis of OME and the decision for tympanostomy tube insertion were made. Two to four weeks after the first pretest, the second measurement (pre-test $2=\mathrm{T} 2$ ) was administered during the outpatient surgery. When parent(s) and child revisited the hospital six weeks later for a check-up, i.e., otoscopy and tympanometry, the third measurement (post-test=T3) was scheduled.

Data collection The information presented here includes all data gathered during the project, which means that data from the earlier study ${ }^{8}$ have been included as well, so the sample is more sufficient. The subset of data gathered after the publication of the first study has been subjected to the same statistical analyses, which resulted in comparable outcomes as were reported earlier. ${ }^{8}$

Eligibility criteria Children were recruited from the Otolaryngology Department of the University Hospital of Maastricht in the most southern part of the Netherlands. Criteria for inclusion were: (1) age between 12 and 48 months, (2) suffering from chronic or recurrent OME for at least 3 months in both ears as diagnosed by otoscopy and tympanometry, (3) average hearing loss in the better ear of at least $20 \mathrm{~dB}$ during 3 months, and (4) scheduled for tympanostomy tube insertion within 2 to 4 weeks. Hearing losses were assessed using conditioned orientation response audiometry by means of narrow band noises delivered by a clinical audiometer to condition the orientation reflex (deliberate head turn or eye shift) by visual reinforcement (colour images) of the child's response. Children with tympanic membrane perforation, tympanostomy tubes at study entry or any middle ear pathologic condition other than OME were excluded. The present study was approved by the university hospital Medical ethics committee and informed consent was obtained from the proxy, usually the mother.

Participants The total sample consisted of 172 children (103 boys, 69 girls), with a mean age of 17.7 months $(S D=3.0)$ for the age group with a range of 12 to 24 months and 121 children ( 83 boys, 38 girls) with a mean age of 30.0 months $(S D=3.9)$ for the age group ranging from 25 to 48 months. In the former group 
was one child of 23.8 months; in the latter were four children of 24 months. This sex distribution is similar to those in similar studies, indicating male sex as a risk factor for acute and persistent otitis media. ${ }^{13,14}$

Dropouts for several reasons (e.g., change of residence, surgery within one week or more than two weeks, no surgery and incomplete questionnaires) resulted in different numbers of children during the moments of measurement: in the age group of 12 to 24 months 170 children were present at pre-test 1,130 children at pre-test 2 and 136 children at post-test, while the age group of 25 to 48 months comprised 120 children at pre-test 1, 96 children at pre-test 2 and 98 children at post-test.

\section{Statistical methods}

For each of the two questionnaires a principal components factor analysis with varimax rotation was performed. In a first factor solution for each questionnaire, the number of factors was based on two criteria. First, eigenvalues had to be greater than 1 (Kaiser criterion) and, second, only factors were used which had eigenvalues much greater than the following value, as stabilization suggests the next factors are probably the result of measurement variance. ${ }^{15}$ Items with factor loadings of at least .40 were included for the representative factors, and, in the case of items loading on two factors, the choice for the factor of best fit was made by reliability analysis and contextual meaning of the item.

Reliability analysis (Cronbach's $\alpha$ ) was the estimate for internal consistency of the scales in this sample, with the purpose of giving an indication of the statistical fit of different items in each factor.

Responsiveness to clinical change after placement of tympanostomy tubes was measured by the standardized response mean (SRM), which is the mean change score per item divided by its $S D$. The magnitude of change can be classified: a SRM of .20 reflects small responsiveness, .50 moderate responsiveness, and .80 or more large responsiveness to change. ${ }^{16}$ Paired-sample $t$ tests were applied to assess the significance of change after surgery as differences were measured within subjects over time.

\section{Results}

All statistical analyses were carried out using the SPSS Version 10.0 statistical software package. 


\section{Factor structure of questionnaires}

An exploratory analysis was performed for the questionnaires and a three factor structure was inspected, as the developed questionnaires contained three domains before factor analysis. However, this proved to be insufficient. For the age group of 12-24 months factor analyses yielded four factors: 'perceptive speech' (12 items), 'emotional distress' (7 items), 'attention-seeking' (7 items) and 'earrelated symptoms' (4 items), accounting for $29.1 \%$ of the variance. These results are presented in Table 1.

Table 1 Varimax rotated four-factor solution of age-specific questionnaire for specific behaviour in children aged 12 to 24 months related to otitis media with effusion

\begin{tabular}{|c|c|c|c|c|}
\hline \multirow[b]{2}{*}{ Item } & \multicolumn{4}{|c|}{ Factor } \\
\hline & 1 & 2 & 3 & 4 \\
\hline 1. Child's hearing gives rise to parental concern & .51 & -.03 & .08 & .18 \\
\hline 2. Child tries to imitate noises, like 'ahh' & .57 & .09 & .00 & -.01 \\
\hline 3. Child explores the environment by vision & .67 & -.03 & -.01 & .12 \\
\hline 4. Child shows interest in strange noises & .65 & -.14 & -.06 & -.02 \\
\hline 5. Child waves goodbye at parental request & .44 & .34 & -.10 & -.05 \\
\hline 6. Child tries to imitate parental sounds & .65 & .11 & .04 & -.04 \\
\hline 7. Child's attention is attracted at a normal voice & .58 & -.14 & .20 & .01 \\
\hline 8. Child responds to softer sounds & .57 & .05 & .12 & -.04 \\
\hline 9. Child is capable of naming three objects & .54 & .01 & -.09 & .07 \\
\hline 10. Child shows little difficulty talking & .55 & .06 & -.02 & .00 \\
\hline 11. Child doesn't hear any noises while playing & .52 & .04 & .11 & .14 \\
\hline 12. Child's attention is not difficult to attract & .63 & .13 & .25 & -.05 \\
\hline 13. Child cries easily without an obvious reason & .08 & .45 & .37 & .42 \\
\hline 14. Child refuses anything and has been wining & -.02 & .52 & .28 & .35 \\
\hline 15. Child shifts between moods quite suddenly & .11 & .52 & .35 & .26 \\
\hline 16. Child strikes parent as unhappy for no reason & .20 & .69 & .12 & .15 \\
\hline 17. Child often seems to feel nervous and anxious & -.19 & .53 & .03 & .09 \\
\hline 18. Child often gives a weary impression & .09 & .68 & -.13 & .15 \\
\hline 19. Child behaves shyly in the company of strangers & -.11 & .50 & .25 & -.10 \\
\hline 20. Child may get hot-tempered if not understood & .23 & .14 & .45 & -.04 \\
\hline 21. Child behaves usually quite impulsively & -.07 & .02 & .55 & -.03 \\
\hline 22. Child prefers to stay with parent all the time & .08 & .12 & .55 & .10 \\
\hline 23. Child screams a lot while playing & .21 & .05 & .54 & -.02 \\
\hline 24. Child's busy conduct is not easy to inhibit & -.04 & -.01 & .69 & .02 \\
\hline 25. Child asks for attention when parent is busy & -.05 & .08 & .58 & .30 \\
\hline 26. Child panics quickly if parent is out of sight & .17 & .29 & .42 & .21 \\
\hline 27. Child sleeps uneasily and wakes up often & -.06 & .12 & -.02 & .62 \\
\hline 28. Child touches or picks its ears regularly & .16 & .05 & .03 & .50 \\
\hline 29. Child seems to be having an earache & .17 & .10 & .24 & .52 \\
\hline 30. Child has been ill often from a cold or flu & .03 & .06 & -.17 & .47 \\
\hline Eigenvalue & 7.3 & 4.3 & 2.5 & 2.2 \\
\hline Explained variance (\%) & 13.0 & 7.7 & 4.5 & 3.9 \\
\hline
\end{tabular}

Factor loadings $>.40$ are in bold face; $n=170$. Factors are (1) perceptive speech, (2) emotional distress, (3) attention-seeking (4) ear-related symptoms. 
A six factor solution was most satisfactory for the age group of 25 to 48 months: 'productive speech' (4 items), 'emotional discomfort' (6 items), 'oppositional behaviour' ( 8 items) besides sleeping problems ( 4 items), separation anxiety (6 items) and auditory responsivity (5 items), accounting for $38.1 \%$ of the variance, as can be seen in Table 2.

Table 2 Varimax rotated six-factor solution of age-specific questionnaire for specific behaviour in children aged 25 to 48 months related to otitis media with effusion

\begin{tabular}{|c|c|c|c|c|c|c|}
\hline \multirow[b]{2}{*}{ Item } & \multicolumn{6}{|c|}{ Factor } \\
\hline & 1 & 2 & 3 & 4 & 5 & 6 \\
\hline 1. Child shows little difficulty talking & .77 & -.05 & .09 & .04 & -.04 & .11 \\
\hline 2. Child is capable of saying two-word sentences & .71 & .17 & .14 & .05 & .09 & -.03 \\
\hline 3. Child says its name at parental request & .75 & -.05 & .06 & -.09 & -.03 & .00 \\
\hline 4. Child is capable of naming three objects & .71 & .10 & .01 & -.01 & .33 & .05 \\
\hline 5. Child seems to listen with one ear & .04 & .51 & .18 & .21 & .12 & -.04 \\
\hline 6. Child often makes a weary, listless impression & .04 & .67 & .10 & .03 & .16 & -.05 \\
\hline 7. Child often seems to feel nervous and anxious & .08 & .52 & -.10 & .13 & .13 & .19 \\
\hline 8. Child often seems to be lost in daydreams & .08 & .66 & .01 & .18 & -.20 & .03 \\
\hline 9. Child suddenly falls asleep during the day & -.13 & .45 & .14 & .14 & .18 & .01 \\
\hline 10. Child often appears to have a lack of energy & .03 & .59 & -.20 & .23 & .06 & .09 \\
\hline 11. Child appears to be 'sham deaf' & -.07 & .17 & .42 & .12 & -.07 & -.05 \\
\hline 12. Child interrupts parental conversation by talking & -.15 & .13 & .45 & -.07 & .21 & -.28 \\
\hline 13. Child clears away toys when requested & .08 & .05 & .54 & -.09 & .14 & .23 \\
\hline 14. Child doesn't respond to anger when naughty & .22 & -.12 & .41 & -.19 & .28 & .16 \\
\hline 15. Child behaves usually quite impulsively & .07 & -.04 & .47 & .11 & .34 &. .15 \\
\hline 16. Child is usually good and rarely causes trouble & .10 & .04 & .62 & .05 & .24 & .23 \\
\hline 17. Child often gets attention by behaving clownishly & -.08 & -.09 & .63 & .14 & .06 & -.09 \\
\hline 18. Child often has minor injuries, despite warnings & .04 & .06 & .52 & .32 & -.08 & .03 \\
\hline 19. Child is troubled a lot by nightmares and screams & .01 & -.06 & .06 & .61 & .08 & .11 \\
\hline 20. Child sleeps uneasily and wakes up often at night & -.14 & .14 & .11 & .60 & -.07 & .06 \\
\hline 21. Child moves the head back and forth & .17 & .20 & .08 & .47 & .11 & -.08 \\
\hline 22. Child seems to be dizzy and falling over often & .18 & .25 & .04 & .56 & .01 & .00 \\
\hline 23. Child shifts between moods quite suddenly & .15 & .23 & .22 & .33 & .42 & .00 \\
\hline 24. Child prefers to stay with parent all the time & .10 & .12 & .18 & .04 & .61 & -.04 \\
\hline 25. Child refuses anything and has been whining & .05 & .29 & .18 & .25 & .48 & .04 \\
\hline sy parent & .09 & .02 & .27 & .09 & .55 & -.28 \\
\hline 27. Child panics quickly when parent is out of sight & .18 & .06 & .08 & .28 & .58 & .10 \\
\hline 28. Child shows a strong need of physical contact & -.04 & .06 & .01 & -.04 & .65 & -.01 \\
\hline 29. Child turns head toward a sound & .14 & .12 & -.03 & -.08 & -.01 & .57 \\
\hline 30. Child turns head up toward a sound & .04 & .04 & .01 & -.07 & -.17 & .51 \\
\hline 31. Child smiles easily at parent and familiar people & .00 & .44 & -.16 & -.06 & .12 & .47 \\
\hline 32. Child is easily comforted by a soothing voice & .03 & .15 & .18 & .03 & .04 & .61 \\
\hline 33. Child's attention is not difficult to attract & .24 & .30 & .48 & -.10 & -.02 & .46 \\
\hline Eigenvalue & 8.0 & 3.9 & 3.3 & 2.7 & 2.4 & 2.2 \\
\hline Explained variance (\%) & 13.6 & 6.6 & 5.6 & 4.6 & 4.1 & 3.7 \\
\hline
\end{tabular}

Factor loadings $>.40$ are in bold face; $n=120$. Factors are (1) productive speech, (2) emotional discomfort, (3) oppositional behaviour, (4) sleeping problems, (5) separation anxiety and (6) auditory responsivity. 


\section{Psychometric evaluation of 'OME-specific behaviour'}

The reduced questionnaires contained 30 items for the age group of 12 to 24 months and 33 items for the age group of 25 to 48 months. These remaining items constituted the basis for further statistical analyses.

\section{Internal consistency of factor scores}

The internal consistency for each factor at pre-test 1 is described in Table 3. The choice for using only data from pre-test 1 was based on the larger amount of data available compared to data at pre-test 2 and post-test. The alphas ranged from .52 for the ear-related symptoms ( 4 items) to .83 for perceptive speech (12 items), with the intermediate values of .70 for attention-seeking ( 7 items) and .78 for emotional distress (7 items) for the questionnaire for children aged 12 to 24 months. For the age group of 25-48 months, internal consistency scores showed a range from .63 for sleeping problems ( 4 items) to .79 for productive speech ( 4 items). The following results were found for the other factors: auditory responsivity (5 items), .66, oppositional behaviour (8 items) .70, emotional discomfort (6 items) .71 and separation anxiety (6 items) .72 . These results indicate that the factors for speech and language development showed the strongest homogeneity of response for both age groups at pre-test 1 . Most values were above the recommended value of .70 .

Table 3 Reliability coefficients for factors related to 'OME-specific behaviour' (ages 12 to 24 and 25 to $\mathbf{4 8}$ months) at first pre-test

\begin{tabular}{lccc}
\hline & & \multicolumn{2}{c}{ Crohnbach $\alpha$} \\
\cline { 3 - 4 } Factor & No. of items & $\begin{array}{c}\mathbf{1 2} \text { to } \mathbf{2 4} \text { months } \\
(\boldsymbol{n = 1 7 0 )}\end{array}$ & $\begin{array}{c}\mathbf{2 5} \text { to } \mathbf{4 8} \text { months } \\
(\boldsymbol{n}=\mathbf{1 2 0})\end{array}$ \\
\hline Perceptive speech & 12 & .83 & .79 \\
Productive speech & 4 & & \\
Emotional distress & 7 & .78 & .71 \\
Emotional discomfort & 6 & & .70 \\
Attention-seeking & 7 & .70 & .63 \\
Oppositional behaviour & 8 & .52 & .72 \\
Ear-related symptoms & 4 & & .66 \\
Sleeping problems & 4 & & \\
Separation anxiety & 6 & & \\
Auditory responsivity & 5 & &
\end{tabular}

\section{Intercorrelations between factors}

As depicted in Table 4, the Pearson correlations between factors for the younger age group ranged from .11 to .42 (average .20), while the older age group values ranged from .03 to .41 (average .25) at pre-test 1. It could be assumed that the 
scales measure different aspects of the construct in the two questionnaires, since correlations ranged from low to moderate.

Table 4 Pearson correlations between factor scores of 'OME-specific behaviour' questionnaires for children aged 12-24 months $(n=170)$ and 25 to 48 months $(n=120)$

\begin{tabular}{lcccccccccc}
\hline Factor & $\mathbf{1}$ & $\mathbf{2}$ & $\mathbf{3}$ & $\mathbf{4}$ & $\mathbf{5}$ & $\mathbf{6}$ & $\mathbf{7}$ & $\mathbf{8}$ & $\mathbf{9}$ & $\mathbf{1 0}$ \\
\hline 1. Perceptive speech & & & & & & & & & & \\
2. Emotional distress & .12 & & & & & & & & & \\
3. Attention-seeking & $.21^{2}$ & $.42^{2}$ & & & & & & & & \\
4. Ear-related symptoms & $.18^{1}$ & $.30^{1}$ & .11 & & & & & & & \\
5. Productive speech & & & & & & .12 & .17 & .08 & $.24^{2}$ & $.20^{1}$ \\
6. Emotional discomfort & & & & & & & .18 & $.35^{2}$ & $.33^{2}$ & $.26^{2}$ \\
7. Oppositional behaviour & & & & & & & & $.21^{1}$ & $.41^{2}$ & .15 \\
8. Sleeping problems & & & & & & & & & $.30^{2}$ & .03 \\
9. Separation anxiety & & & & & & & & & & .06 \\
10. Auditory responsivity & & & & & & & & & & \\
\hline
\end{tabular}

Correlations above the diagonal for 12 to 24 months age group, below the diagonal for group 25 to 48 months old. ${ }^{1} p<.05$, 2-tailed, ${ }^{2} p<.01$, 2-tailed.

\section{Test-retest reliability and sensitivity to change after intervention}

The test-retest stability was calculated between pre-test 1 and pre-test 2 for all factors by a paired-sample $t$ test, with a Bonferroni correction. For the age group 12 to 24 months all factors were stable over time $(\alpha=.05 / 7=.007)$. Sensitivity to change of the revised questionnaires after insertion of tympanostomy tubes was assessed by the SRM as depicted in Table 5 .

For the age group 12 to 24 months the SRM can be described as large for the factor perceptive speech, .93 between pre-test 1 and post-test and 1.04 between pre-test 2 and post-test. The SRM was moderate to large for the factor earrelated symptoms, as the value was .74 between pre-test 2 and post-test and .85 between pre-test 1 and post-test. For the factors emotional distress and attention-seeking, values were small, ranging from .10 to .41 . The overall score showed a large SRM both for pre-test 1 versus post-test (.89) and pre-test 2 versus posttest (1.01). The paired-sample $t$ tests showed significant changes for all factors and total questionnaire scores in the age group 12-24 months $(\alpha=.01)$, except for attention-seeking between pre-test 1 and post-test.

In the age group 25 to 48 months the SRMs were moderate for the factor productive speech, with values of .54 between pre-test 1 and post-test and .57 between pre-test 2 and post-test. Comparable values were noted for the factor emotional discomfort, .51 between pre-test 1 and post-test and .58 between pre-test 2 and post-test, respectively. SRMs were small for the factors oppositional behaviour, sleeping problems, separation anxiety and auditory responsivity, ranging from 
.22 tot .31 . The SRM was moderate for the total score between pre-test 1 and post-test (.57) and large for pre-test 2 versus post-test (1.65). For productive speech, emotional discomfort, sleeping problems and the total questionnaire score, significant changes were found as measured with paired-sample $t$ tests $(\alpha=.007)$.

Table 5 Sensitivity to change for factors related to 'OME-specific behaviour' as measured by comparison of outcomes before (pre-test 1 and pre-test 2) and after (post-test) surgery

\begin{tabular}{|c|c|c|c|c|c|}
\hline \multirow[b]{2}{*}{ Factor } & \multirow[b]{2}{*}{ Test } & \multicolumn{2}{|c|}{$\begin{array}{c}12-24 \text { months } \\
(n=115)\end{array}$} & \multicolumn{2}{|c|}{$\begin{array}{c}25-48 \text { months } \\
(n=86)\end{array}$} \\
\hline & & SRM & $95 \% \mathrm{Cl}$ & SRM & $95 \% \mathrm{Cl}$ \\
\hline \multirow[t]{2}{*}{ Perceptive speech } & pre-test 1-post-test & .93 & $6.64-9.91^{1}$ & & \\
\hline & pre-test 2-post-test & 1.04 & $7.93-11.34^{1}$ & & \\
\hline \multirow[t]{2}{*}{ Emotional distress } & pre-test 1-post-test & .29 & $.63-2.95^{1}$ & & \\
\hline & pre-test 2-post-test & .41 & $1.24-3.24^{1}$ & & \\
\hline \multirow[t]{2}{*}{ Attention-seeking } & pre-test 1-post-test & .10 & $-.50-1.72$ & & \\
\hline & pre-test 2-post-test & .29 & $.53-2.35^{1}$ & & \\
\hline \multirow[t]{2}{*}{ Ear-related symptoms } & pre-test 1-post-test & .85 & $3.27-5.08^{1}$ & & \\
\hline & pre-test 2-post-test & .74 & $2.59-4.32^{1}$ & & \\
\hline \multirow[t]{2}{*}{ Total score } & pre-test 1-post-test & .89 & $11.75-17.95^{1}$ & & \\
\hline & pre-test 2-post-test & 1.01 & $13.79-19.99^{1}$ & & \\
\hline \multirow[t]{2}{*}{ Productive speech } & pre-test 1-post-test & & & .54 & $1.15-2.65^{2}$ \\
\hline & pre-test 2-post-test & & & .57 & $.96-2.11^{2}$ \\
\hline \multirow[t]{2}{*}{ Emotional discomfort } & pre-test 1-post-test & & & .51 & $1.03-2.51^{2}$ \\
\hline & pre-test 2-post-test & & & .58 & $1.47-3.18^{2}$ \\
\hline \multirow[t]{2}{*}{ Oppositional behaviour } & pre-test 1-post-test & & & .24 & $.14-2.49$ \\
\hline & pre-test 2-post-test & & & .22 & $.25-2.14$ \\
\hline \multirow[t]{2}{*}{ Sleeping problems } & pre-test 1-post-test & & & .31 & $.34-1.89^{2}$ \\
\hline & pre-test 2-post-test & & & .31 & $.29-1.60^{2}$ \\
\hline \multirow[t]{2}{*}{ Separation anxiety } & pre-test 1-post-test & & & .30 & $.41-2.61$ \\
\hline & pre-test 2-post-test & & & .23 & $.08-2.31$ \\
\hline \multirow[t]{2}{*}{ Auditory responsivity } & pre-test 1-post-test & & & .26 & $.19-1.95$ \\
\hline & pre-test 2-post-test & & & .28 & $.23-1.88$ \\
\hline \multirow[t]{2}{*}{ Total score } & pre-test 1-post-test & & & .57 & $5.42-11.93^{2}$ \\
\hline & pre-test 2-post-test & & & 1.65 & $4.93-11.34^{2}$ \\
\hline
\end{tabular}

Standardized response mean (SRM): mean change score divided by $S D .{ }^{1} p<.05 / 5=.01,2$-tailed, as measured by a paired-sample $t$ test. ${ }^{2} p<.05 / 7=.07$, 2-tailed, as measured by a paired sample $t$ test.

\section{Discussion}

The major purpose of the present study was to explore the psychometric qualities of two new questionnaires, developed to assess behavioural expressions that might be associated with OME at two age periods in a population of very young 
children with chronic and recurrent symptoms. The earlier study only described the first clinical test results. ${ }^{8}$

At content level, for each age group the factors seemed to be specific for the developmental stage: sensorial exploration of the environment seems to be crucial for the age group 12-24 months, as reflected by perceptive speech and attentionseeking and the older the child gets, the more important the interaction with the environment and the child's response to auditory stimulation becomes, as visible in the factors productive speech and separation anxiety for the age group 25-48 months (Tables 1 and 2). At least present results reflected the presence of some important developmental milestones, like the maturation of the orientation response at 13 months and the independence of early separation starting by the age of 2 years, as found in literature. ${ }^{10,17}$ The finding that the factor structure did not show an exact statistical fit with the theoretical formulation of scales may be explained in two ways. First, the nature of this first factor analysis was exploratory and, second, the present study showed that more specificity may be present in behaviours assumed to be related to OME. On theoretical grounds the scales were formulated quite generally.

The sensitivity to change, as a measure of validity, delivers information about the effect of tympanostomy tube placement on behavioural outcomes. The outcomes seemed quite promising, especially for the age group 12-24 months with large SRMs for factors that seem to be more directly influenced by OME, like speech and symptoms related to functioning of the ear. The responsiveness was smaller for the age group 25-48 months, which may be due to the smaller number of children available. The overall values were large, at least on the longer term (pretest 1-post-test), indicating good responsiveness to change on the questionnaires as a whole.

However, it is important to put these results in a reasonable perspective. First, the study population seems to be quite homogeneous given the presence of a chronic hearing loss of at least 3 months, but the route of referral might be considered as heterogeneous because children were referred by either universal hearing screening programs or general practitioners. This may yield different symptom patterns: the first group did not pass universal hearing screening tests and may be otherwise relatively asymptomatic, while parent-reported symptoms and concerns about hearing loss or developmental delay often support the decision for referral to an ENT department in the group referred by general practitioners. The different symptom patterns are expected to be reflected in parental report on questionnaires and reflect higher unexplained variance. This hypothesis requires further research in which both groups are separated, as only the second more homogeneous group is really important in terms of developing a casefinding questionnaire. The reason is that epidemiological data show that only 1 - 
$2 \%$ of high-risk children get surgery, given the chronic and recurrent nature of the disease and the risk of adverse developmental sequelae. ${ }^{18}$ The questionnaire may play an important additional role in subsequent detection of children expected to benefit most from surgery.

Although it has been commonly acknowledged that these outcomes need to be studied with a view on resolution and further prevention of possible negative sequelae of OME in clinical practice, the second issue is whether these could be specifically related to the presence of OME. Other confounding factors, e.g., phase of child development, socioeconomic status, parental IO and education, are known to influence speech and language development, learning functions and behaviour of the child and so also to be associated with the possible sequelae of OME. This situation may explain some of the variance. Although the influence of these other variables should be accounted for, caregivers do have the opportunity of observing the hearing and behaviour of their child in a noisy home environment over a prolonged period of time..$^{19}$ It is hypothesized that they might be capable of perceiving subtle changes in the child's hearing related behavior, which should be expected, given the intermittent and recurrent nature of OME. From a clinical point of view, these subtle but detectable changes could be very important for clinicians to objectify the subjective effects of interventions, e.g., tympanostomy tube placement. Recent studies have shown the indirect relationships between OME and developmental consequences. Factors like caregivers' responsiveness and the quality of the home environment may play a mediating role in this relationship through the hearing loss of the child. ${ }^{20}$ The accumulation of these factors in combination with chronic or recurrent symptoms result in the greatest risk for compromised development. These questionnaires may not only assist the screening and diagnostic process of children showing chronic symptoms but also help caregivers understand the behaviour of their child, as knowledge about their child's condition is necessary when learning to manage effectively the sequelae of OME.

To measure the just-mentioned subtle effects, it becomes important to use a questionnaire with sufficient statistical power to detect small changes closely associated with insertion of a tympanostomy tube. This necessitates a questionnaire that is disease-specific, like the ones under development and sensitive to within-subject changes. In conclusion, the present study is one of the first attempts to ask parents about behavior that may be associated with $\mathrm{OME}$, in an ongoing process of studying the content validity of the questionnaires. 


\section{References}

1. Van de Lisdonk EH, van Balen FAM, van Weert HCPM, Eekhof JAH, Appelman CLM, Eizenga WH. Dutch College of General Practitioners-Practice Guideline Otitis Media with Effusion. Huisarts en Wetenschap. 2000;43:171-177.

2. Zielhuis GA, Rach GH, van den Broek P. The natural course of otitis media with effusion in preschool children. European Archives of Otorhinolaryngology. 1990;247:215-221.

3. Rosenfeld RM, Kay D. Natural History of Untreated Otitis Media. The Laryngoscope. 2003;113:1645-1657.

4. Rosenfeld RM, Culpepper L, Doyle KJ, Grundfast KM, Hoberman A, Kenna MA. et al. Clinical practice guideline: otitis media with effusion. Otolaryngology-Head \& Neck Surgery. 2004;130:S95S118.

5. Timmerman AA, Anteunis $\sqcup C$, Meesters CMG. Response-shift bias and parent-reported Quality of Life in Children with Otitis Media. Archives of Otolaryngology-Head \& Neck Surgery. 2003;129:987-991.

6. Karkanevatos A, Lesser THJ. Grommet insertion in children: a survey of parental perceptions. Journal of Laryngology and Otology. 1998;112:732-741.

7. Mclsaac WJ, Coyte PC, Croxford R, Asche CV. Otolaryngologists' perceptions of the indications for tympanostomy tube insertion in children. Canadian Medical Association Journal. 2000;162:12851288.

8. Timmerman AA, Anteunis $\sqcup C$, Meesters CMG. The initial development of an instrument for the description of 'Otitis Media with Effusion Specific Behaviour' in young children. International Journal of Behavioral Medicine. 1999;6:255-267.

9. Sweitzer RS. Audiologic evaluation of the infant and young child. In: Jaffe BF. ed. Hearing loss in children: a comprehensive text. Baltimore, MD: University Park Press, 1977:101-131.

10. Northern JL, Downs MP. Development of auditory behaviour. In: Hearing in children. Baltimore (MD): Williams \& Wilkins, 1978:77-92.

11. Halberstadt-Freud HC. Psychodiagnostic testing with children and adolescents. Lisse, the Netherlands: Swets \& Zeitlinger, 1989.

12. Goldfarb CE, Roberts W. Developmental monitoring in primary care. Canadian Family Physician. 1996;42:1527-1536.

13. Alho OP, Oja $\mathrm{H}$, Koivu $\mathrm{M}$, Sorri $\mathrm{M}$. Risk factors for chronic otitis media with effusion in infancy: each acute otitis media episode induces high but transient risk. Archives of OtolaryngologyHead \& Neck Surgery. 1995;121:839-843.

14. Bennett KE, Haggard MP. Behaviour and cognitive outcomes from middle ear disease. Archives of Diseases in Childhood. 1999;80:28-35.

15. Van Breukelen GJP. ed. Analysis of questionnaires: factor analysis. Maastricht, the Netherlands: University of Maastricht, 1996.

16. Liang MH, Fossel AH, Larson MG. Comparisons of five health status instruments for orthopedic evaluation. Medical Care. 1990;28:632-642.

17. Illingworth RS. The development of the infant and young child-normal and abnormal. 8th ed. London: Churchill Livingstone, 1983.

18. Engel JAM, Anteunis UC, Hendriks JJT. Treatment with grommets in the Netherlands: incidence in children from birth to 12 years. In: Tos M, Thomsen J, Balle V. eds. Otitis media today. The Hague: Kugler Publications, 1999:451-455.

19. Hellier WPL, Corbridge RJ, Watters G, Freeland AP. Grommets and patient satisfaction: an audit. Annals of the Royal College of Surgeons in England. 1997;79:428-431. 


\section{Psychometric evaluation of 'OME-specific behaviour'}

20. Roberts J, Hunter L, Gravel J, Rosenfeld R, Berman S, Haggard M. et al. Otitis media, hearing loss and language learning: controversies and current research. Developmental \& Behavioral Pediatrics. 2004;25:110-122. 



\section{Response-shift bias and parent-reported quality of life in children with otitis media}

Angelique A. Timmerman Lucien J.C. Anteunis Cor M.G. Meesters 


\section{Abstract}

Objective: To validate the 6-item quality-of-life survey (OM-6) and to investigate response-shift bias regarding children with otitis media.

Setting: Otorhinolaryngology department of a university hospital that serves the southernmost part of the Netherlands.

Patients: Seventy-seven children (age range 12-38 months) experiencing persistent otitis media with effusion and scheduled for placement of tympanostomy tubes.

Survey: The OM- 6 measures health-related quality of life in 6 domains: physical suffering, hearing loss, speech impairment, emotional distress, activity limitations and caregiver concerns.

Intervention: Parents completed the OM- 6 before surgery (pre-test) and 6 weeks after surgery (post-test). At the posttest, parents also completed a retrospective version of the pre-test (retrospective pre-test).

Results: For most items, the test-retest reliability was good $(r>.80)$. The internal consistency of the OM- 6 was satisfactory $(\alpha=.79)$. The construct validity, determined by correlating the ear-related global quality-of-life measure and the OM- 6 summary score, was fair $(r=-.77, p<.01)$. Prospective change in quality of life on the $\mathrm{OM}-6$ ranged from moderate (standardized response mean $\geq 0.5$ ) to large (standardized response mean $\geq 0.8$ ). Response-shift bias was present at the group level $(t=-3.3, p<.01)$. Retrospective change was significant for hearing loss $(z=-3.3$, $p<.05)$ and ear-related global quality of life' $(z=-3.6, p<.05)$.

Conclusions: The validity of the OM- 6 has been proved in a Dutch population. The data suggest that parents underestimate the seriousness of hearing loss and overestimate the quality of life of their child before surgery, indicating a response shift. Treatment results could lead parents to realize that the situation before surgery had been worse than they thought. 


\section{Introduction}

In medical practice concerning infants, a caregiver, in most cases the parent, makes decisions about seeking medical consultation on the basis of perceived symptoms of the child. This situation resembles that of other care-dependent groups, such as developmentally disabled or psychiatric patients. ${ }^{1}$

This could be applied to otitis media with effusion (OME) as well. Otitis media with effusion has a high prevalence in childhood; almost $90 \%$ of children experience at least one episode in the first few years of life, and up to one third have recurrent problems with $\mathrm{OME} .^{2-4}$ Although $\mathrm{OME}$ is mainly known as a 'silent disease', it has been associated with symptoms such as common cold, mouth breathing, ear infection, and hearing loss. ${ }^{5}$ Except for children detected by an ongoing hearing screening program, parental suspicion usually leads to consultation of the general practitioner and often referral to an ears, nose and throat surgeon. ${ }^{6}$ Caregiver concern usually results from a noticed change in behaviour related to a child's hearing loss, because expression is assumed to be predominantly nonverbal during the first years of life. ${ }^{7}$ The developmental rate of the young child may not meet parental expectations and gives rise to concerns about the seriousness and duration of hearing-related symptoms.

The general practitioner or ears, nose and throat (ENT) surgeon has to specify and objectify these parental concerns through further questioning, inspection of the tympanic membrane, and if possible, estimation of hearing thresholds. The situation becomes complicated for the surgeon when there seems to be no objective indication for surgical intervention (such as grommet insertion or adenoidectomy), yet parental concern and desire for surgical intervention remain.

The basis of parental concern is generally subjective symptoms, such as hearing loss, poor appetite, irritability and loss of energy, which may have negative consequences on the quality of life in children with OME. One attempt to objectify the presence of subjective symptoms has resulted in the development, validation and application of the 6-item quality-of-life survey (OM-6) in the United States. The aim of this instrument, developed by Rosenfeld and colleagues ${ }^{8}$, is to measure health-related quality of life (HROL) in the presence of chronic OME or recurrent acute otitis media. In this context, HROL reflects the parents' subjective perception of the current health status of the child and refers to the possible impairment in functioning and well-being of the child as a consequence of OME. In addition, a 'real change' in HROL after surgery is increasingly needed to justify any intervention for OME in the absence of objective symptoms. ${ }^{9,10}$

As an extension of the earlier OM- 6 study $^{8}$, the possible effect of parental perceptions on their report about the child's HROL is examined herein. Assessment of response shift on HRQL changes constitutes the main goal of the present study. 
For example, the placement of tympanostomy tubes in children with OME, often a chronic condition, creates a sudden resolution, which may elicit an adaptation in parental perception. It is hypothesized that, after treatment of OME, parents realize that the previous HROL of the child was worse than they had recognized, as they are now able to make a comparison between the situation before and after surgery. This phenomenon has been described as scale recalibration, a variant of response-shift bias, which indicates that after intervention a change has taken place in the respondent's internal standard of measurement. ${ }^{11}$ When parents overestimate the HROL before surgery, not taking response-shift bias into consideration may result in an underestimation of the reported treatment effects. ${ }^{12}$

This study is also an attempt to validate the OM-6 in a Dutch population of children with chronic OME. Validation of the OM- 6 is a necessary requisite for the assessment of hypothesized changes in HROL resulting from surgical intervention.

\section{Methods}

\section{Participants}

The participating children were seen in the Department of OtorhinolaryngologyHead and Neck Surgery at the University Hospital of Maastricht, which also serves a regional function in the southernmost part of the Netherlands. This population was part of an ongoing study concerning OME and specifically related behaviours that had been approved by the University hospital Medical Ethics Committee. The following eligibility criteria were met: (1) age at entry between 12 and 36 months; (2) chronic or recurrent OME in both ears for at least three months as diagnosed by an ENT surgeon through otoscopy; (3) hearing loss of at least $20 \mathrm{~dB}$ in the better ear; (4) tympanostomy tubes insertion scheduled as outpatient surgery within 2 to 4 weeks after diagnosis of OME, and (5) ability of the accompanying parent or other caregiver to read and understand the Dutch language. These criteria were comparable to those used in the first OM- 6 study ${ }^{8}$, except for our inclusion of only young children at study entry. The first OM-6 study included children aged 6 months to 12 years. Exclusion criteria consisted of: (1) tympanic membrane perforation, (2) tympanostomy tubes at study entry, (3) middle ear pathologic condition other than OME, and (4) any known neurological disorder. 


\section{Quality of life and response shift bias}

The parents of participating children received a letter with information about the goals and procedures of the OM- 6 study and written informed consent was obtained.

\section{Survey}

The OM- 6 was translated from English into Dutch, in consultation with a native English speaker. ${ }^{8}$ The OM- 6 contains 6 items representing HRQL associated with OME: (1) physical suffering, (2) hearing loss, (3) speech impairment, (4) emotional distress, (5) activity limitations, and (6) caregiver concerns. The scoring format consisted of a 7-point scale for the items, ranging from 1 (not present or no problem) to 7 (extreme problem), with a midpoint of 4 (moderate problem). A global measure, also present in the original English version, summarizing ear-related global quality of life was included as well. The global measure was scored by a 10-point visual analogue scale, which runs from 0 (worst possible quality of life) to 10 (best possible quality of life), with a midpoint of 5 (half way between worst and best).

The OM- 6 data sampling relative to the treatment of OME over time is shown in Figure 1.

\begin{tabular}{lll} 
Week: 0 & Week: 2-4 & Week: 8-10 \\
\hline Otolaryngologist: $\rightarrow \quad$ & Outpatient surgery: $\rightarrow$ & Follow-up: \\
Diagnosis OME & Treatment for OME & $\begin{array}{l}\text { Postoperative } \\
\text { tympanostomy } \\
\text { tube Check }\end{array}$ \\
& & $\begin{array}{l}\text { Post-test and } \\
\text { retrospective pre-test }\end{array}$
\end{tabular}

Figure 1 A schematic presentation of the data-sampling periods using the 6-item quality-of-life survey, relative to the treatment of otitis media with effusion (OME)

At each OM-6 measurement, the situation at that time was assessed. Caregivers were asked to what degree the symptoms, as described in each item, had been a problem for their child. Answers were based on either individual symptoms or problems or on global effects.

During the study, the OM- 6 was completed by parents without assistance. Possible bias resulting from interactions with an interviewer is eliminated in this way (Richard M. Rosenfeld, MD, written communication, March 1998). A subgroup 
completed the OM- 6 at study entry (baseline test) after diagnosis of OME; all parents completed a pre-test on the day of surgery. At follow-up, which included otoscopy and tympanometry 6 to 8 weeks after the intervention, 2 surveys (posttest and retrospective pre-test) were completed. The retrospective pre-test reassessed the parental perception of the child's condition at the time of the pre-test, to evaluate the presence of a response-shift (see also Figure 1).

\section{Statistical analyses}

Before performing statistical tests on a group level, some calculations of individual scores were necessary to evaluate HROL change scores. Test-retest reliability was assessed using the Pearson correlation coefficient $(r)$ between the scores on the baseline test and pre-test administered within 7 days before surgery. Internal consistency was measured by examining the statistical relations between items with similar content. Construct validity was assessed by the relationship between item or survey summary scores and the ear-related global quality of life. Responsiveness to clinical change after placement of tympanostomy tubes was measured by the Standardised Response Mean (SRM), which is the mean change score per item divided by its SD. ${ }^{13}$

In the presence of a response shift between the pre-test and the retrospective pre-test scores, the latter test is a better reference point than the post-test for calculating responsiveness to change. ${ }^{14}$ Confirmation of significant differences at the group level was determined by a paired-samples $t$ test. The Wilcoxon signed rank test was applied to indicate the direction of response shift for individual responses. ${ }^{14}$ Finally, retrospective responsiveness to clinical change was measured by means of the SRM.

\section{Results}

The sample consisted of 77 children, 48 boys and 29 girls, with a mean \pm SD age of

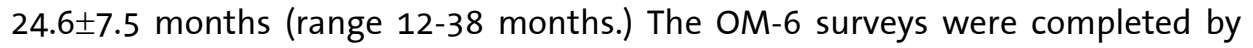
mother $(79 \%)$, father $(16 \%)$ or both $(5 \%)$. The number of surveys evaluated was 68 for the pre-test and 69 each for the post-test and retrospective pre-test. The baseline survey was completed in a subgroup of 19 only.

Among the pre-test scores, caregiver concerns, speech impairment and physical suffering had the highest median values of almost 4; followed by hearing loss and emotional distress, with median values of 3; while activity limitations had the lowest median value of 2 (Table 1). 
Table 1 Survey results and test-retest reliability of the 6-item quality-of-life survey (OM-6)

\begin{tabular}{lcc}
\hline Item & Test Retest-Reliability ${ }^{1}$ & ${\text { Item } \text { Response }^{2}}^{-}$ \\
\hline Physical suffering & $0.88^{* *}$ & $3.5(3.1-4.1)$ \\
Hearing loss & $0.94^{* *}$ & $3.3(2.9-3.8)$ \\
Speech impairment & $0.94^{* *}$ & $3.7(3.2-4.2)$ \\
Emotional distress & $0.89^{* *}$ & $3.1(2.7-3.6)$ \\
Activity limitation & $0.85^{* *}$ & $2.4(2.0-2.9)$ \\
Caregiver concern & $0.74^{* *}$ & $3.6(3.3-3.9)$ \\
Global ear-related quality of life & $0.98^{* *}$ & $6.9(6.4-7.4)$ \\
Survey summary score & $0.94^{* *}$ & $3.2(3.0-3.6)$ \\
\hline
\end{tabular}

'For the test-retest reliability, 12 surveys were sampled for all items on the baseline pre-test, except for physical suffering $(n=11)$. ${ }^{* *}$ For all items, correlation is significant at 2-tailed 01 level at 2-tailed $p=.01 ;{ }^{2}$ Data are given as median ( $95 \%$ confidence interval). Median values are based on 62 surveys sampled at the pre-test.

Table 2 Prospective survey responsiveness to change of the OM-6 after surgery ${ }^{1}$

\begin{tabular}{lc}
\hline Item & ${\text { Standardized Response } \text { Mean }^{\mathbf{2}}}^{\text {Physical suffering }}$ \\
Hearing loss & $0.66(0.87-2.09)$ \\
Speech impairment & $0.87(1.08-2.07)$ \\
Emotional distress & $0.64(0.66-1.64)$ \\
Activity limitation & $0.79(0.87-1.80)$ \\
Caregiver concern & $0.76(0.75-1.58)$ \\
Survey score & $0.92(0.85-1.56)$ \\
\hline
\end{tabular}

${ }^{1}$ Data are given as value (95\% confidence interval), based on 54 baseline test and pre-test surveys (number of surveys sampled before and after surgery); ${ }^{2}$ Calculated as mean change score divided by SD. Values $>0.8$ are indicative of a large responsiveness to change.

No parent had experienced a month without any concerns at all. Parents reported most often the presence of speech impairment (mean \pm SD, 3.6 \pm 1.8 ), while the least often reported was activity limitations (mean $\pm S D, 2.5 \pm 1.7)$. The pre-test was used as a reference point.

For each item, the test-retest reliability was good ( $r>80)$, including caregiver concerns $(r=.74)$. Ear-related global quality of life had the highest reliability $(r=.98)$. Internal consistency was satisfactory $(\alpha=.79)$. The most striking correlation was found between emotional distress and activity limitations $(r=.69)$. The correlation between hearing loss and speech impairment $(r=.46)$ was lower than expected, but in line with the results of Rosenfeld and colleagues. ${ }^{8}$ Construct validity, as determined by the correlation between the ear-related global quality of life measure and the OM- 6 summary score, was fair $(r=-.77, p<.01)$.

Prospective responsiveness to clinical change as indicated by the SRM ranged from moderate $(S R M \geq 0.5)$ to large $(S R M \geq 0.8)$ for this population. The exact values are given in Table 2, with the survey summary score $(S R M=1.13)$ showing the 
largest sensitivity to change, followed by caregiver concerns $(\mathrm{SRM}=.92)$ and hearing loss (SRM=.87).

The median difference between the pre-test and the retrospective pre-test scores was significant at the group level $(t=-3.3, p<.01)$, indicating that a response-shift bias is present. This phenomenon is visualized in Figure 2, reflecting that a

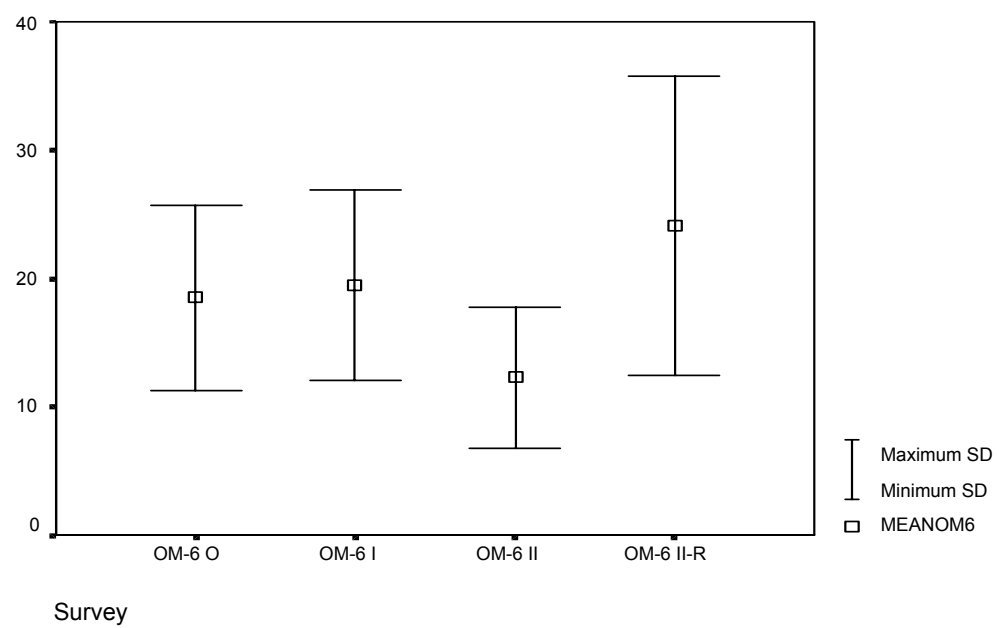

Figure 2 The phenomenon of response-shift bias. Mean values and SDs are depicted the group level, at different times during the study: baseline test, at study entry; pre-test, at outpatient surgery; post-test, 6 to 8 weeks after surgery; and retrospective pre-test, 6 to 8 weeks after surgery. OM- 6 indicates 6 -item quality-of-life survey.

greater change after surgery is observed if the retrospective pre-test and posttest are compared, instead of the pre-test and post-test.

Two findings confirm this statement. First is the larger retrospective responsiveness to clinical change for most items of the OM-6, as seen in Table 3. A comparison of the prospective (Table 2) and retrospective (Table 3) SRMs confirms the tendency of a positive response shift for most scales of the OM-6. The differences, calculated as the retrospective SRM minus the prospective SRM, were as follows: emotional distress, .04; caregiver concerns, .10; speech impairment, .20; physical suffering, .40 ; and hearing loss, .70 with the largest retrospective shift in parental response. There were two exceptions with a negative response shift: the survey summary score (SRM=-.04) and activity limitations (SRM=-.03). 
Table 3 Retrospective survey responsiveness to change of the 6-item quality-of life survey (OM-6) after surgery ${ }^{1}$

\begin{tabular}{lc}
\hline \multicolumn{1}{c}{ Item } & ${\text { Standardized Response } \text { Mean }^{\mathbf{2}}}^{\circ}$ \\
\hline Physical suffering & $1.04(1.53-2.56)$ \\
Hearing loss & $1.57(2.05-2.87)$ \\
Speech impairment & $0.87(0.93-1.72)$ \\
Emotional distress & $0.83(0.80-1.54)$ \\
Activity limitation & $0.73(0.81-1.70)$ \\
Caregiver concern & $1.02(1.01-1.70)$ \\
Survey score & $1.09(1.22-1.92)$ \\
\hline
\end{tabular}

${ }^{1}$ Data are given as value (95\% confidence interval), based on 59 post-test and retrospective pre-test surveys (number of surveys sampled after surgery); ${ }^{2}$ Calculated as mean change score divided by SD. Values of $>.80$ are indicative of a large responsiveness to change.

Second, retrospective pre-test versus post-test analyses revealed a higher number of positive changes for individual items compared with pre-test versus posttest analyses, as reflected in significant $z$ scores for each of the items (Table 4). This indicates that the OM- 6 scores at the pre-test had generally been underestimations of HROL problems. Comparing the retrospective pre-test with the pretest scores, differences in hearing loss were significant $(z=-3.3, p<.05)$. In contrast, the results for ear-related global quality of life $(z=-3.6, p<.05)$ suggest an overestimation of HROL before surgery. This may be indicative of changing internal standards of parents during the study.

Table 4 Wilcoxon signed rank comparisons of the 6-item quality-of-life survey (OM-6) during the study ${ }^{1}$

\begin{tabular}{|c|c|c|c|c|c|c|c|c|c|}
\hline \multirow[b]{2}{*}{ Item } & \multicolumn{3}{|c|}{ Pre-test vs. post-test ${ }^{2}$} & \multicolumn{3}{|c|}{$\begin{array}{c}\text { Retrospective pre-test } \\
\text { vs. post-test }{ }^{3}\end{array}$} & \multicolumn{3}{|c|}{$\begin{array}{c}\text { Pre-test vs. } \\
\text { Retrospective pre-test }{ }^{4}\end{array}$} \\
\hline & - & + & z score & - & + & $\begin{array}{c}\text { z score } \\
* *\end{array}$ & - & + & z score \\
\hline Physical suffering & 31 & 7 & -4.1 & 2 & 42 & -5.5 & 12 & 26 & -1.9 \\
\hline Hearing loss & 39 & 8 & -4.8 & 2 & 53 & -6.4 & 11 & 29 & $-3.3^{*}$ \\
\hline Speech impairment & 34 & 7 & -4.2 & 1 & 39 & -5.5 & 16 & 20 & -0.4 \\
\hline Emotional distress & 36 & 8 & -4.7 & 1 & 36 & -5.1 & 18 & 17 & -0.6 \\
\hline Activity limitations & 31 & 3 & -4.3 & 3 & 33 & -4.6 & 13 & 19 & -1.3 \\
\hline Caregiver concern & 41 & 6 & -5.0 & 4 & 43 & -5.3 & 16 & 20 & -0.9 \\
\hline Global ear-related quality of life & 12 & 42 & -4.7 & 48 & 2 & -6.0 & 31 & 11 & $-3.6^{*}$ \\
\hline
\end{tabular}

${ }^{14}+$ ' sign indicates an increase in reported health-related quality-of-life problems; '- sign, a decrease in reported problems; ${ }^{2}$ For physical suffering, 55 surveys were sampled; speech impairment, 61; activity limitations, 62 and the remaining scales, 63; ${ }^{3}$ For physical suffering, 61 surveys were sampled; speech impairment, 65; activity limitations, 66 and the remaining scales, 67; ${ }^{4}$ For physical suffering, speech impairment and activity limitations 61 surveys were sampled, 63 were sampled for the remaining scales; ${ }^{*} p<.05 ;{ }^{* *} p<.001$ 


\section{Discussion}

Caregiver perceptions influence their reports on quality of life in young children with OME. The results of this study are comparable to those of the original study ${ }^{8}$ of the OM- 6 ; however, the results were obtained from different age groups. The young age of our study population, 12-38 months versus 6 months to 12 years in the first OM- 6 study, necessitated the exclusive use of parental report. Validation of the OM- 6 is necessary and has been shown in a Dutch population in this study. However, parents are subject to internal and external factors influencing their perception. Confirmation of this is found in 64 surveys in which there was minimal correlation between audiometric (objective) hearing loss and prospective (subjective) hearing loss before surgery $(r=.06, p=.65)$. It would seem that parents are in general not sensitive to the degree of hearing loss before surgery.

In recent studies, ${ }^{6,8,15}$ parental perceptions have been found to be poor predictors of childhood hearing loss, an important symptom of OME and an item of the OM6. Although the accuracy of parental prediction was not an explicit study hypothesis herein, some comments should be made. It is not realistic to expect from parents a similar accuracy in predicting the child's hearing compared with audiometric testing in a sound-free environment. The parent and child are subject to constant distractions in their daily life, personal and environmental. The OM- 6 is a convenient method of assessing the consequences of OME and hearing loss, separate from otoscopy and audiometry. Parental concern about their child's hearing, as measured by the OM-6, can serve as a supplement to standard diagnostic procedures.

To our knowledge, reported quality-of-life studies in children with OME have not considered the effects of response-shift bias on parental reporting. Our results suggest there were changes in parental perception during the study, confirming the presence of response shift and questioning pre-test and post-test differences as indicators of change. ${ }^{14}$ This is clear in the comparison of the prospective and retrospective SRMs (Tables 2 and 4), which show small to large positive differences at the retrospective measurement for most of the scales. Not using the retrospective pretest would include a risk of missing substantial changes and result in missed treatment indications, such as insertion of tympanostomy tubes. In this way, response shift can be viewed as an important component of treatment effect. ${ }^{11}$ The significant differences between the pre-test and retrospective pre-test scores for ear-related global quality of life and hearing loss support for this proposition (Table 3 ).

As evidenced by parents' underestimating the seriousness of hearing loss and overestimating the quality of life of their child before surgery, an adaptation to the presence of symptoms appears to have taken place, with a positive effect on 
perceived HROL. ${ }^{16}$ Caregivers have difficulty in accurately identifying the extent of hearing loss present before surgery for multiple reasons, which are not mutually exclusive. ${ }^{17}$ In chronic conditions, such as OME often is during childhood, this response-shift bias can be understood as an attempt by parents to internally normalize the experienced level of HRQL. The underlying assumption is that parents want to think and feel positive about themselves and their child, even in the presence of symptoms. ${ }^{9,18}$ Anticipatory effects may also be present, ${ }^{14,19}$ as parental expectations about future HROL could be heightened at the pre-test by already having scheduled the child for tympanostomy tube placement. At the retrospective pre-test, parents are able to compare HROL before and after surgery. The results of treatment may lead parents to realize that the situation before surgery was worse than they had thought. This is especially true for a child experiencing OME for the first time, as parents become knowledgeable about the disorder and its possible consequences ${ }^{12}$, affecting their self-reported test scores. This uncertainty is compounded by the fluctuating nature of the hearing loss resulting from OME and by differing developmental rates among children. The first issue has been dealt with by evaluation of the child's middle ear status at each completion of the OM- $6 .{ }^{8}$ The problem of differing developmental rates has been addressed by structuring each item of the OM- 6 as a single item, listing several ways in which OME may affect the function within that domain, with the possibility of assessing age-appropriate symptoms. ${ }^{8}$

In conclusion, response shift bias is an important factor in assessing the effects of surgery in children with OME. Our results suggest that the dynamic nature of a quality-of-life measurement, manifested as a change in parental frame of reference, needs to be considered. Otherwise, there is a risk of underestimating the effects of tympanostomy tube placement on subjective measures, such as the HROL of young children and parental concerns.

\section{Acknowledgment}

Richard M. Rosenfeld, MD, is acknowledged for his permission to use the OM- 6 in our study and for the valuable comments on the manuscript. 


\section{References}

1. Holcomb WR, Morgan P, Adams NA, Ponder H, Farrel M. Development of a structured interview scale for measuring quality of life of the severely mentally ill. Journal of Clinical Psychology. 1993;49:830-40.

2. Engel JAM, Anteunis UC, Volovics A, Hendriks JJT, Marres EHMA. Prevalence rates of otitis media with effusion from 0 to 2 years of age: healthy-born versus high-risk-born infants. International Journal of Pediatric Otorhinolaryngology. 1999;47:243-51.

3. Hindley P. Psychiatric aspects of hearing impairments. Journal of Child Psychology and Psychiatry. 1997;38:101-17.

4. Vernon-Feagans L, Manlove EE, Volling BL. Otitis media and the social behavior of day-careattending children. Child Development. 1996;67:1528-39.

5. Engel JAM, Anteunis UC, Volovics A, Hendriks JJT, Manni JJ. Chronic otitis media with effusion during infancy: have parent-reported symptoms prognostic value? A prospective longitudinal study from 0 to 2 years of age. Clinical Otolaryngology. 1999;24:417-23.

6. Anteunis LC, Engel JA, Hendriks JJT, Manni JJ. A longitudinal study of the validity of parental reporting in the detection of otitis media and related hearing impairment in infancy. Audiology. 1999;38:75-82.

7. Timmerman AA, Anteunis UC, Meesters CMG. The initial development of an instrument for the description of 'Otitis Media with Effusion Specific Behavior' in young children. International Journal of Behavioral Medicine. 1999;6:255-67.

8. Rosenfeld RM, Goldsmith AJ, Tetlus L, Balzano A. Quality of life for children with otitis media. Archives of Otolaryngology-Head \& Neck Surgery. 1997;123:1049-1054.

9. Hellier WPL, Corbridge RJ, Watters G, Freeland AP. Grommets and patient satisfaction: an audit. Annals of the Royal College of Surgeons in England. 1997;79:428-31.

10. Rosenfeld RM, Bhaya MH, Bower CM, Brookhouser PE, Casselbrant ML, Chan KH. et al. Impact of tympanostomy tubes on child quality of life. Archives of Otolaryngology-Head \& Neck Surgery. 2000;126:585-92.

11. Sprangers MAG, Schwartz CE. Integrating response shift into health-related quality of life research: a theoretical model. Social Science \& Medicine. 1999;48:1507-15.

12. Hoogstraten J, de Meijer E, Sprangers $M$. The response-shift notion and retrospective selfreports: an overview of the literature. Dutch Journal for Psychology and connected sciences. 1985;40:488-502.

13. Liang $M H$, Fossel $A H$, Larson MG. Comparisons of five health status instruments for orthopedic evaluation. Medical Care. 1990;28:632-42.

14. Robinson EAR, Doueck HJ. Implications of the pre/post/then design for evaluating social group work. Research on Social Work Practice. 1994;4:224-39.

15. Stewart MG, Ohlms LA, Friedman EM, Sulec M, Duncan NO, Fernandez AD. et al. Is parental perception an accurate predictor of childhood hearing loss? A prospective study. OtolaryngologyHead \& Neck Surgery. 1999:120:340-44.

16. Wilson IB. Clinical understanding and clinical implications of response shift. Social Science \& Medicine. 1999;48:1577-88.

17. Schwartz CE, Sprangers MAG. Methodological approaches for assessing response shift in longitudinal health-related quality-of-life research. Social Science \& Medicine. 1999;48:1531-48.

18. Allison PJ, Locker D, Feine JS. Quality of life: a dynamic construct. Social Science \& Medicine. 1997;45:221-30. 
Quality of life and response shift bias

19. Adang EMM, Kootstra G, Engel GL, van Hooff JP, Merckelbach HLGJ. Do retrospective and prospective quality of life assessments differ for pancreas-kidney transplant recipients? Transplant International. 1998;11:11-15. 



\title{
Psychometric evaluation of the OM8-30 questionnaire in Dutch children with otitis media
}

\author{
Angelique A. Timmerman \\ Lucien J.C. Anteunis \\ Michelene N. Chenault \\ Cor M.G. Meesters \\ Mark P. Haggard
}

European Archives of Oto-Rhino-Laryngology and Head \& Neck Surgery In review process 


\section{Abstract}

Objective: The Dutch translation of the OM8-30 questionnaire, originally developed in the UK on a large clinical sample, has been applied for validation in an ENT sample, with the aim of assessing otitis media impact and identifying treatment needs in children suffering from chronic otitis media (OM) and/or upper respiratory tract infections (URTI).

Methods: Caregivers of 246 children completed the OM8-30 and also the generic Strengths and Difficulties (SDQ) questionnaire, prior to otolaryngologist consultation.

Results: Factor analysis confirmed the hypothesized six-factor structure, accounting for $55.5 \%$ of the variance. The internal consistency was satisfactory to good for all of the physical and developmental facets ( $\alpha$-values $\geq .68$ ). The correlation matrix with the SDO scales and total difficulties score showed significant relationships for almost all of the OM8-30 developmental facets and sub-aggregate $(p<.01)$, supporting the concurrent validity of the OM8-30 as a measure of impact in otitis media.

Conclusions: This first examination of the Dutch OM8-30 shows that the psychometric characteristics are sufficiently good for the assessment of disease impact, and that this can be subdivided into impact on physical health and on developmental aspects. Recommendations for further research include the study of confounders such as hearing, age and previous operations so that these can be adjusted out, and the determination of which subgroup of children may benefit from tympanostomy tubes. 


\section{Introduction}

The appropriate indications for surgical intervention of children suffering from chronic otitis media (OM) have been controversial for decades. The development and validation of efficient means for this purpose has received little detailed attention in research or clinical practice. Concern has been raised about the overuse of tympanostomy (middle ear ventilation tube) surgery for several reasons. First, the favourable natural course of the disease in most children is widely acknowledged $^{1}$ as is the lack of large developmental sequelae of those affected. Second, randomised clinical trials (RCTs) of tympanostomy tubes have shown benefits to hearing but null, or only short-term and marginal benefits to developmental measures in children., ${ }^{2,3}$ The 'watchful waiting' policy, consequently recommended by clinical practice guidelines ${ }^{4,5}$, seems to apply mainly to the numerous otherwise healthy children with only mild signs and symptoms of middle ear effusion (MEE) that are considered for treatment in countries with high intervention rates. However, it is also recognised clinically that subgroups of 'highrisk' children exist, suffering from persistent or recurrent OM. Possible complications or co-present factors make them potentially susceptible to its effects, e.g., speech and language delay, learning and behaviour problems, visual impairments, genetic syndromes or craniofacial abnormalities. ${ }^{6}$ Such children may be at increased risk for compromised development and quality of life and would equally be expected to show more beneficial effects from the intervention. ${ }^{7}$ Compromised developmental outcomes are seen where the bilateral OME persists longer than 9-12 months and/or a substantial conductive hearing loss of more than $25 \mathrm{~dB}$ is present in the best ear persistent for at least 3 months, combined with a high infection load due to the presence of siblings. ${ }^{3,8,9}$ Selection of the (possibly small) subgroup of children that may benefit the most from surgery is difficult due to the lack of standardised approaches for assessing the general health and developmental impact of chronic OM.

Case-finding for children with persistent or recurrent $O M$ is enabled by the disease-specific OM8-30 questionnaire. It has been developed within the UK national Trial of Alternative Regimens in Glue Ear Treatment (TARGET) for a structured assessment of OM impact for child and environment as perceived by caregivers. $^{7}$ One of its aims is to identify individual treatment needs, taking into consideration both the general severity of disease impact and the specific ability to benefit from surgical intervention with ventilation tubes and/ or adenoidectomy. This enables ENT-physicians to take the impact of OM into account in a systematic way, as well as measured hearing and examinable ear pathology.

In the current study, the OM8-30 was translated and applied to examine its psychometric characteristics in a Dutch population. First, the interrelationships be- 
tween the impact measures were examined by assessing whether the original factor structure is confirmed. Second, the internal consistency of the distinguished facets of items in a symptom area was assessed. Internal consistency values need to range from reasonable to good in order to justify further use.

Specific hypotheses were formulated to assess the discriminatory ability of the OM8-30. The concurrent (criterion) validity was determined by assessing correlations of the OM8-30 scores with the Dutch translation of the 'Strengths and Difficulties Questionnaire' (SDQ), a generic measure covering the most important current facets of child behaviour and emotions (i.e., emotional symptoms, conduct problems, hyperactivity, inattention, and peer problems). These correlations were expected to be low for the more specific physical facets (i.e., divergent validity), due to the fact that the SDQ covers the broad construct of psychosocial adjustment. ${ }^{10}$ However, it is a suitable measure for assessing concurrent (criterion) validity for developmental impact measures in this age range.

The formulated hypotheses for this validation and standardisation study can be summarised as: (1) the factor structure of the OM8-30 obtained for a Dutch sample will be highly similar to the original 6-factor structure, (2) internal consistency will be reasonable to good for all OM8-30 facets, and (3) moderate to high correlations will be found between the developmental facets and sub-aggregate score of the OM8-30 and the behaviour dimensions of the SDO.

\section{Methods}

\section{Background to international standardisation}

The present study also contributes to the collaborative international project 'Eurotitis 2'. At time of writing data exist from 9 European countries plus New Zealand for the standardisation and validation of the OM8-30 questionnaire. ${ }^{11}$ The aim of 'Eurotitis 2' is to develop a bias-adjustable questionnaire for the assessment of chronic OM impact in each individual child, giving comparable results for different languages, cultures and health care systems, once clinical markers of disease severity are taken into account. Standardisations will be pursued in the near future for all 11 translated versions of the questionnaire. The data from the present study have already shaped decisions about the evolution of this project. 


\section{Questionnaires}

\section{OM8-30 questionnaire}

Origins of the English version The OM8-30 is a short-form questionnaire which can be applied for assessment of the physical and developmental impact in children aged 3-8 years with a history of chronic OM. It can be used as follows: (1) at baseline (e.g., first consultation at ENT department) the severity of impact can be determined and hence the need for treatment, and (2) at follow-up (e.g., medical check-up) the benefit of treatment on impact can be assessed. The OM830 is intended for use in case of strong suspicions, based on disease history of either chronic OM or recurrent acute OM (RAOM) presence.

The questionnaire has been developed from 83 items (out of an initial 200 items) retained in the development of a set of outcome measures for the TARGET RCT as conducted by the MRC Multi-centre Otitis Media Study Group. ${ }^{7,12,13}$ Content validity was ensured by including only those facets frequently reported in an openended questioning about concerns of a large sample of parents whose children had reached ENT with ear/hearing problems. Customary psychometric procedures were then used for selecting the best items from a larger item pool composed of questions in existing questionnaires or recognised clinical impact areas. Criteria applied in sequence were: response distribution, rate of missing data, item-whole correlation (with 'whole' defined as the set of items in a facet retained in the validation process) and the related Cronbach's alpha. The UK standardisation sample consisted of 441 children eligible for randomisation and suffering from persistent mild to severe OM. Items were selected to maximise construct validity according to their ability to substitute for the facet measure (i.e., the entire set for the facet). Other data sources were also included to ensure validity for the facets of behaviour included and the items reflecting reported hearing difficulties. For behaviour a large normative factor-analytic study was conducted to define the best four generic dimensions of mild behaviour problems. The three dimensions showing a significant case-control difference from the clinical sample (i.e., an OM sequelae effect) were included in the trial outcome measures for comprehensiveness, but as one of these was modest only the two largest were included in the OM8-30. For reported hearing difficulties, the nine best out of the available ten items were chosen and scaled on the basis of regression with hearing levels. Structural equation modelling enabled the development of the short-form (3-6 items per facet) from the full version (5-15 items per facet). The OM8-30 and further information about its development, research and clinical applications can be found at: http://www.mrc-cbu.cam.ac.uk/ess.

Dutch translation The OM8-30 was translated into Dutch by a native speaking Dutch psychologist in consultation with another native Dutch speaker. The 
Dutch version was back-translated into English and checked by the originators of the English version.

The scoring format of each item in the OM8-30 is either dichotomous (e.g., parent quality of life items) or ordinal Likert-type, and the basis of response is mostly the symptom frequency. The questionnaire actually contains 32 items, instead of the 30 suggested by the title. There are two reasons for this: there is an additional conditioning question ('colds') under respiratory symptoms, which can be used to condition response scoring on items where 'only when he has a cold' is as an available response or it can be treated as an ordinary separate item. Second, the section for sleep patterns contains one numbered item with two sub-sections (not separately numbered) about tiredness of the child, due to the addition of the 'school prospects' in the current OM8-30 version. The items contain quantifiers for severity or frequency of a problem, e.g., 'in the last three months, how many times has your child had an earache?'.

The items are scored and summed with appropriate weighting into six facet scores: (1) combined global health, ear problems and sleep patterns $(1+3+3=7$ items), (2) respiratory symptoms (6 items), (3) reported hearing difficulty (4 items), (4) behaviour problems (6 items), (5) combined speech, language and educational prospects (4 items), (6) parent quality of life (5 items). The facet scores are calculated by formulae containing standardized quantifiers for the scaling of item response levels, based on multiple regressions and so optimally summarising the covariance structure in the TARGET sample. In contrast with the imposition of a fixed a priori coding scheme (e.g., $0,1,2,3$ ) this reflects severity differences in item content more precisely and specifically and so processes the available data more efficiently. The title of the questionnaire 'OM8-30' reflects the 8 facets included. However, for present purposes, three of the closely related physical health facets were merged into 'combined global health, ear problems and sleep patterns'. The reason for doing this was that for a given sample size, the most stable results with a multivariate technique such as factor analysis are encouraged when the preliminary data reduction is reliable (e.g., by totalling several items) and when the numbers of variables and factors are few. The merging (justified by high inter-correlation of the items) thus created a minimum of four items per facet and avoided distracting or false loadings for specific health facets given the present emphasis on validation of the developmental impact facets. The facet reported hearing difficulty (RHD) can be used for bias adjustment when using the OM8-30 aggregate facet scores. It adjusts for parental overor under-exaggeration by fitting the residuals from a previous regression of the subjective RHD on the objective hearing level or a tympanometric equivalent.

Two main aims in the late development and early application/validation stages are to avoid the proliferation of sub scores and alternative methods of scorings 
Table 1 The OM8-30: items, facets and scoring format ${ }^{1}$

\begin{tabular}{|c|c|c|c|}
\hline $\begin{array}{l}\text { OM8-30 items } \\
\text { (abbreviated) }\end{array}$ & Item no. & Facet $^{1}$ & Scoring format \\
\hline Global health & 1 & GLEA & Very good; good; fair; poor \\
\hline Colds & & $\begin{array}{l}\text { Conditioning } \\
\text { Question }\end{array}$ & $\begin{array}{l}\text { Once a week; once } 2-3 \text { weeks; once } 1-3 \text { months; once } 4-6 \\
\text { months; less often; never; not sure }\end{array}$ \\
\hline Sore throat & 2 & RESP & Not at all; once; $2-3$ times; $4-5$ times; 6 or more times \\
\hline Mouth breathing & 3 & RESP & Never; rarely; often; always; only when a cold; not sure \\
\hline Blocked nose & 4 & RESP & Never; rarely; often; always; only when a cold; not sure \\
\hline Runny nose & 5 & RESP & No; yes-clear; yes-purulent; only when a cold; not sure \\
\hline Snoring & 6 & RESP & Never; rarely; often; always; only when a cold; not sure \\
\hline Ear problems & 7 & GLEA & Not at all; once; $2-3$ times; $4-5$ times; 6 or more times \\
\hline Ear infections & 8 & GLEA & $0 ; 1 ; 2-3 ; 4$ or more; not sure \\
\hline Earache & 9 & GLEA & $0 ; 1 ; 2-3 ; 4$ or more; not sure \\
\hline Hearing & 10 & RHD & Normal; slightly below normal; poor; very poor; not sure \\
\hline Mishearing & 11 & RHD & No; rarely; often; always; not sure \\
\hline Hearing group & 12 & RHD & No; rarely; often; always; not sure \\
\hline Repeat & 13 & RHD & No; rarely; often; always; not sure \\
\hline Active child & 14 & $\mathrm{BEH}$ & $\begin{array}{l}\text { Is very active and does not sit still when necessary; can } \\
\text { usually sit still when necessary; can sit still for a long } \\
\text { period; is not active enough }\end{array}$ \\
\hline Concentration & 15 & $\mathrm{BEH}$ & $\begin{array}{l}\text { Up to } 2 \text { minutes; up to } 5 \text { minutes; } 5-10 \text { minutes; } 10-15 \\
\text { minutes; more than } 15 \text { minutes }\end{array}$ \\
\hline Attention & 16 & $\mathrm{BEH}$ & $\begin{array}{l}\text { Less than once a month; once a month; once a week; } \\
\text { once a day; two or three times a day }\end{array}$ \\
\hline Whining & 17 & $\mathrm{BEH}$ & $\begin{array}{l}\text { Less than once a month; once a month; once a week; } \\
\text { once a day; two or three times a day }\end{array}$ \\
\hline Unhappy & 18 & $\mathrm{BEH}$ & $\begin{array}{l}\text { Less than once a month; once a month; once a week; } \\
\text { once a day; two or three times a day }\end{array}$ \\
\hline Take out & 19 & $\mathrm{BEH}$ & Never; sometimes; often; always \\
\hline Pronounciation & 20 & SPEC & No; rarely; often; always; not sure \\
\hline Delay speech & 21 & SPEC & No; a little; moderately; a lot; not sure \\
\hline Articulation & 22 & SPEC & No; rarely; often; always; not sure \\
\hline Sleep problems & 23 & GLEA & Almost always; sometimes; hardly ever \\
\hline Tiredness & $24 a$ & GLEA & Almost always; sometimes; hardly ever \\
\hline $\begin{array}{l}\text { Tired-ENT prob- } \\
\text { lem }\end{array}$ & $24 b$ & GLEA & Almost always; sometimes; hardly ever; not applicable \\
\hline School prospects & 25 & SPEC & Often worried; sometimes worried; never worried \\
\hline Tired parent & 26 & PQDOL & Yes; no \\
\hline Attention parent & 27 & POQOL & Yes; no \\
\hline Demanding child & 28 & PŌOL & Yes; no \\
\hline Energy parent & 29 & POQOL & Yes; no \\
\hline Effort parent & 30 & POQOL & Yes; no \\
\hline
\end{tabular}

${ }^{1}$ GLEA: combined global health, ear problems and sleep patterns; RHD: reported hearing difficulty; RESP: respiratory symptoms; BEH: behaviour problems; SPEC: combined school prospects, speech and language; POOL: parent quality of life. 
by showing that the data obtained justify a small number geared to specific intended purposes, and to optimise the formulae for those scores that are accepted in this way. The above facet structure emerged from classification of the problems as seen by parents and was used, via selection of items for consistency and construct validity on moving to the short form OM8-30.

The facet scores used in this study came from the derivation developed and used on the TARGET data, which means that these are not necessarily optimal for the Dutch covariance. The advantage is that generalisation is possible by applying an a priori formula, not relying upon a local optimum that might not be replicated. Validation of a translation can usefully comprise confirmation by factor analysis that a similar facet structure is retrieved and that a similar aggregate domain structure (by requesting a number of factors two or three times smaller than that present in the facets) is also present. Two facet aggregates embrace the 'physical' domain combining the physical health and respiratory scores (13 items) and the 'developmental' domain combining behaviour, speech and school prospects and parent quality of life (15 items). Table 1 gives the summary wording for the sign or symptom and the scoring format for each item in a specific facet.

\section{Strengths and Difficulties Questionnaire}

The Strengths and Difficulties Questionnaire (SDQ) is a generic instrument for the assessment of psychosocial adjustment. This is used as a research tool but also short enough to be used for screening and treatment evaluation purposes in clinical assessment. The SDO is a brief measure consisting of one page of items assessing behaviour in children: (1) emotional symptoms, (2) conduct problems, (3) hyperactivity-inattention and, (4) peer problems. In addition, a separate scale (5) pro-social behaviour is included, reflecting the present personal strengths of the child. The SDO contains 25 items, 5 items per scale with a 3-point response format: $0=$ 'not true', 1='somewhat true' and 2='certainly true'. Subscale scores can be computed for all problem facets to yield a total difficulties score, with higher scores reflecting more difficulties. The Dutch parent version of the SDQ used in this study, was translated and pre-tested by van Widenfelt. ${ }^{10}$ The psychometric properties have been evaluated and adequate validity and reliability were reported for the Dutch version. ${ }^{10,14}$

The SDQ was originally developed by Goodman ${ }^{15}$ as an indicator of psychological adaptation in a general population of children and adolescents. The SDO has proven to be an excellent tool for discrimination between and within community and clinical samples in several earlier studies. ${ }^{16,17}$ Versions of the SDQ are available for parents and teachers of 4-16-year-olds and a nearly identical version for self-report by 11-16-year-olds. 


\section{Study design}

In the period between April 2004 and July 2005 data were collected at the Ear, Nose and Throat (ENT) department of the University Hospital of Maastricht, which also delivers regional ORL and related services for the southernmost part of the Netherlands. Caregivers, usually the parent, of children consulting the ENT department with upper respiratory and ear- or hearing-related complaints with a history of persistent or recurrent middle ear disease were asked to participate in the study, prior to seeing the ENT-physician with their child. This was done to prevent them from being biased through information about the diagnosis of their child's condition. After giving informed consent, the parents filled out the OM8-30 and SDO once without any further assistance. To prevent interviewer bias data concerning the diagnosis and hearing levels were collected from the medical files after clinical consultation. This study was approved by the university hospital Medical Ethics Committee and written informed consent was obtained from the proxy of the participating child, usually the parent.

\section{Study population}

The parents of 246 children, 132 boys and 114 girls, completed the OM8-30 and SDO. The mean age of the total sample was 5.2 years $(S D=1.6$ year, range $2.2-9.8$ years). The presence of upper respiratory tract infections and/or chronic OM was documented at the day of OM8-30 completion as the middle ear effusion directly results from chronic adenoid infection in about $50 \%$ of cases. ${ }^{18-20}$ One-hundredand-eleven children (43.5\%) suffered from at least unilateral OM as diagnosed by otoscopy and tympanometry and 66 children (25.9\%) had bilateral OM at the day of questionnaire completion. Data about OM presence were not available in the medical files for 7 children and for 3 children the medical files were untraceable. The average bilateral hearing level was $20.7 \mathrm{~dB}(\mathrm{SD}=11.4 \mathrm{~dB}$, range 1.2-49.4 dB) as measured in 135 of the children by pure tone audiometry (frequencies 0.5, 1, 2 and $4 \mathrm{KHz}$ ). Audiogram data were not available for all children, due to the fact that these were not collected during each hospital visit for children already under treatment. There is a highly significant difference in hearing threshold between the children with chronic OM $(n=49)$ and those without $(n=85),(t(132)=-5.36$, $p<.0005)$, with hearing thresholds on average being better for children not suffering from $O M$.

Of the present sample, 44 children (18.1\%) visited the ENT department for the first time; these can be subdivided into 4 children (9.1\%) referred after universal hearing screening around the age of 5 years and 40 (90.9\%) based on symptoms present. Of the remaining 199 children (81.9\%) who had underwent treatment at 
any time before this visit, 42 children (20.2\%) received surgery leading up to this (check-up) visit. This number can be subdivided depending on the treatment: 10 children (4.1\%) received tympanostomy tubes, 12 children (4.9\%) tympanostomy tubes and an adenoidectomy, 3 children (1.2\%) an adenoidectomy, 13 children $(5.3 \%)$ an adenotonsillectomy, and 1 child $(0.4 \%)$ a tonsillectomy. There were 3 children (1.2\%) who received other ENT-related surgery (i.e., tympanoplasty, reconstruction for choanal atresia and marsupialisation of a cyst).

\section{Statistical analyses}

The Statistical Package for Social Sciences (SPSS, version 11.5) was used to perform the statistical analyses. In the validation process of the OM8-30 an exploratory principal components analysis was conducted, then factor analysis using varimax rotation, to assess the presence of the predicted six-factor structure. Internal consistency was measured by reliability analysis (Cronbach's $\alpha$ ) of the several OM8-30 facets and Pearson item-total correlations were calculated to indicate the statistical contribution of each item to the scale. Concurrent validity was investigated by means of Pearson correlation coefficients between the facets and aggregate scores of the OM8-30 and SDQ.

The issue of missing data was handled by guarded imputation. For both questionnaires a maximum of one item per score was allowed to be missing. The facets had differing numbers of items (3-6), so that the percentage of missing items tolerated differed for each facet. Missing items in the OM8-30 were replaced by the lowest ('no problem') response value because in datasets with relatively few missing items it can be shown by regression that this is an adequate imputed value, often being due to omission of 'no problem' responses. In the SDQ a missing value within a scale was replaced by the average of the remaining items. Although this is not precise or sophisticated imputation, it reconciles a simple, clinically realistic and achievable standard for maximal use of data available with a reduced loss of cases through missing values for items.

\section{Results}

\section{Factor analysis}

Factor analysis with varimax rotation was carried out, yielding six factors with eigenvalues $>1$. This offered a more interpretable solution than did 5 or 7 , accounting for $55.5 \%$ of the variance. The factor loading threshold was set at .30 to confirm the factor structure (Table 2). The items loaded convincingly, with most 
Table 2 Principal components factor analysis with varimax rotation for the $0 \mathrm{M8-30^{1 }}$

\begin{tabular}{|c|c|c|c|c|c|c|}
\hline \multicolumn{7}{|c|}{ Factors $^{2}$} \\
\hline OM8-30 items & GLEA $^{3}$ & RHD $^{3}$ & RESP $^{3}$ & $\mathrm{BEH}^{3}$ & SPEC $^{3}$ & $\mathrm{PQOL}^{3}$ \\
\hline Frequency earache & .84 & & & & & \\
\hline Ear infections & .80 & & & & & \\
\hline Ear problems & .78 & & & & & \\
\hline Tired-ENT problem & .68 & & .49 & & & \\
\hline Sleep problems & .52 & & & & & \\
\hline Tiredness & .52 & & & & & \\
\hline Global health & .34 & & & & & \\
\hline Mishearing & & .87 & & & & \\
\hline Repeat & & .84 & & & & \\
\hline Hearing group & & .83 & & & & \\
\hline Hearing & & .80 & & & & \\
\hline Blocked nose & & & .69 & & & \\
\hline Snoring & & & .66 & & & \\
\hline Mouth breathing & & & .63 & & & \\
\hline Sore throat & & & .60 & & & \\
\hline Runny nose & & & .43 & & & \\
\hline Whining & & & & .78 & & \\
\hline Attention & & & & .69 & & \\
\hline Active child & & & & .61 & & \\
\hline Concentration & & & & .58 & & \\
\hline Unhappy & & & & .45 & & \\
\hline Take out & & & & .37 & & \\
\hline Articulation & & & & & .88 & \\
\hline Pronounciation & & & & & .85 & \\
\hline Delay speech & & & & & .84 & \\
\hline School prospects & & & & & .30 & .60 \\
\hline Energy parent & & & & & & -.71 \\
\hline Attention parent & & & & & & -.62 \\
\hline Demanding child & & & & -.40 & & -.62 \\
\hline Effort parent & & & & & & -.51 \\
\hline Tired parent & & & & & & -.32 \\
\hline Eigenvalue & 6.1 & 3.4 & 2.6 & 2.0 & 1.8 & 1.4 \\
\hline Explained variance (\%) & 19.5 & 10.9 & 8.5 & 6.5 & 5.7 & 4.4 \\
\hline
\end{tabular}

${ }^{1} n=246 ;{ }^{2}$ Secondary factor loadings <.30 have been omitted; cross-loadings are indicated in italics; ${ }^{3} \mathrm{GLEA}$ : combined global health, ear problems and sleep patterns; RHD: reported hearing difficulty; RESP: respiratory symptoms; BEH: behaviour problems; SPEC: combined school prospects, speech and language; PQOL: parent quality of life.

of the factor loadings $>$.40. The facets of 'global health-ear problems-sleep patterns' (GLEA), reported hearing difficulty (RHD), respiratory symptoms (RESP), behaviour problems (BEH), combined speech, language and educational prospects (SPEC) and parent quality of life (POOL) were all retrieved in the 6-factor 
solution. GLEA was the strongest factor, explaining $19.5 \%$ of the variance, as expected based on the number of items in this facet and the known prior relation of facets. It was followed by RHD (10.9\%), RESP (8.5\%), BEH (6.5\%), SPEC (5.7\%), and POOL (4.4\%). There were three items with substantial cross-loadings: 'demanding child' also loaded -.40 on BEH, 'tiredness-ENT symptoms' loaded .49 on RESP and 'school prospects' loaded .60 on POOL. These are the items reflecting most strongly the non-independence of the factors.

This distinction between physical and developmental functioning has been further elaborated in the factor analytic derivation of two sub-aggregates from the OM8-30 facets. These are described as 'physical health', containing all physical health facets (EARS, SLEEP, RESP, GLOBAL health) while 'developmental impact' contains all developmental facets (SPEC, SCHOOL, PQOL, BEH). The RHD facet is not included due to its separate function in bias adjustment. In the Dutch data, this summarising two-factor model explained $52.7 \%$ of the variance and all facets, except for RHD, loaded $>.60$ on only one of the two factors. The advantage of this model is that it summarises the impact of chronic $\mathrm{OM}$ in two reliable and easy-to-identify general factors, including several relevant measures in a sufficiently specific manner, supporting both the content validity of the OM8-30 and future application in small samples.

\section{Internal consistency}

The results of the reliability analysis for the assessment of internal consistency are presented in Table 3. Most reliability coefficients (Cronbach's $\alpha$ ) may be considered satisfactory (.70-.80) or good (>.80). Alpha values ranged from .68 for RESP to .87 for RHD, with intermediate values of .71 for both BEH and POOL facets. For SPEC and GLEA the $\alpha$ values were good as well: .80 and .82 respectively.

Table 3 Internal consistency of the OM8-30 for the total sample

\begin{tabular}{lccc}
\hline Facets $^{\mathbf{2}}$ & No. of items & Mean (SD) & Cronbach's $\boldsymbol{\alpha}^{\mathbf{1}}$ \\
\hline GLEA & 7 & $5.9(3.3)$ & .82 \\
RHD & 4 & $3.8(3.1)$ & .87 \\
RESP & 5 & $4.7(2.4)$ & .68 \\
BEH & 6 & $4.6(2.6)$ & .71 \\
SPEC & 4 & $3.0(2.8)$ & .80 \\
POOL & 5 & $6.0(3.0)$ & .71 \\
\hline
\end{tabular}

${ }^{1}$ Internal consistency has been assessed by Cronbach's alpha; $n=246$ for total sample, except for POOL with $n=245 .{ }^{2} \mathrm{GLEA}$ : combined global health, ear problems and sleep patterns; RHD: reported hearing difficulty; RESP: respiratory symptoms; BEH: behaviour problems; SPEC: combined school prospects, speech and language; POOL: parent quality of life. 


\section{Concurrent validity}

The concurrent validity of the developmental facets of the OM8-30 questionnaire was examined by means of the correlation pattern with the SDO. As the behaviour facets were not closely matched between the two instruments, the correlations between the OM8-30 developmental facets, sub-aggregate and the SDO total difficulties are most relevant (Table 4). These are all satisfactorily high, ranging from $r=.27$ to $r=.64$ with $p$-values $<.002$ for all correlations. For the relationships between SDO total difficulties and both the BEH facet and OM8-30 developmental sub-aggregate, values over .60 were found. The correlation of the SDO total difficulties with $\mathrm{POOL}$ is reasonable at -.54 , indicating that parental quality of life deteriorates when more behavioural problems are present. The correlation between SPEC and SDO total difficulties proved to be modest ( $r=.27)$, as was expected, because no items related to speech, language and education are present in the SDO.

The correlations found between SDO Emotion and GLEA $(r=.45, p=.002)$ and SDO emotion and the physical sub-aggregate $(r=.43, p=.002)$ are of some interest. These seem to indicate that if a child has more symptoms in the physical sphere, such as ear-related symptoms and sleep problems, more emotion-focused (e.g., unhappy, sad) behaviours will be present.

Table 4 Concurrent validity measured by correlations between the developmental facets and subaggregate of the OM8-30 and SDQ ${ }^{1}$

\begin{tabular}{|c|c|c|c|c|}
\hline \multicolumn{5}{|c|}{ OM8-30 facets ${ }^{2}$} \\
\hline & BEH & SPEC & POOL & $\begin{array}{l}\text { Developmental } \\
\text { sub-aggregate }\end{array}$ \\
\hline \multicolumn{5}{|l|}{ SDQ scales ${ }^{3}$} \\
\hline Emotion & $.35^{*}$ & .08 & $-.38^{*}$ & $.35^{*}$ \\
\hline Conduct & $.48^{*}$ & $.17^{*}$ & $-.35^{*}$ & $.39^{*}$ \\
\hline Hyper & $.68^{*}$ & $.30^{*}$ & $-.46^{*}$ & $.58^{*}$ \\
\hline Peer & $.36^{*}$ & $.23^{*}$ & $-.39^{*}$ & $.41^{*}$ \\
\hline Pro-social & $-.30^{*}$ & -.10 & $.19^{*}$ & $-.22^{*}$ \\
\hline Total score & $.64^{*}$ & $.27^{*}$ & $-.54^{*}$ & $.62^{*}$ \\
\hline
\end{tabular}

${ }^{1}$ Pearson product-moment correlations have been calculated; $n=246$ for the OM8-30 questionnaire, except for PQOL with $n=245$. For the SDO $n=243$; ${ }^{2} \mathrm{BEH}$ : behaviour problems; SPEC: combined school prospects, speech and language; POOL: parent quality of life; Developmental sub-aggregate: score combining BEH, SPEC and PQOL; ${ }^{3}$ Emotion: emotional symptoms; Conduct: conduct problems; Hyper: hyperactivity-inattention; Peer: peer problems; Pro-social: pro-social behaviour; ${ }^{*}$ Correlation significant at $p<.05 / 24=.002$ (Bonferroni correction). 


\section{Discussion}

The study produces three main findings, which can be summarised as follows.

\section{Validity pattern of the OM8-30 facets}

The factor analysis on the Dutch data yields a structure closely reflecting that of the measures derived for TARGET and embodied in the OM8-30.7 Further, the highest eigenvalue and some high factor loadings, which largely reflect factor consistency, are found for items in the first of the physical factors extracted here (GLEA). The loading pattern reflects the fact that it started as three facets (GLOBAL health, EARS, SLEEP) in the TARGET database while developing the OM830. It is not surprising that the item global health has a relatively low loading, this being somewhat separable from ENT disorders, due to its general character. The pattern is well summarised by saying that the sleep items correlate just sufficiently with the ear infection items.

It is possible that parents who are sensitive to a child's health have a concept of physical functioning that is more unitary and/or more publicly shared than is seen with aspects of educational or behavioural functioning, reflected in the often lower factor loadings found in most of the developmental facets. ${ }^{21,22}$

The second finding relates to internal consistency. For all six OM8-30 facets this was satisfactory to good, in spite of the small number of items present in some of the facets. It was especially true for RHD and SPEC, which contain the lowest number (4) of items for the facets in the OM8-30 and still showed the highest reliability coefficients ( $>.80$ ), indicating that the items in these facets adequately reflect the measured constructs.

Thirdly, concurrent validity was examined by the correlations of the OM8-30 developmental sub-aggregate and the facets included in it with the behaviour scales and total score of the SDO. Correlations between OM8-30 and SDO scales were moderate but mostly significant, and those between the OM8-30 facets and the SDO total score were moderate to good. The correlation was good for the OM8-30 sub-aggregate and SDO total score as well.

The SDO facets having the highest and lowest correlations with the developmental sub-aggregate demand some comment. The highest is SDO hyperactivityinattention. This can be explained by the fact the OM8-30 behaviour items originally came from two aspects of behaviour showing OM sequelae effects: anxiety and a broader area named 'inappropriate or context-insensitive behaviour', which showed the largest effects of an OME history, and contained a subset of hyperactivity items. These results confirm the reflection of inappropriate behaviour by the OM8-30, as hyperactivity and inattention have already been related to 
the presence of OME. ${ }^{23}$ The weakest correlations are found between SDQ prosocial and the developmental sub-aggregate and facets. This is understandable in the light of the fact that the TARGET sociability measure was deliberately excluded by the criteria for the item reduction in producing the OM8-30 short-form. This measure showed only a marginal effect of OME, not justifying the use of items to support it in a short form. Given the ability to explain these outlier correlation values, the overall pattern of correlation delivers a degree of mutual validation between the developmental facets of the OM8-30 and SDO. These questionnaires can be considered measures of the construct 'psychosocial adjustment of the child', in terms of relatively concrete behavioural characteristics and competencies.

The presence of significant correlations for PQOL with all of the SDQ facets deserves comment. The parents' perception of their quality of life is not only related to the psychosocial adjustment of the child by means of the parent-child relationship. Probably there is also a reciprocal influence present with the disease. ${ }^{24}$ In other words, parent quality of life appears to be associated with the effects of the child's disease on their daily functioning and emotional status, which in turn has an effect on the psychosocial adjustment of the child. This association is confirmed by the results of a Dutch study, indicating that caregivers with a better health-related quality of life (HROoL) rated their child's HROoL higher than caregivers with a poorer emotional status or HROoL themselves ( $p<.001$ and $p \leq .002$ ). Multiple regression analyses showed that caregiver HRQoL appears to be the best predictor of child HROoL and caregiver emotional status the best predictor of child FHS. Another finding was that caregiver HROoL modified the association between recurrent acute OM (RAOM) frequency and child FHS and caregiver emotional status modified between RAOM frequency and child HROoL as well $(p=.03) .{ }^{25}$ These findings favour the inclusion of parent quality of life in a measure primarily centred on the health status of the child, in this way reflecting the reciprocal OM impact on parent and child.

\section{Implications for research and clinical use}

The psychometric characteristics of the OM8-30 in a Dutch population have been confirmed as adequate to good. The result is a questionnaire that is sufficiently validated for the assessment of chronic OM impact on the psychosocial adjustment of the child, including multiple factors considered important for child development. It can be used as a tool to measure both the physical and wider developmental impact of OM on children, which may support treatment decisions by assessing the individual need and ability to benefit from ventilation tubes. OM is a common but fluctuating condition, and the decision to intervene by only 
considering disease aspects such as a conductive hearing loss of more than $25 \mathrm{~dB}$ present in the best ear for at least 3 months, as recommended by the clinical practice guidelines ${ }^{5,26}$, does seem to avoid over-medicalising the problems of the milder sufferers receiving the diagnosis. The risk of over-intervention, potentially harmful for the individual child, has to be set against the failure to intervene appropriately if consultation coincides with a short-term resolution in a fluctuating and recurrent history of $\mathrm{OM}$. The answer to both issues would be to conduct an assessment, which includes impact and also spans time. Most questionnaire responses inevitably average over time because of respondents' memory for the experiences that inform their responses, and the questionnaire instructions can extend or focus this to some extent. The child FHS also averages over time by using parental questioning. This can be further enhanced by repeated assessments if required, but relative to a measure of hearing or middle ear function which can change over a matter of days, the type of measurement with the OM830 makes a start towards the required stability.

Some limitations of the current research design need to be mentioned for a correct perspective on the results and guidance for future OM8-30 applications.

First, data for this convenience sample was collected in accordance with local routine medical practice. This implies that the sample contains children that already underwent surgery before questionnaire completion, besides the fact that there was a subgroup (also) suffering from URTI. From a methodological point of view, occurrence of treatment would certainly disrupt the association between reported impact and measures of ear or hearing status. However, the issues addressed in this study did not include treatment, but only the inter-relationships between the items that reflect OM impact.

Second, although this sample seems to contain 'high-risk' children suffering from persistent or recurrent $\mathrm{OM}$, needing to be identified for prolonged developmental impact ${ }^{6,27}$, generalisation of the present results should be done cautiously. The reason is that the seriousness of the disease impact present for the total sample is not well defined. This links to the question of what cut-off values on the defined scores can be used for selecting children that may benefit from intervention, an issue for further study with the OM8-30.

In future research it would be important to examine the influence of possible confounders related to the amount of chronic OM impact on the OM8-30 scores, such as hearing level, number and type of previous operations and the age of the child. For the developmental impact, the absolute scores must by definition improve with age. ${ }^{3,28}$ Age reduces the prevalence and results in the final resolution of OM, enhanced by the maturation of the child's immune system and, to a lesser extent, anatomical growth. As clinical samples are referred on the basis of having 
a problem, the age trend for physical health would be expected to be comparable to that in the general population. In order to avoid misunderstandings, it may be appropriate to present results stratified into cross-sectional age bands or with statistical control for age as covariate.

It is concluded that clinical assessment can be usefully supplemented by the OM8-30 in order to support informed treatment decisions in chronic OM. The OM8-30 has been developed to provide both a means for discounting biases in parental report as well as a reliable framework for clinical questioning. Future effort is therefore justified, to evaluate the clinical usefulness of the OM8-30 for a comprehensive and standardised chronic OM impact assessment.

\section{Acknowledgements}

Elaine Nicholls and Helen Spencer from the Multi-centre Otitis Media Study Group (MRC) at Cambridge (UK), are appreciated for their assistance in the preparation of this paper. 


\section{References}

1. Rosenfeld RM, Kay D. Natural history of untreated otitis media. The Laryngoscope. 2003;113:1645-1657.

2. Paradise JL, Feldman HM, Campbell TF, Dollaghan CA, Colborn DK, Bernard BS. Effect of early or delayed insertion of tympanostomy tubes for persistent otitis media on developmental outcomes at the age of three years. New England Journal of Medicine. 2001;344:1179-1187.

3. Rovers MM, Black N, Browning GG, Maw R, Zielhuis GA, Haggard MP. Grommets in otitis media with effusion: an individual patient data meta-analysis. Archives of Diseases in Children. 2005;90:480-485.

4. Van de Lisdonk EH, van Balen FAM, van Weert HCPM, Eekhof JAH, Appelman CLM, Eizenga WH. Dutch college of general practitioners-practice guideline Otitis media with effusion. Huisarts en Wetenschap. 2000;43:171-177.

5. Rosenfeld RM, Culpepper L, Doyle KJ, Grundfast KM, Hoberman A, Kenna MA. et al. Clinical practice guideline: Otitis media with effusion. Otolaryngology-Head \& Neck Surgery. 2004;130:S95S118.

6. Ruben RJ. Host Susceptibility to Sequelae. In: Rosenfeld, RM, Bluestone, CD, eds. Evidence-Based Otitis Media. $2^{\text {nd }}$ ed. Hamilton, Canada: BC Decker Inc. 2003:505-514.

7. Haggard MP, Smith SC, Nicholls EE. Quality of life and child behaviour. In: Rosenfeld RM, Bluestone CD, eds. Evidence-Based Otitis Media. $2^{\text {nd }}$ ed. Hamilton, Canada: BC Decker Inc. 2003:401429.

8. Anteunis UC, Engel JAM. Maastricht Otitis Media with Effusion Study (dissertation). Maastricht, the Netherlands: Maastricht University, 2000.

9. Morris PSL, Leach AJ. Is early surgical referral for children with persistent otitis media with effusion (OME) appropriate? Medical Journal of Australia. 2003;179:436-437.

10. Widenfelt van, BM, Goedhart AW, Treffers PDA, Goodman R. Dutch version of the Strengths and Difficulties Questionnaire (SDO). European Child \& Adolescent Psychiatry. 2003;12:281-289.

11. Haggard $M$, Nicholls E, Gregori $M$, Spencer $H$, Francois $M$, Pitkaranta A. et al. Internationally comparable measures of impact in children with OME-The Eurotitis project to standardise OM830. XVIII IFOS Congress: Rome; 25-30 June, 2005.

12. Haggard $M$, Spencer $H$, Gregori $M$. Internationally standardised clinical description: can it be achieved in ENT? ENT News. 2007;16:69-72.

13. Haggard $M$, Spencer $H$, Gregori $M$. Overcoming international differences for clinical comparisons and research. ENT News. 2007;16:68-71.

14. Muris P, Meesters C, van den Berg F. The Strengths and Difficulties Questionnaire (SDQ). Further evidence for its reliability and validity in a community sample of Dutch children and adolescents. European Child \& Adolescent Psychiatry. 2003;12:1-8.

15. Goodman R. The strengths and difficulties questionnaire: a research note. Journal of Child Psychology and Psychiatry. 1997;38:581-586.

16. Goodman R. Psychometric properties of the strengths and difficulties questionnaire. Journal of the American Academy of Child and Adolescent Psychiatry. 2001;40:1337-1345.

17. Klasen H, Woerner W, Wolke D, Meyer R, Overmeyer S, Kaschnitz W. et al. Comparing the German version of the Strengths and Difficulties Questionnaire (SDQ-Deu) and the Child Behaviour Checklist. European Child \& Adolescent Psychiatry. 2000;9:271-276.

18. Alho OP, Oja H, Koivu M, Sorri M. Chronic otitis media with effusion in infancy. How frequent is it? How does it develop? Archives of Otolaryngology-Head \& Neck Surgery. 1995;121:432-437. 


\section{OM8-30 questionnaire}

19. Kubba H, Pearson JP, Birchall JP. The aetiology of otitis media with effusion: a review. Clinical Otolaryngology. 2000;25:181-194.

20. West JV. Acute upper airway infections. British Medical Bulletin. 2002;61:215-230.

21. Bennet KE, Haggard MP. Accumulation of factors influencing children's middle ear disease: risk factor modelling on a large population cohort. Journal of Epidemiology and Community Health. 1998;52:786-793.

22. Brouwer CNM, Maille AR, Rovers MM, Grobbee DE, Sanders EAM, Schilder AGM. Health-related quality of life in children with otitis media. International Journal of Pediatric Otorhinolaryngology. 2005;69:1031-1041.

23. Timmerman AA, Anteunis $\amalg C$, Meesters CMG. The initial development of an instrument for the description of 'Otitis Media with Effusion Specific Behaviour' in young children. International Journal of Behavioural Medicine. 1999;6:255-267.

24. Eiser C, Morse R. Can parents rate their child's health-related quality of life? Results of a systematic review. Quality of Life Research. 2001;10:347-357.

25. Brouwer CNM. Health-related quality of life in children with recurrent acute otitis media (dissertation). Utrecht, the Netherlands: Utrecht University, 2003.

26. Boomsma $\sqcup$, Balen van, FAM, Rovers MM, Wiersma T, Goudswaard AN. Summary of the practice guideline 'Otitis media with effusion' (second revision) from the Dutch College of General Practitioners. Nederlands Tijdschrift voor Geneeskunde. 2006;150:2028-2032.

27. Rovers MM, Schilder AGM, Zielhuis GA, Rosenfeld RM. Otitis media. The Lancet. 2004;363:465473.

28. Engel JAM, Anteunis $\sqcup C$. Treatment with ventilation tubes in the Netherlands: incidence in children from birth to 12 years of age, 1990-1994. Nederlands Tijdschrift voor Geneeskunde. 1999;143:902-905. 



\section{The level of psychosocial adaptation in young school children with otitis media}

Angelique A. Timmerman Cor M.G. Meesters Lucien J.C. Anteunis Michelene N. Chenault 


\section{Abstract}

Objective: Assessment of the level of psychosocial adaptation in Dutch children with persistent and/or recurrent otitis media (OM) compared to a community sample. The goal of this study was to determine the presence of behavioural effects related to a history of hearing loss from recurrent or persistent $O M$.

Methods: Caregivers of 160 children, age range 4-7 years, suffering from either upper respiratory tract infections (URTI) and/or OM completed the generic Strengths and Difficulties Questionnaire (SDQ) and impact supplement before consulting the ENT-physician.

Results: In the ENT sample significant differences were found for the SDO subscales hyperactivity-inattention and emotional symptoms, besides the total difficulties score and impact rating, compared to the U.S. community sample ( $p s<.0005)$. Classification of severity for SDQ symptom scores, according to U.S. normative scoring bands, showed significant differences for SDQ total difficulties $(p=.0001)$, emotional symptoms $(p=.044)$, hyperactivity-inattention $(p=.000)$ and pro-social behaviour ( $p=.001$ ). This is expressed in a larger cumulative percentage of scores in the high difficulties (>90\% of scores) band for the SDO hyperactivityinattention, emotional symptoms and impact which show ranges of $21.9 \%$, $15.6 \%$ and $13.8 \%$, respectively.

Conclusions: The level of psychosocial adaptation seems to be compromised in the Dutch ENT sample for both internalising (emotional symptoms, less personal strengths) and externalising (hyperactivity-inattention) behaviour dimensions, which indirectly supports the cumulative effects of a disease history with chronic otitis media, resulting in poorer attention skills and fewer social interactions present. The classification of SDQ symptom severity, indicates that any behavioural effect of otitis media and resulting hearing loss is expected to be within the high difficulties band, which is asking for vigilance regarding possible developmental and educational sequelae during childhood. 


\section{Introduction}

The assessment of developmental sequelae in Ear, Nose and Throat (ENT) problems, such as chronic otitis media (OM), has been the subject of several studies ${ }^{1,2}$, especially in the field of language development., ${ }^{3,4}$ Although there is some evidence to suggest a link between chronic OM and language delay at 2-3 years, there are no lasting effects reported on language development in children older than 5 years of age. The natural decline in persistence and/or recurrence of OME as the child grows older, resulting in a less frequent intermittent hearing loss after 3 years of age, is probably an important explanation here., Any later developmental effects of persistent $O M$ in early childhood are hypothesized not to result from basic language delays, but from poorer attention to oral language. These developmental effects have been described by Vernon-Feagans ${ }^{6}$, stating 'that children with mild to moderate hearing losses have learned to 'tune out' language and attend to less auditory parts of the environment, avoiding situations with ambient noise or many children talking (p. 356-357)'. This is described in the 'Interactive Language and Attention model' in Figure 1.

Children with persistent $\mathrm{OM}$ in early childhood may have developed a coping strategy leading to less attention being paid to (oral) language in later school situations, where sustained attention is necessary to comprehend information. This may also alter the way parents respond to them, creating a pattern early in life that is less effective compared to healthy children, characterised by the presence of a less responsive environment, initiating less verbal interaction, and in addition also affecting psychosocial adaptation. ${ }^{7,8}$

The present study attempts to assess the value of this theoretical model by describing the level of psychosocial adaptation in children suffering from chronic $\mathrm{OM}$ at early school age by using the Strengths and Difficulties Questionnaire (SDO). It is hypothesized that children suffering from chronic OM show both more internalising (i.e., emotional symptoms and fewer social interactions) and externalising behaviours (i.e., poorer attention skills, easily distracted) compared to a community sample of children.

\section{Methods}

The clinical sample of this cross-sectional study included 160 Dutch children, 87 boys and 73 girls, with a mean age of 5.8 years $(S D=1.0$, range $4-7$ years) visiting the ENT-department of the University Hospital Maastricht, in the period between April 2004 and July 2005. The study was approved by the university hospital Medical Ethics Committee and after obtaining informed consent, caregivers 
completed the parent version of the SDQ prior to consulting the ENT physician. Only children with a disease history of persistent or recurrent middle ear disease and suffering from either upper respiratory tract infections (URTI) and/or chronic $\mathrm{OM}$ on the day of assessment were enrolled.

\section{PROCESSES}

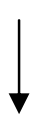

AGE

Risk/ Protective factors
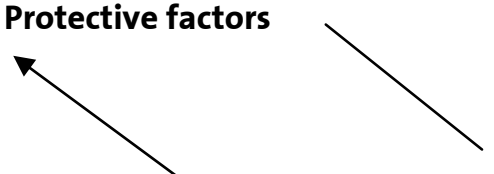

Otitis media

Birth

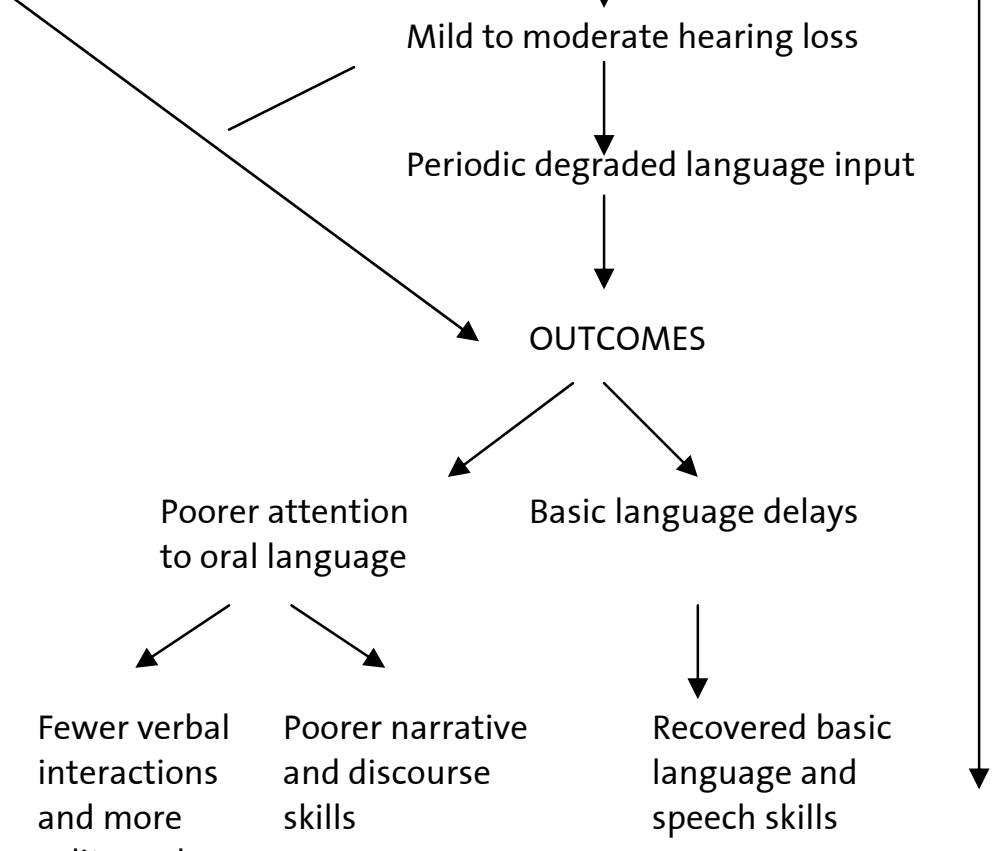

solitary play

7 years

Figure 1 The Interactive Language and Attention Model according to Vernon-Feagans ${ }^{6}$ 
This information was documented from the medical files in consultation with an ENT physician and audiologist. The average bilateral hearing level found was 20.0 $\mathrm{dB}(\mathrm{SD}=11.5 \mathrm{~dB}$, range 1.3-49.4 dB) measured by pure tone audiometry (frequencies $0.5,1,2$ and $4 \mathrm{KHz}$ ).

A community sample of U.S. children participating in the National Health Interview Survey (NHIS) conducted by the National Centre for Health Statistics, was used for comparison. The NHIS is an annual household survey with a nationally representative sample of the civilian population of the United States, in which a respondent in the household, usually a parent, is interviewed about the child's health. ${ }^{9}$ The SDO was included in the 2001 NHIS supplement and complete data were obtained for 2779 children (1458 boys and 1321 girls) in the age range of 4-7 years.

The SDQ is a brief screening measure, covering the most important range of psychopathological symptoms as an indicator of psychological adaptation in a general population of children and adolescents..$^{10}$ Very good to excellent psychometric qualities have been found for discrimination between and within community and clinical samples. ${ }^{11,12}$ The SDO is intended for children aged 3-16 years and in the present study the parent version was used. The questionnaire consists of 25 attributes, asking about behaviour in the past 6 months and responses are scored on a 3-point Likert scale (i.e., $0=$ not true, $1=$ somewhat true, $2=$ certainly true). These attributes are allocated to 5 subscales of 5 items each: (1) emotional symptoms, (2) conduct problems, (3) hyperactivity-inattention, (4) peer problems, and (5) pro-social behaviour (personal strengths). Except for the pro-social behaviour scale, positive items are coded reverse. For the total difficulties score to be calculated, the four symptom subscale scores reflecting difficulties are summed, with a score ranging from 0 to 40 .

The SDO also contains an impact supplement, assessing perceived impairment in the social functioning of the child. ${ }^{13}$ This section is only scored after the parent reports the child to have at least minor difficulties. The impact rating contains 5 items evaluating whether the difficulties: (1) distress or upset the child, (2) interfere with home life, friendships, classroom learning or leisure activities. The scoring format is somewhat different from the symptom items using a 4-point scoring format: $0=$ not at all, $0=$ only a little, $1=$ quite a lot, $2=$ a great deal.

For the evaluation of differences in behavioural difficulties between the ENT and community samples, the mean values of this last sample were used as test values in a one-sample $t$-test. In order to classify the severity of reported difficulties, it has been suggested that about $80 \%$ of the children are in the 'low difficulties band', the intermediate $10 \%$ in the 'medium difficulties' and the top $10 \%$ in the 'high difficulties' band. ${ }^{10}$ To test the hypothesis that our ENT sample 80 and 90 percentiles correspond with this classification, non-parametric chi-square tests 
were performed for each of the SDO scales, total difficulties score and impact rating in order to compare observed with expected values. Normative SDO scoring bands based on this classification have been developed for the U.S. community data already ${ }^{14}$ and were used for comparison. Cumulative frequency distributions were calculated to assess whether the clinical sample exhibited more serious difficulties and these were depicted in a bar-chart. All statistical analyses were performed using the Statistical Package for the Social Sciences (SPSS, version 11.5).

\section{Results}

In the ENT sample SDO emotional symptoms, hyperactivity-inattention, total difficulties score and impact rating were found to be significantly different from the community sample mean values $(p s<.0005)$, with the largest differences found for SDQ total difficulties (1.8) and hyperactivity-inattention (0.9), as shown in Table 1. The SDQ prosocial behaviour scale showed no significant differences, with mean values of 8.4 for the community sample versus 8.5 for the ENT sample, indicating the presence of comparable personal strengths for both groups of children. For SDQ conduct problems the scores were almost the same for the ENT and community samples (1.5 vs. 1.4), which was also found for SDQ peer problems (1.4 vs. 1.3).

Table 1 One way $t$-test comparing mean parent reported SDQ symptom scores in U.S. community $(N=2779)$ and Dutch ENT samples $(N=160)$

\begin{tabular}{lcc}
\hline Sample & Community & ENT $^{1}$ \\
\hline SDO scales & Mean (SD) & Mean (SD) \\
\hline Total difficulties & $7.4(5.3)$ & $9.2(5.9)^{*}$ \\
Emotional symptoms & $1.5(1.7)$ & $2.3(2.2)^{*}$ \\
Conduct problems & $1.4(1.6)$ & $1.5(1.5)$ \\
Hyperactivity-Inattention & $3.2(2.5)$ & $4.1(3.0)^{*}$ \\
Peer problems & $1.3(1.5)$ & $1.4(1.6)$ \\
Pro-social behaviour & $8.4(1.9)$ & $8.5(1.6)$ \\
Impact $^{1}$ & $0.2(1.0)$ & $9.6(1.4)^{*}$ \\
\hline
\end{tabular}

${ }^{1} N=159$; Significant difference at $p<.0005$.

The classification of SDO symptom severity is depicted in Table 2, with cumulative percentages specified for the ENT sample after the U.S. normative scoring ranges. The chi-square test revealed statistically significant outcomes for the SDQ total difficulties $(p=.0001)$, emotional symptoms $(p=.044)$, hyperactivityinattention $(p=.000)$ and prosocial behaviour $(p=.001)$. For peer problems, proso- 


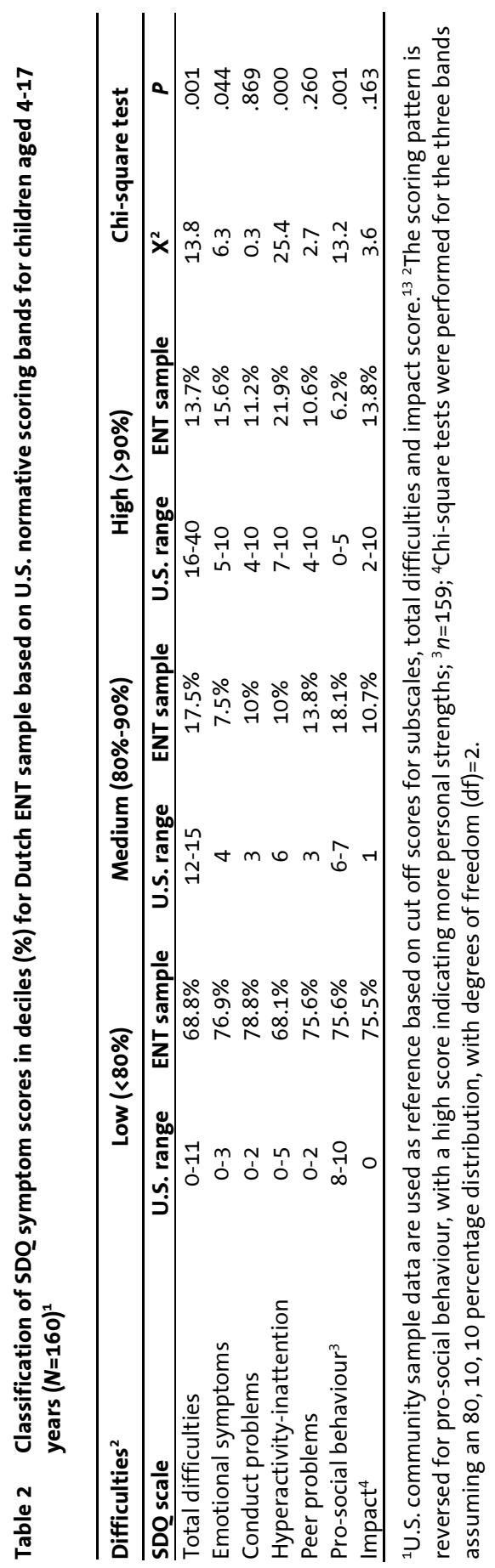




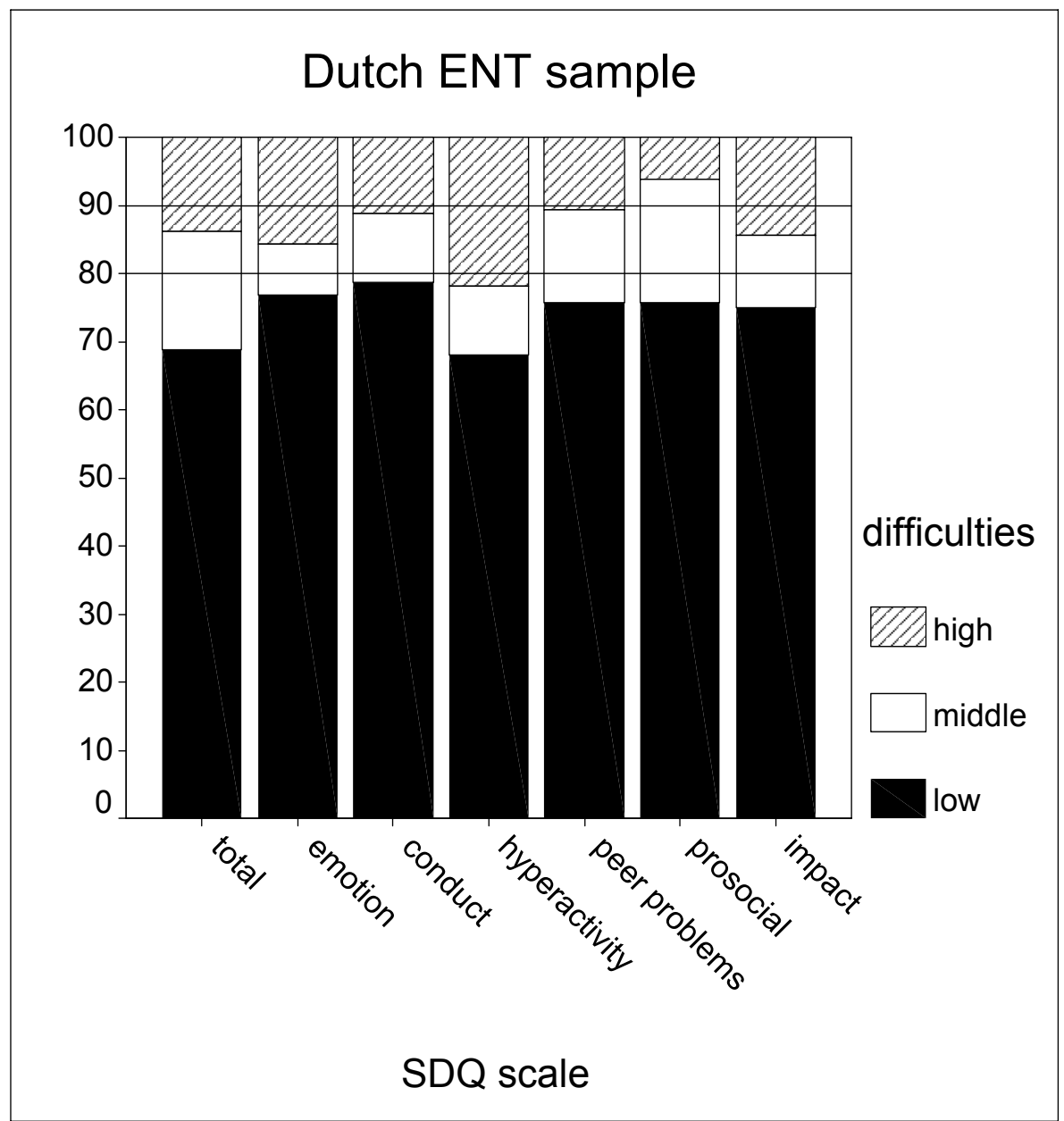

Figure 2 Cumulative percentages of SDO scores in Dutch ENT sample classified into low ( $<80 \%)$, medium (80\%-90\%) and high (> 90\%) difficulties using U.S. normative scoring bands ${ }^{14}$

cial behaviour and total difficulties, it is primarily a shift from the low to the medium difficulties band which was remarkable, compared with the U.S. scoring ranges. There was a higher proportion for SDO hyperactivity-inattention (21.9\%) in the high difficulties band, while emotional symptoms had a higher score in the high difficulties band (15.6\%) (see also Figure 2). In the low difficulties band, a smaller range has also been found for the total difficulties score (69\%) and hyperactivity-inattention (68.1\%) indicating that less than $70 \%$ of the observed values were below the expected $80 \%$ for these scales in the ENT sample. 


\section{Discussion}

The current findings support the hypothesis that more internalising and externalising behaviours may be present in children suffering from chronic OM, as a significant difference was found in emotional symptoms and hyperactivityinattention between the ENT and community samples. These results are in line with literature on the developmental impact of a history characterised by hearing difficulties.

First, in a prospective study, children suffering from chronic OM with a mean age of 7 years (range 4-11 years) were found to have the highest scores on items such as 'trouble with concentrating', 'unable to sit still', 'easily distracted' and 'does not listen to rules' before tympanostomy tubes surgery, all showing a significant improvement after intervention (57\%, 50\% and 27\%, respectively). Large improvements were also found for items such as 'complains of aches or pains' (43\%), 'feels sad, unhappy' (41\%), which may be indicative of internalising behaviour, but these items were scored much lower before surgery than the externalising behaviour items. ${ }^{15}$ An explanation for this finding may be that parents are less focused on internalising behaviours in children, as it probably attracts less attention or causes less trouble in the home or school environment. Second, in a longitudinal birth cohort study ${ }^{16}$ the largest association was found between parent reported hyperactive behaviour, neurotic behaviour and the presence of hearing difficulty in children at the age of 5 years, with the association still present at the age of 10 years for hyperactive behaviour.

Emotional symptoms and hyperactivity-inattention showed significant classifications of more than $15 \%$ and $20 \%$, respectively, in the highest difficulties band according to U.S. normative scoring ranges, expecting a maximum of $10 \%$, also supporting the study hypotheses (Figure 2). This was also true for pro-social behaviour with more than $18 \%$ of scores in the medium difficulties band, indicating that less compensating social skills may be present in the ENT sample. SDO total difficulties scores as well as peer problems also had a larger score range in the medium compared to the high difficulties band. This last finding may be an expression of the fact that $O M$ is a relatively mild condition and as Haggard et al. ${ }^{17}$ state: 'a scale designed to discriminate beyond the $90^{\text {th }}$ percentile is suboptimal because any behavioural effect of $O M$ is likely within the normal range, not in the psychiatric extreme (p. 385)'. This implies that the SDO, as a brief screening measure, has been able to assess these behavioural effects of hearing loss in this clinical sample.

However, it has to be mentioned that this is a first explorative, although promising study and that the cross-sectional nature of the present investigation precludes conclusions regarding cause-effect relationships. Another limitation is 
that no Dutch community data were collected during this study, which would probably have enhanced the comparability of the samples on cultural and demographic aspects.

The findings seem to deliver support for the Interactive Language and Attention Model $^{6}$ for children with a history of OM and concomitant hearing loss through the presence of more behaviours related to inattention and fewer social interactions. Another interesting fact is that the perceived impact of behavioural difficulties in the ENT sample is somewhat higher than expected by the U.S. community norms in the highest difficulties band. It may be an expression of the fact that the hearing loss measured in the ENT sample is mild to moderate and that only the cumulative effects of the disease history over time, which is present in a small subgroup of children suffering from chronic OM, can result in lasting developmental sequelae. ${ }^{18}$

The merit of the present study has been that the findings suggest a compromised psychosocial adaptation in the ENT-sample, which may be a reason for more vigilance regarding possible developmental and educational effects of chronic otitis media during childhood.

\section{Acknowledgements}

The authors are grateful to Prof. dr. L. Vernon-Feagans for her permission to use 'The Interactive Language and Attention Model' in this study. 


\section{Psychosocial adjustment in otitis media}

\section{References}

1. Higson J, Haggard M. Parent versus professional views of the developmental impact of a multifaceted condition at school age: Otitis media with effusion ('glue ear'). British Journal of Educational Psychology. 2005;75:623-643.

2. Timmerman AA, Anteunis L, Meesters CM. First psychometric evaluation of a disease-specific questionnaire for children's behavior related to otitis media with effusion. Psychological Reports. 2005;97:819-831.

3. Roberts J, Hunter L, Gravel J, Rosenfeld R, Berman S, Haggard M, et al. Otitis media, hearing loss an language learning: controversies and current research. Developmental and Behavioral Pediatrics. 2004;25:110-122.

4. Wallace IF, Gravel JS, Schwartz RG, Ruben RJ. Otitis media, communication style of primary caregivers and language skills of 2 year olds: A preliminary report. Developmental and Behavioral Pediatrics. 1996;17:27-35.

5. Rosenfeld RM, Kay D. Natural History of Untreated Otitis Media. Laryngoscope. 2003;113:16451657.

6. Vernon-Feagans L. Impact of otitis media on speech, language, cognition and behaviour. In: Rosenfeld RM, Bluestone CD, eds. Evidence-Based Otitis Media. BC Decker Inc.; Hamilton, Canada. 1999: 353-374.

7. Roberts JE, Burchinal MR, Medley LP, Zeisel SA, Mundy, Roush J, et al. Otitis media, hearing sensitivity and maternal responsiveness in relation to language during infancy. The Journal of Pediatrics. 1995;126:481-489.

8. Roberts JE, Burchinal MR, Zeisel SA, Neebe EC, Hooper SR, Roush J, et al.

Otitis media, the caregiving environment and language and cognitive outcomes at 2 years. Pediatrics. 1998;102:346-354.

9. Simpson GA, Bloom B, Cohen RA, Blumberg S, Bourdon KH. U.S. children with emotional and behavioral difficulties: data from the 2001, 2002, and 2003 National Health Interview Surveys, Hyattsville, USA: National Center for Health Statistics, 2005.

10. Goodman R. The Strengths and Difficulties Questionnaire: a research note, Journal of Child Psychology and Psychiatry. 1997;38:581-586.

11. Goodman R. Psychometric properties of the strengths and difficulties questionnaire. Journal of the American Academy of Child and Adolescent Psychiatry. 2001;40:1337-1345.

12. Klasen H, Woerner W, Wolke D, Meyer R, Overmeyer S, Kaschnitz W, et al. Comparing the German version of the Strengths and Difficulties Questionnaire (SDQ-Deu) and the Child Behavior Checklist. European Child \& Adolescent Psychiatry. 2000;9:271-276.

13. Goodman R. The extended version of the Strengths and Difficulties Questionnaire as a guide to child psychiatric caseness and consequent burden. Journal of Child Psychology and Psychiatry. 1999;40:791-799.

14. Bourdon KH, Goodman R, Rae DS, Simpson G, Koretz DS. The Strengths and Difficulties Questionnaire: U.S. normative data and psychometric properties. Journal of the American Academy of Child and Adolescent Psychiatry. 2005;44:557-564.

15. Issa A, Bellman $M$, Wright A. Short-term benefits of grommet insertion in children. Clinical Otolaryngology. 1999;24:19-23.

16. Bennett KE, Haggard MP. Behaviour and cognitive outcomes from middle ear disease. Archives of Diseases in Childhood. 1999;80:28-35.

17. Haggard MP, Smith SC. Impact of otitis media on child quality of life. In: Rosenfeld RM, Bluestone CD, eds. Evidence-Based Otitis Media. BC Decker Inc.; Hamilton, Canada. 1999,375-398. 
Chapter 7

18. Ruben RJ. Host susceptibility to sequelae. In: Rosenfeld RM, Bluestone CD, eds. Evidence-Based Otitis Media. BC Decker Inc.; Hamilton, Canada. 1999,505-514. 
General discussion 



\section{Introduction}

This thesis focused on the description of the impact of chronic OM and related conductive hearing loss during childhood, with the goal of identifying children at risk for compromised developmental outcomes on the long term. Chronic impact has been conceptualised as FHS, a multidimensional construct including symptoms, functional well-being, general health perceptions and overall OoL. ${ }^{1}$ It is often used synonymously with HROoL. ${ }^{2}$

The main findings of the thesis are presented first, followed by methodological issues and limitations related to the development and application of FHS questionnaires in chronic OM. Conclusions will be formulated together with recommendations for further questionnaire development and use in research and clinical practice.

\section{Main findings}

The greater part of this thesis has been directed at the development and psychometric validation of questionnaires for the assessment of chronic OM during childhood, due to the lack of appropriate questionnaires at the start of the thesis. The development of the 'Otitis Media with Effusion Specific Behaviour'3,4 (OMESBO) questionnaires delivered two questionnaires with 30 and 33 items, consisting of 4 and 6 domains for the ages 12-24 and 25-48 months, respectively. The domains of the OME-SBO are related to speech development, internalising and externalising behaviour and physical functioning (e.g., ear-related symptoms, hearing, sleep patterns). Construct validity, internal consistency and reproducibility were found to be ranging from reasonable to good. Sensitivity to change was insufficient for the behaviour domains in both age groups, which was also the case for items related to sleep and hearing in children aged 25-48 months (Chapters 3-4).

The OM8-30 questionnaire ${ }^{5}$ showed a factor analytic pattern for the Dutch ENT sample comparable to that in the original English version, consisting of 6 FHS facets assumed to be representative for children at school age (3-8 years) including items related to physical functioning (ear infections, hearing, respiratory symptoms), development (behaviour, speech and language, educational performance, parent quality of life) and global health. Relationships between both the OM8-30 behaviour facet, developmental sub-aggregate and SDO total score were high, confirming the construct validity of the OM8-30 (Chapter 6).

The ultra short-form questionnaire OM- $6^{6}$, containing 6 items (i.e., physical suffering, hearing loss, speech impairment, emotional distress, activity limitations, caregiver concerns) showed good reliability for all items. Prospective responsive- 
ness after tympanostomy tubes insertion was only large for the items caregiver concerns and hearing loss in a Dutch sample of infants aged 12-38 months. ${ }^{7}$ The significant difference found between the pre-test and retrospective pre-test at group level, indicates the presence of a response shift after surgery. This is reflected in the large retrospective responsiveness for all items after surgery and the significant difference for hearing loss and global ear-related QoL (Chapter 5).

The level of psychosocial adaptation at school age assessed with the SDQ seems to differ most between children from ENT and community samples with respect to hyperactivity-inattention and emotional symptoms. These results deliver indirect support for the Interactive Language and Attention Model $^{8}$ describing the cumulative effects of a history with chronic OM during early childhood in terms of problems with sustained attention (Chapter 7).

The closing of this thesis has been a systematic review of published questionnaires for the assessment of chronic OM impact during the last decade (19972007). Several questionnaires were developed that adequately describe the multiple aspects of FHS (OM8-30, OMO-22, OM-6), with promising psychometric qualities. The choice of the questionnaire is dependent on whether the purpose is discrimination between groups of patients or evaluation of treatment effects within patients. This process is complicated by the lack of information regarding psychometric qualities of most questionnaires, which need to be assessed an described in future studies (Chapter 2).

\section{Issues for discussion}

\section{Generic versus disease-specific}

For the assessment of the impact of chronic OM a disease-specific questionnaire seems preferable over a generic one, given the narrower range of outcomes tailored to the condition, allowing for shorter questionnaires which is an important requisite for use in routine care. Another advantage is that disease-specific measures are more sensitive to clinical important changes relevant to both patient and physician. ${ }^{9,10}$ However, HROoL in itself can be considered a generic concept determined by many intrinsic and extrinsic influences, as are behavioural manifestations. Several of the questionnaires used to assess chronic OM impact (OME-SBO, OM-6) are reflections of the coping ability of both caregiver and child with the effects of the disease. This contains a risk of not finding any or only small effects of chronic OM or treatment on the daily functioning of the child, which was the case for the developmental domains of both the OME-SBO and the OM-6 (Chapters 3-5). 
HROoL is usually measured by health profiles besides single indicators (e.g., visual analogue scales), which attempt to assess all important aspects related to this construct by the identification of domains effected by the disease or treatment in general. ${ }^{10,11}$ These profile measures require large sample sizes in the first stage of questionnaire development, one of the limitations in the development of the OME-SBO. During the process of item reduction, which has been already carried out satisfactorily for the OM8-30 questionnaire,12 (Chapter 6), it becomes important that those aspects of life involved in the 'OM illness experience' are represented. In this context, the term 'semigeneric measures' has been introduced..$^{13}$ It attempts to reconcile the need for HORoL or FHS assessment in chronic OM, complementing objective and highly specific measures of physical symptoms (i.e., ear infections, hearing loss).

\section{Discrimination versus responsiveness}

Another issue is that choosing the most appropriate questionnaire depends on the purpose and setting for application (Chapter 2). The identification of children at risk that need referral to secondary care is important for the general practitioner, but also for the ENT physician making a decision on the most appropriate clinical management for children with chronic OM. ${ }^{3}$ The chronic OM clinical guidelines for both primary and secondary care state that treatment is recommended in case of an adverse influence on the functioning and development of the child, combined with a bilateral chronic OM for at least 3 months and a hearing loss $>30 \mathrm{~dB} \cdot{ }^{14,15}$ Measurement properties of questionnaires for this goal require discriminating validity ${ }^{16}$ between children with often subtle differences in disease severity at one point in time, with a minimum of measurement error within the child. This is a difficult mission for two reasons. First, there are no clear indicators or cut-off points in the currently available questionnaires to decide what signifies that there is none, mild, moderate or severe impairment of daily functioning. In routine care the decision to intervene will be based on the disease history, influenced by caregiver preferences. ${ }^{17}$ This relates to the second point, as it is quite difficult to give a reliable estimate of whether both the presence of chronic OM and hearing loss are stable over time, given the often recurrent nature of the disease. The first issue cannot be easily solved as no classification norms are described for the currently available questionnaires for chronic OM impact (Chapter 2). Repeated administrations of a questionnaire over time may result not only in more reliable assessments, an important prerequisite for discriminative purposes, it takes also takes the effects of persistence and intermittent hearing loss into consideration. The OMO-22 ${ }^{18}$ and OM8-30 seem most appropriate for this purpose, given the adequate discriminating validity (Chapter 2). 
Questionnaires for the assessment of FHS in chronic OM can also serve the purpose of describing time-related changes which can be useful for the ENT physician, evaluating the effects of treatment. Responsiveness is a demand that relates to the ability of a questionnaire to detect changes over time, requiring multiple assessments. ${ }^{16}$ The ability to detect clinically important changes over time has been conceptualised as the effect size, which gives an indication of the presence of a small, moderate or large sensitivity to change. ${ }^{19}$ An example is the standardised response mean (SRM) used to evaluate the effects of surgery with the OM-6 (Chapter 5). It is therefore important that changes over time are related to chronic $\mathrm{OM}$ and not to other moderating factors. These factors can be divided into endogenous (e.g., season, allergy, respiratory symptoms) and exogenous (e.g., quality of day-care or home environment) which may moderate any possible effects of surgery on the daily functioning of the child. ${ }^{20,21}$ The risk factor approach has not been an explicit focus of this thesis. Only the age of the child, probably the most important moderating variable in terms of child development, has been accounted for in the development and application of age-specific questionnaires, such as the OME-SBO and OM8-30 (Chapters 3, 4 and 6). The OM-6 seems to be the most appropriate instrument for evaluating responsiveness to clinical change, due to its satisfying measurement properties and low administrative burden, in spite of the relatively wide age range (Chapter 2).

\section{Item selection and proxy report}

Chronic $O M$ is generally considered to be a mild condition which implies that the items for assessing FHS must represent both behaviours in the normal range and those that are readily observable to the caregiver. ${ }^{12}$ It has been shown that caregivers are more capable of judging the more concrete signs of physical functioning than aspects of emotional and social functioning. ${ }^{22}$ It may also be an expression of the fact that disease effects are strong at the level of symptoms, which is reflected in the high factor loadings of ear-related problems and reported hearing difficulty on the OM8-30 (Chapter 6). Proxy reports of more observable physical domains, but not on emotional domains, have been found to be more highly correlated with reports of patients, both in children and adults. ${ }^{10,23}$ This may be one possible explanation of the small sensitivity to change found on the developmental domains of the OME-SBO and OM-6 (Chapters 4-5).

These findings have implications for the assessment of FHS in chronic OM in several ways. Items have to be formulated in an indirect concrete manner (i.e., Do you have to repeat questions or has there been any ear discharge during the past 4 weeks?') instead of asking direct abstract questions (i.e., Has there been a change in your child's hearing after surgery?'). The presence of response shift bias 
in caregiver report seems to confirm that while assessing change it is difficult to remember how the situation was before surgery, as there is a significant difference between the scores on the pre-test and retrospective pre-test (Chapter 5). In young children proxy report is necessary to provide information on the daily functioning of the child, with the disadvantage that reports of chronic OM impact may be biased by the way the caregiver is affected. In chronic conditions caregivers tend to perceive an illness to have more negative consequences than the child itself, which may be caused by a bias toward a specific mindset, resulting in an overestimated perceived impact. 2,24 These findings are not only reflected in the large responsiveness to change for caregiver concerns and hearing loss on the OM-6 (Chapter 5). Another source of support is the greater parenting stress assessed in a recurrent OM group. The parents of the OM group also perceived their children as more demanding than those of the control group. ${ }^{25}$ It makes proxy report in itself important due to the dependent nature of the relationship between caregiver and child, which is reflected in domains such as attention seeking and separation anxiety on the OME-SBO (chapters 3-4). The caregiver can also deliver information about the impact on family functioning which is one of the constituting parts of child HROLL, that may buffer against any detrimental effects of chronic OM and hearing loss. The accuracy of proxy reports may be influenced by the emotional and practical burden chronic OM causes for the caregiver. Several FHS questionnaires for chronic OM assess this aspect, (i.e., OM survey, COIEO, OM8-30, OoL-tubes, OMO-22 and OM-6) (Chapter 2). It has been assessed that inappropriate behaviour which can be labelled as contextinsensitive behaviour (i.e., acting out, aggressiveness) was easier to observe for caregivers than context-sensitive behaviour (i.e., anxiety, sadness). ${ }^{24}$ (Mark P. Haggard, written communication, June 2007). Although caregiver concern has not been an explicit focus of this thesis, caregivers underestimated the seriousness of hearing loss and overestimated the quality of life of their child before surgery, which seems an expression of a change in the frame of reference of the caregiver (Chapter 5). Including items related to the practical burden for child and family (e.g., work or school days missed, the number of physician visits) in a FHS questionnaire, can give an objective counterbalance to subjective items such as caregiver QoL or concerns.

It is the caregiver who makes the decision to seek treatment resulting from the mental construct about chronic OM impact, which will also influences satisfaction with treatment. ${ }^{26}$ For an appropriate judgement of treatment effects it is necessary to know what concern is caused by the aspects related to chronic OM. Impact has been conceptualised as the result of a combined symptom frequency and concern rating. Higson ${ }^{27}$ found that reported high frequency for behaviour symptoms is rarely without high concern, while a broad range of concern has 
been assessed for the lower impact frequencies. The issue of parental concern has not been a focus of this thesis, yet it may complicate routine clinical care when not appropriately addressed. Different views of the importance attached to several symptoms related to chronic OM by caregiver and health professional may not only result in higher medical consumption, pressure to intervene, but also in a compromised HROoL for caregiver and child.

\section{Age and child development}

The age of the child suffering from chronic OM is important in the assessment of lasting developmental effects. Maturation of the immune system results in a decrease of the prevalence ratio with increasing age. ${ }^{28}$ Any lasting effects of chronic $\mathrm{OM}$ on child development are supposed to result from exposure in early childhood and is conceptualised as coping strategy of inattention to oral language during childhood, resulting in negative effects on complex speech processes and less social interactions. ${ }^{8}$ The striking difference for the SDO hyperactivity-inattention scale between community and ENT samples delivers indirect evidence for lasting developmental effects of chronic OM during childhood (Chapter 7). However, this finding needs to be interpreted cautiously as no longitudinal assessments have been made, which is a precondition for the assessment of any lasting effects in chronic $\mathrm{OM}$. The main reason for this is the potential interaction between the developmental age of the child and the severity and persistence of chronic $\mathrm{OM}^{2}$ Intrinsic qualities and developmental speed of the individual child can either buffer against or strengthen possible effects of chronic $\mathrm{OM}$ and concomitant hearing loss. For the evaluation of this potential interaction in future studies, it is necessary to develop norms for the general population regarding crucial developmental milestones (e.g., expressive and receptive speech, sustained attention) and relate them to children with a history of chronic $O M$ at different ages during childhood.

\section{Conclusions}

The conclusions can be summarised as follows:

- The assessment of FHS in chronic OM needs to include both physical aspects (related to ear infections and hearing loss) and developmental aspects, conceptualised as OM-related behaviour. These two aspects are reflected in the questionnaires (OME-SBO, OM-6, OM8-30) developed or translated and applied in this thesis. 
- Psychometric qualities of the questionnaires were overall satisfying, small sample sizes seem to limit finding the subtle changes related to a relatively mild condition such as chronic OM.

- Questionnaires for the assessment of FHS in chronic OM can serve both discriminative and evaluative purposes depending on the need for either discrimination between subjects during the diagnostic process or evaluating change. The OMO-22 and OM8-30 seem appropriate for the first purpose; the OM- 6 for the assessment of clinical change after surgery.

- Classification norms for the assessment of impact severity are not available for any FHS measure, which complicates comparisons between diagnostics groups and healthy children.

- The influence of proxy perception has been demonstrated in the presence of response shift bias after the sudden resolution of chronic OM, indicating an adaptation to the effects of chronic OM before surgery.

- Physical symptoms are more easy for caregivers to observe than OMrelated behaviour, as these are more directly related to the manifestation of the disease than developmental domains which only showed small changes after surgery.

- Caregiver concern has not been the focus of this thesis, although impact in chronic $\mathrm{OM}$ can be described as a combination of frequency and concern, influencing the decision to seek treatment.

- Developmental effects of chronic OM during later childhood have been related to less attention to oral language, which has been indirectly confirmed by comparison with a community sample.

- The interaction between the developmental age of the child and the persistence of chronic OM in terms of disease severity over time is important. This has been reflected in the development and application of agespecific questionnaires in this thesis.

\section{Recommendations for research and clinical practice}

Several recommendations can be made for further questionnaire development and application for the assessment of FHS in chronic OM. First, there is the need to balance psychometric qualities of the questionnaires with interpretability and fitness for purpose. In this respect it is important to develop short and easy to administer questionnaires for routine use in clinical practice. The questionnaires must cover disease-specific aspects related to chronic OM while also reflecting child developmental issues. There is a need for questionnaires covering several smaller age ranges during childhood, in order to balance brevity with both as- 
pects in a psychometrically sound manner. The nature of chronic OM asks for longitudinal studies assessing the persistence of the associated hearing loss during childhood before any definitive inferences about developmental effects can be made. Another issue is the evaluation of risk factors because adequate assessment and management can result in protecting the child against possible adverse developmental effects of chronic OM. An important task for future research is the development of population norms for the classification of disease effects on FHS in chronic OM, which enhances differentiation in disease impact. For clinical practice it is important to integrate FHS questionnaire use in routine care, for assessing the needs of the individual patient. It may be necessary to combine the assessment of FHS with psycho-educating the caregiver about chronic OM, for caregiver concerns to be identified. This may not only be important for shared decisions on clinical management, but also for caregiver sensitivity to possible detrimental effects of persistent hearing loss for the FHS of the child. 


\section{References}

1. Ferrans CE, Zerwic JJ, Wilbur JE, Larson JL. Conceptual model of health-related quality of life. Journal of Nursing Scholarship. 2005;37:336-342.

2. Haggard MP, Smith SC. Impact of otitis media on child quality of life. In: Rosenfeld RM, Bluestone CD, eds. Evidence-Based Otitis Media. BC Decker Inc.; Hamilton, Canada. 1999:375-398.

3. Timmerman AA, Anteunis LC, Meesters CMG. The initial development of an instrument for the description of 'Otitis Media with Effusion Specific Behavior' in young children. International Journal of Behavioral Medicine. 1999;6:255-267.

4. Timmerman AA, Anteunis LC, Meesters CMG. First psychometric evaluation of a disease-specific questionnaire for children's behavior related to otitis media with effusion. Psychological Reports. 2005;97:819-831.

5. Haggard $M$, Spencer $H$, Gregori $M$. Internationally standardised clinical description: can it be achieved in ENT? ENT News. 2007;16:69-72.

6. Rosenfeld RM, Goldsmith AJ, Tetlus L, Balzano A. Quality of life for children with otitis media. Archives of Otolaryngology-Head \& Neck Surgery. 1997; 123:1049-1054.

7. Timmerman AA, Anteunis LC, Meesters CMG. Response-shift bias and parent-reported quality of life in children with otitis media. Archives of Otolaryngology-Head \& Neck Surgery. 2003;129:987-991.

8. Vernon-Feagans L. Impact of otitis media on speech, language, cognition and behaviour. In: Rosenfeld RM, Bluestone CD, eds. Evidence-Based Otitis Media. BC Decker Inc.; Hamilton, Canada. 1999: 353-374.

9. Patrick DL, Deyo RA. Generic and disease-specific measures in assessing health status and quality of Life. Medical Care. 1989;27:S217-S232.

10. Guyatt GH, Feeny DH, Patrick DL. Measuring health-related quality of life. Annals of Internal Medicine. 1993;118:622-629.

11. Spieth LE, Harris CV. Assessment of health-related quality of life in children and adolescents: an integrative review. Journal of Pediatric Psychology. 1996;21:175-193.

12. Haggard MP, Smith SC, Nicholls EE. Quality of life and child behavior. In: Rosenfeld RM, Bluestone CD, eds. Evidence-Based Otitis Media. BC Decker Inc.; Hamilton, Canada. 2003:401-429.

13. Haggard MP, Smith SC \& MRC Multicentre Otitis Media Study Group. Measurement of the impact of otitis media: effects on health-related quality of life. Proceedings of the 7th International Symposium on Recent Advances in Otitis Media with Effusion; June 1-5, 1999; Ft. Lauderdale, Florida.

14. Rosenfeld RM, Culpepper L, Doyle KJ, Grundfast KM, Hoberman A, Kenna MA, et al. Clinical practice guideline: Otitis media with effusion. Otolaryngology-Head \& Neck Surgery. 2004;130:S95S118.

15. Boomsma $\sqcup$, van Balen FAM, Rovers MM, Wiersma T, Goudswaard AN. Summary of the practice guideline 'Otitis media with effusion' (second revision) from the Dutch College of General Practitioners. Nederlands Tijdschrift voor Geneeskunde. 2006;150:2028-2032.

16. Guyatt $\mathrm{GH}$, Kirshner B, Jaeschke R. Measuring health status: what are the necessary measurement properties? Journal of Clinical Epidemiology. 1992;45:1341-1345.

17. Rosenfeld RM. Amusing parents while nature cures otitis media with effusion. International Journal of Pediatric Otorhinolaryngology. 1998;43:189-192.

18. Richards M, Giannoni C. Quality-of-life outcomes after surgical intervention for otitis media. Archives of Otolaryngology-Head \& Neck Surgery. 2002;128:776-782. 
19. Juniper EF, Guyatt GH, Willan A, Griffith LE. Determining a minimal important change in a disease-specific quality of life questionnaire. Journal of Clinical Epidemiology. 1994;47:81-87.

20. Bennet KE, Haggard MP. Accumulation of factors influencing children's middle ear disease: risk factor modelling on a large population cohort. Journal of Epidemiology and Community Health. 1998;52:786-793.

21. Vernon-Feagans L, Miccio AW, Yont KM. Speech, language, pragmatics and attention. In: Rosenfeld RM, Bluestone CD, eds. Evidence-Based Otitis Media. BC Decker Inc.; Hamilton, Canada. 2003:360-382.

22. Brouwer CNM, Maille AR, Rovers MM, Grobbee DE, Sanders EAM, Schilder AGM. Health-related quality of life in children with otitis media. International Journal of Pediatric Otorhinolaryngology. 2005;69:1031-1041.

23. Matza LS, Swensen AR, Flood EM, Secnik K, Kline Leidy N. Assessment of health-related quality of life in children: a review of conceptual, methodological and regulatory issues. Value in health. 2004; 7:79-92.

24. Eiser C, Morse R. Can parents rate their child's health-related quality of life? Results of a systematic review. Quality of Life Research. 2001;10:347-357.

25. Forgays DK, Wasserman RC. Recurrent otitis media and parenting stress in mothers of two-yearold children. Journal of Developmental and Behavioral Pediatrics. 1992;13:321-325.

26. Haggard MP, Higson JM. What matters in the clinical presentation of otitis media with effusion? Differences between parental and professional perspectives. Proceedings of the $7^{\text {th }}$ International Symposium on Recent Advances in Otitis Media with Effusion; June, 1-5, 1999; Ft. Lauderdale, Florida.

27. Higson J, Haggard M. Parent versus professional views of the developmental impact of a multifaceted condition at school age: Otitis media with effusion ('glue ear'). British Journal of Educational Psychology. 2005;75:623-643.

28. Engel JAM, Anteunis UC. Treatment with ventilation tubes in the Netherlands: incidence in children from birth to 12 years of age, 1990-1994. Nederlands Tijdschrift voor Geneeskunde. 1999;143:902-905. 
Summary 



\section{Summary}

Otitis media (OM) is a highly prevalent childhood condition which is accompanied by middle ear effusion (MEE), in both acute and chronic episodes. In chronic $\mathrm{OM}$, the likelihood of spontaneous resolution depends on the type of OM present: chronic OM with unknown onset and duration shows the worst prognosis, implying that there is a subgroup of children not recovering, due to the persistent and recurrent nature of the disease. It has been hypothesized that persistent hearing loss caused by chronic OM may adversely affect child developmental outcomes. Research in this area over the past 30 years has resulted in considerable controversy, resulting in differing clinical management strategies over time. The most recent clinical practice guideline states that the nature of chronic OM asks for an 'individualised management', taking not only the degree and temporal pattern of the hearing loss into consideration but also the impact of the hearing loss on the daily functioning of the child. This information is usually delivered by caregiver questioning during clinical assessment. The main objective of this thesis has been to describe the impact of chronic $\mathrm{OM}$ and associated hearing loss during childhood, in order to support the identification of children at risk for adverse developmental outcomes. Questionnaires seem the most appropriate outcome measures for this goal, but need to be developed and validated before any systematic implementation takes place.

A literature search has been conducted (Chapter 2 ) to identify the currently available questionnaires and their psychometric properties as they have developed in the past 10 years. The questionnaires assessed chronic OM impact by describing the functional health status (FHS). From the 15 identified questionnaires the OM8-30, OMO-22 and OM- 6 most adequately reflect the multidimensional aspects FHS in children with chronic OM, covering physical symptoms, developmental impact and burden for family and child, besides Health Related Quality of Life (HROOL). All questionnaires are parent-completed and the targeted child age range exhibited a continuum between 0 and 18 years. The content validity, a prerequisite, was found to be adequate for 11 questionnaires. For the OM8-30 and the OMO-22 internal consistency and reproducibility have been evaluated as good, making them appropriate to discriminate disease impact severity in children with chronic OM. This may provide support for treatment decisions regarding surgical intervention. The OM- 6 demonstrates good responsiveness to clinical change, making the questionnaire appropriate for evaluating treatment effects over time. It must be kept in mind that the validation of questionnaires is an ongoing process. The necessity of psychometric qualities depends not only on in- 
tended purpose of the questionnaire, but has to be in balance with the practical burden and needed breadth of FHS assessment.

This thesis has been further directed toward the development and psychometric validation of several questionnaires for FHS of children suffering from chronic $\mathrm{OM}$, as there were no validated questionnaires available at the start. The developmental process has been described for the 'Otitis Media with Effusion Specific Behaviour questionnaire (OME-SBO) for both the age groups 12-24 and 25-48 months (Chapters 3 and 4). The factor analysis for a sample of 172 children, resulted in 30 items, 4 domains (perceptive speech, emotional distress, attentionseeking and ear-related symptoms) for the OME-SBO 12-24. For the OME-SBO 2548, 33 items and 6 domains (productive speech, emotional discomfort, oppositional behaviour, sleeping problems, separation anxiety and auditory responsivity) were found, using a sample of 121 children. The construct validity and internal consistency ranged from reasonable to good. The sensitivity to change, as described by the Standardised Response Mean (SRM), was small for most of the behaviour domains on both questionnaires, while it was moderate to large for the speech domains, ear-related symptoms and total scores. The findings indicate that the OME-SBO 12-24 and OME-SBO 25-48 need further validation on a larger sample of children, as it could be questioned whether responsiveness was sufficient, in spite of promising reliability aspects.

The validation of the ultra-short form OM- 6 questionnaire developed for children between 0-12 years was described for a Dutch ENT sample of 77 infants aged 1238 months (Chapter 5). The 6 items of the OM- 6 represent domains of FHS (physical suffering, hearing loss, speech impairment, emotional distress, activity limitations and caregiver concerns) combined with a visual analogue scale for the assessment of child global ear-related quality of life. Besides satisfactory internal consistency and test-retest reliability, the construct validity as determined by the correlation between the OM- 6 summary score and global ear-related quality of life scale, was reasonable. The significant difference between the prospective and retrospective pre-test showed that a response shift bias was occured after surgery, indicating that there had been a change in the caregiver's frame of reference, as result of the sudden resolution of chronic OM. At domain level there was an underestimation of the seriousness of hearing loss before surgery and an overestimation of global ear-related quality of life.

The OM8-30 questionnaire was filled out by parent of 246 Dutch children and was developed for children with ear or hearing problems related to chronic $\mathrm{OM}$ at school age (3-8 years). The factor analytic pattern was comparable for the English and Dutch ENT samples, consisting of 32 FHS items related to the facets ear problems, hearing loss, respiratory symptoms, speech impairment, educational per- 
formance, behaviour, parent quality of life and global health (Chapter 6). High factor loadings were only found for ear problems, hearing loss and speech development, indicating that aspects of educational and behavioural functioning may be less unitary and more difficult to report for caregivers. This distinction has been reflected in the factor analytic derivation of two sub-aggregates from the OM8-30 facets: physical health and developmental impact. The internal consistency was at least satisfactory for most OM8-30 facets, except for respiratory symptoms. The concurrent validity was assessed by the correlation pattern with the generic Strengths and Difficulties (SDO) questionnaire developed for describing psychosocial adjustment in children aged 4 to 16 years. The relationships between the OM8-30 behaviour dimension and SDO total difficulties score and between the developmental sub-aggregate and SDO total difficulties score were high, supporting the construct validity of the OM8-30. The correlations between the SDQ total difficulties score and OM8-30 parent quality of life showed a deterioration when more behaviour problems were present, reflecting a compromised psychosocial adjustment.

The SDO has been used for the assessment of differences in the presence of this construct in both Dutch ENT and U.S. community samples (Chapter 7). The goal here has been to assess the value of the Interactive Language and Attention Model hypothesizing that outcomes of chronic OM and mild to moderate hearing loss combined with periodic degraded language input result in poorer attention to oral language as a coping strategy in later school situations. Higher scores on SDO hyperactivity - inattention and SDO emotional symptoms were reported to be present in the ENT sample. Classification of Dutch ENT scores according to U.S. normative scoring bands showed that SDQ hyperactivity - inattention, SDO emotional symptoms and SDO pro-social behaviour received higher scores, representing more severe problems, when compared to a community sample. This is reflected by a larger percentage of scores in the high difficulties band (>90\% of the SDQ scores) for SDO hyperactivity - inattention and SDO emotional symptoms, while for SDQ pro-social behaviour this was true for the medium difficulties band (80\%-90\% of the SDQ scores) in the Dutch ENT sample. The findings provide support for the Interactive Language and Attention Model for a subgroup of children with a (cumulative) disease history of OM, through the presence of more behaviours related to inattention and less social interactions when compared to a community sample.

The main conclusions were described and several methodological issues were raised regarding the development, validation and application of questionnaires for the assessment of chronic OM impact (General discussion). The psychometric qualities were overall satisfying, small sample sizes seem to limit finding the 
subtle changes related to a condition such as $\mathrm{OM}$ with a mild to moderate hearing loss.

The use of a disease-specific questionnaire is necessary, although HROoL is a generic concept and a reflection of the coping ability of parent and child with disease effects. The introduction of semi-generic measures reconciles the need for HROoL or FHS assessment in chronic OM, complementing highly specific measures of physical symptoms. Both aspects are represented in the questionnaires (OME-SBO, OM-6, OM8-30) used. Choosing for the most appropriate questionnaire depends on the purpose and setting for application. First, the identification of children at risk for adverse consequences is important for both the general practitioner and ENT physician and requires a questionnaire with adequate discriminating validity at one point in time. This is complicated by the lack of currently available classification norms for questionnaires for chronic OM impact and the recurrent nature of the disease, limiting a reliable estimate of disease history. Repeated administrations of the same questionnaire may solve both issues and result in a more reliable estimate. Second, evaluating change over time can be very useful for an ENT-physician assessing the effects of treatment in terms of responsiveness. This requires multiple assessments and it is important that changes over time are related to chronic OM. Two kinds of moderating factors can be discerned: endogenous (e.g., allergy, season) or exogenous (e.g., quality of day-care or home environment).

The risk factor approach has not been a focus of this thesis, although the age of the child, has been taken into account by using age-specific questionnaires. This is probably the most important moderating variable in terms of child development. There is indirect evidence for lasting developmental effects of chronic OM during childhood, which has to be interpreted cautiously. No longitudinal assessments have been made, necessary for the determination of the interaction between developmental age and disease severity over time is important. Intrinsic qualities of the child can buffer against or strengthen the possible adverse effects of chronic OM.

The mild nature of chronic OM necessitates items that represent behaviours both in the normal range and readily observable for caregivers. This is complemented by the fact that disease effects are usually strong at the level of symptoms, not on social-emotional functioning. It implies that items have to be formulated in an indirect concrete manner assessing behaviours, instead of abstract direct questions requesting information about broad constructs (e.g., hearing). In young children proxy report is necessary, but may be biased through the personal condition of the caregiver, but also by the burden caused by chronic OM. The dependent nature of the relationship between child and caregiver makes proxy report important, including questionnaire items (e.g., number of physician visits) related 
to the practical burden caused for child and family, can give an objective counterbalance to subjective OoL items. It is also the caregiver who expresses symptoms, requests medical intervention and evaluates treatment effects. For the appropriate judgement of treatment satisfaction it is necessary to evaluate both symptom frequency and caregiver concern in future studies. The last aspect may not only compromise outcome evaluations, the functioning of both child and family, but also complicate routine medical care in terms of higher medical consumption.

Several recommendations for further questionnaire development and application related to FHS in chronic OM were closing this thesis, requesting mutual involvement between research and clinical practice. For research purposes it is important to develop questionnaires covering smaller age ranges. The nature of chronic $O M$ requests longitudinal studies assessing the persistence of associated hearing loss during childhood, before making inferences about any lasting developmental effects. Smaller age ranges support the need to balance adequate psychometric qualities with the usage of short and easy to administer questionnaires in clinical practice. The integration of questionnaire use in routine care may enhance an adequate response to the needs of the individual child with chronic OM. It is not possible without active involvement of the caregiver, who may be sensitive for possible detrimental effects of persistent hearing loss on FHS. Psycho-educating the parent about chronic OM may support the identification of risk factors related to this condition, as detection and early management may result in protecting the child from possible developmental effects. An important task for future research is the development of norms for the classification of disease effects related to development throughout childhood. Differentiation in disease impact then becomes easier between children, which enables 'the right child getting the right surgery' for the often small group of children suffering from chronic OM impact. 



\section{Samenvatting}





\section{Samenvatting}

Otitis media (OM) is een ziektebeeld met een hoge prevalentie gedurende de kindertijd dat gepaard gaat met middenoor effusie, aanwezig bij zowel acute als chronische episoden. In het geval van chronische $O M$, is het vermogen van spontaan herstel afhankelijk van het aanwezige type: chronische $O M$ van een onbekende duur laat de slechtste prognose zien, met tot gevolg dat er een kleine subgroep van kinderen is die niet herstelt, door de persisterende en intermitterende aard van de aandoening. Er wordt verondersteld, dat het persisterende gehoorverlies als een mogelijk gevolg van chronische OM kan leiden tot negatieve ontwikkelingsuitkomsten. Het onderzoek dat gedurende de afgelopen 30 jaar hieromtrent is verricht, laat tegenstrijdige uitkomsten zien, resulterend in verschillende behandelstrategieën de afgelopen decennia. De meest recente richtlijn geeft aan dat het nodig is om van een op het individu toegesneden klinische aanpak uit te gaan, gezien de aard van chronische OM. Dit betekent dat er niet alleen rekening moet worden gehouden met de mate en het tijdsverloop van het gehoorverlies, maar ook met het effect op het dagelijkse functioneren van het kind. Deze informatie wordt normaliter uitgevraagd bij ouders gedurende de anamnese. Het doel van deze dissertatie is om te komen tot een beschrijving van de gevolgen van chronische $\mathrm{OM}$ en het ermee gepaard gaande gehoorverlies gedurende de kindertijd, zodat het mogelijk wordt om kinderen die een risico lopen op negatieve ontwikkelingsuitkomsten vroegtijdig op te sporen. Vragenlijsten vormen voor dit doel meest passende uitkomstmaten, die voor enig systematisch gebruik ontwikkeld en gevalideerd dienen te worden.

Er werd een literatuuronderzoek verricht (Hoofdstuk 2) om vast te stellen welke vragenlijsten reeds ontwikkeld waren, zodat de psychometrische kwaliteiten geëvalueerd konden worden. De vragenlijsten stellen de gevolgen van chronische OM vast door het beschrijven van de effecten op het dagelijks leven van het kind, in de onderzoeksliteratuur gedefinieerd als functionele gezondheid status (FHS). Er werden 15 vragenlijsten gevonden, waarvan de OM8-30, OMO-22 and OM-6 de meervoudige dimensionaliteit van FHS het beste blijken te weerspiegelen voor kinderen met chronische OM. De volgende dimensies zijn vertegenwoordigd: lichamelijke symptomen, ontwikkelingseffecten, belasting voor kind en gezin, naast de gezondheidsgerelateerde kwaliteit van leven (HROOL). De vragenlijsten worden door de ouder ingevuld en het leeftijdscontinuüm is 0-18 jaar. De inhoudsvaliditeit werd voldoende bevonden voor 11 vragenlijsten, een basisvoorwaarde bij het kiezen van een vragenlijst. Voor de OM8-30 en de OMO-22 werden de interne consistentie en reproduceerbaarheid als goed beoordeeld, dit betekent dat de vragenlijsten geschikt zijn voor het discrimineren van de ernst van chroni- 
sche OM. Dit zou beslissingen ten aanzien van chirurgisch ingrijpen kunnen ondersteunen. De OM- 6 bleek het meest betrouwbaar voor het vaststellen van de klinische verandering, zodat het instrument gebruikt kan worden om de effecten van behandeling te evalueren. De validatie van vragenlijsten is echter een voortgaand proces en de eisen die worden gesteld aan de psychometrische kwaliteiten is niet alleen afhankelijk van het doel, maar dient ook te worden afgewogen naar de tijdsbelasting bij afname en de te meten FHS dimensies.

Het accent van deze dissertatie heeft gelegen op de ontwikkeling en psychometrische validatie van vragenlijsten die de FHS vaststellen bij kinderen met chronische $\mathrm{OM}$, aangezien er geen gevalideerde instrumenten beschikbaar waren. Het proces van ontwikkeling en validatie van de 'Otitis Media met Effusie Specifieke gedragsvragenlijst (OME-SBO) voor de leeftijd 12-24 en 25-48 maanden werd beschreven (Hoofdstukken 3 en 4). Een factor analyse met data van 172 kinderen, resulteerde in 30 items, verdeeld over 4 dimensies (waargenomen spraak, emotionele spanning, aandachtzoekend gedrag en oorgerelateerde symptomen) voor de OME-SBO 12-24. Voor de OME-SBO 25-48 met data van 121 kinderen, leidde dit tot 33 items, verdeeld over 6 dimensies (spraakproductie, emotioneel ongemak, opstandig gedrag, slaapproblemen, separatie angst en gehoor functie). De construct validiteit en interne consistentie varieerden van redelijk tot goed. De sensitiviteit voor verandering, beschreven door de gestandaardiseerde gemiddelde veranderingscore (SRM), was klein voor de meeste gedragsdimensies van beide vragenlijsten, terwijl een gemiddelde tot grote SRM werd gevonden voor de spraakgerelateerde dimensies, oorgerelateerde symptomen en de totaal scores. De bevindingen duiden erop, dat verdere validatie van de OME-SBO 12-24 and OME-SBO 25-48 bij een grotere steekproef nodig is, gezien de twijfelachtige sensitiviteit voor verandering, ondanks goede uitkomsten voor de betrouwbaarheidsmaten.

De validatie van de korte OM-6 vragenlijst, ontwikkeld voor kinderen tussen 0-12 jaar, werd beschreven voor een Nederlandse steekproef van 77 kinderen van een polikliniek KNO in de leeftijd 12-38 maanden (Chapter 5). De OM-6 bevat 6 items die dimensies van de FHS weerspiegelen (lichamelijke symptomen, gehoorverlies, spraakachterstand, emotionele spanning, beperkte activiteiten en ouderlijke bezorgdheid), aangevuld met een visuele analoge schaal om de kinderlijke globale oorgerelateerde kwaliteit van leven vast te stellen. Naast een bevredigende interne consistentie en test hertest betrouwbaarheid, werd een redelijke construct validiteit gevonden, vastgesteld door de correlatie tussen de OM- 6 totaalscore en de globale oorgerelateerde kwaliteit van leven. Het significante verschil dat werd gevonden tussen de prospectieve en retrospectieve voormeting duidde op de aanwezigheid van een response shift bias na de ingreep, indicatief voor een 
verandering in de perceptie van de ouder of verzorger, veroorzaakt door het plotseling opheffen van chronische OM. Er werd eveneens een onderschatting van de ernst van het gehoorverlies en een overschatting van de globale oorgerelateerde kwaliteit van leven, zoals ervaren voor de ingreep, gemeten na de operatie.

De OM8-30 vragenlijst werd afgenomen bij de ouders van 246 Nederlandse kinderen met oor- en gehoorgerelateerde symptomen gerelateerd aan chronische OM op de lagere schoolleeftijd (3-8 jaar). Het factor analytische patroon bleek vergelijkbaar voor de Nederlandse en Engelse KNO data, bestaand uit 32 FHS items, verdeeld over de dimensies oorproblemen, gehoorverlies, klachten van de luchtwegen, spraak en taal, schoolprestaties, gedrag, ouderlijke kwaliteit van leven en algehele gezondheid. Hoge factor ladingen werden alleen gerapporteerd voor oorproblemen, gehoorverlies en spraak en taal, dit kan betekenen dat dimensies zoals schoolprestaties en gedrag minder eenduidig en moeilijker te rapporteren zijn voor ouders. Dit onderscheid komt eveneens tot uitdrukking in twee domeinen, afgeleid uit een factor analyse, een samenvatting van de dimensies van de OM8-30: lichamelijke gezondheid en ontwikkelingseffecten. De interne consistentie was minimaal bevredigend voor alle OM8-30 dimensies, uitgezonderd klachten van de luchtwegen. De concurrente validiteit werd vastgesteld met behulp van de correlatie matrix met de generieke vragenlijst Sterke en Zwakke Eigenschappen (SDO), ontwikkeld om de psychosociale aanpassing te beschrijven bij kinderen van 4-16 jaar. De correlaties tussen de OM8-30 gedragsdimensie, SDQ totaal score en tussen het OM8-30 domein ontwikkelingseffecten en SDQ totaal score waren hoog, een uitkomst die de construct validiteit van de OM8-30 bevestigt. Er was een verslechtering zichtbaar in de OM8-30 dimensie ouderlijke kwaliteit van leven in relatie tot de SDO totaal score als er meer gedragsproblemen aanwezig bleken te zijn, een weerspiegeling van een verminderde psychosociale aanpassing bij het kind.

De SDO werd eveneens gebruikt voor de vaststelling van verschillen in dit construct tussen een Nederlandse KNO en een Amerikaanse populatie steekproef (Hoofdstuk 7). Het doel was om de waarde van het Interactieve Taal en Aandacht Model te toetsen, uitgaande van de hypothese dat de uitkomsten van chronische OM met mild tot matig gehoorverlies, gecombineerd met periodes van verminderde aanwezigheid van taal, resulteren in een verminderde aandacht voor gesproken taal in latere school situaties. Er werden hogere scores gevonden op de SDQ hyperactiviteit - inattentie en SDO emotionele symptomen in de Nederlandse steekproef. De classificatie van de scores van de Nederlandse KNO steekproef op basis van Amerikaanse populatie normen, liet zien dat de op de dimensies SDQ hyperactiviteit - inattentie, SDQ emotionele symptomen en SDQ pro-sociaal gedrag dimensies meer probleemgedrag aanwezig was. Dit komt tot uitdrukking door een hoger scoringspercentage in de categorie 'veel moeilijkheden' (> 90\% 
van de SDQ scores) voor SDQ hyperactiviteit - inattentie en SDQ emotionele symptomen, terwijl de hoogste score voor SDQ pro-sociaal gedrag werd gevonden in de categorie 'gemiddelde moeilijkheden' (80\%-90\% van de SDO scores). Deze bevindingen ondersteunen het Interactieve Taal en Aandacht Model, voor een groep kinderen met een (cumulatieve) ziektegeschiedenis van OM, door de aanwezigheid van meer aandachtproblemen en minder sociale interacties in de KNO steekproef.

De belangrijkste conclusies werden beschreven en enige methodologische kwesties uitgewerkt met betrekking tot de ontwikkeling, validatie en toepassing van vragenlijsten voor de gevolgen van chronische OM (Discussie). De psychometrische kwaliteiten bleken bevredigend, de kleine steekproeven vormden een beperking die het vinden van subtiele veranderingen bemoeilijkte, die juist passen bij een aandoening als $\mathrm{OM}$ met een mild gehoorverlies.

Het gebruik van een ziektespecifieke vragenlijst is nodig, ondanks het feit dat $\mathrm{HRO}$ oL een generiek concept is en de vaardigheden weerspiegelt bij ouder en kind om met de gevolgen van chronische OM te kunnen omgaan. De introductie van semi-generieke vragenlijsten vormt een oplossing, gezien de noodzaak om HROoL of FHS te meten, zodat het vaststellen van FHS in combinatie met specifieke constructen zoals lichamelijke symptomen, een completer beeld kan geven. Beide aspecten zijn vertegenwoordigd in de gebruikte vragenlijsten (OME-SBO, OM-6, OM8-30). De keuze voor de meest passende vragenlijst is afhankelijk van het doel en de toepassing. Ten eerste, het identificeren van kinderen met het grootste risico op negatieve ontwikkelingsuitkomsten is zowel voor de huisarts als de KNO-arts van belang en dit maakt een vragenlijst met goede discriminerende eigenschappen essentieel. De identificatie wordt bemoeilijkt door het ontbreken van classificatie normen, in combinatie met het intermitterende karakter van $\mathrm{OM}$, zodat de rapportage over de ziektegeschiedenis onbetrouwbaar kan zijn. Herhaalde metingen met een vragenlijst kan dit oplossen en leiden tot een betrouwbare rapportage. Verder kan het evalueren van verandering over een langere tijdsperiode zeer bruikbaar zijn voor een KNO-arts, die de effecten van een behandeling wil vaststellen. Dit vraagt om meerdere metingen en het is van belang, dat de gemeten veranderingen gerelateerd zijn aan chronische OM. Risico factoren kunnen zowel endogeen (bijv. allergie, seizoen) of exogeen (bijv. kwaliteit crèche of steunend gezinsklimaat) zijn. Het onderzoeken van mogelijk aanwezige risico factoren is niet het doel geweest van deze dissertatie, echter er is rekening gehouden met de leeftijd van het kind door het gebruik van leeftijdspecifieke vragenlijsten. Dit is waarschijnlijk de belangrijkste bron van bias, gezien de ontwikkeling van het kind. $\mathrm{Er}$ is indirect bewijs voor langdurige effecten van chronische OM op de ontwikkeling gedurende de kindertijd, hoewel deze bevin- 
dingen tentatief zijn. Er vonden geen longitudinale metingen plaats, noodzakelijk voor de vaststelling van de interactie tussen de ontwikkelingsleeftijd en ernst van de ziekte gedurende de kindertijd. Intrinsieke karakteristieken van het kind kunnen een buffer vormen of juist de mogelijke negatieve effecten van chronische OM versterken.

Het milde karakter van chronische OM maakt de aanwezigheid van gedragsitems noodzakelijk in de normale range die gemakkelijk observeerbaar zijn. Tevens blijken de effecten van de aandoening het meest op de voorgrond te treden op symptoomniveau, niet in het sociaal-emotionele functioneren. Items dienen te worden geformuleerd op een indirecte concrete wijze, zodat gedrag wordt gemeten, in plaats van abstracte directe vragen over brede constructen (bijv. gehoor). Bij jonge kinderen is ouderrapportage noodzakelijk, die vertekend kan zijn door de persoonlijke toestand van de ouder, maar ook door de belasting die chronische OM kan vormen. De afhankelijkheid die de relatie tussen ouder en kind kenmerkt maakt ouderrapportage van belang, echter het toevoegen van items (bijv. aantal doktersbezoeken) gerelateerd aan de praktische belasting voor kind en gezin, kan een objectief tegenwicht vormen ten aanzien van de subjectieve OoL items. Het is namelijk de ouder, die symptomen naar voren brengt, verzoekt om medische interventie en die de effecten van behandeling evalueert. Voor een adequate vaststelling van de tevredenheid over een behandeling is het nodig om zowel de frequentie van symptomen, als ook de ouderlijke bezorgdheid in kaart te brengen in toekomstige studies. Niet alleen vanwege de invloed op behandelevaluaties, het functioneren van kind en gezin, maar ook door het risico op een hogere medische consumptie.

Enige aanbevelingen voor verdere ontwikkeling en toepassing van vragenlijsten voor FHS bij chronische OM, vormden de afsluiting van deze dissertatie. Dit impliceert een nauwe wisselwerking tussen onderzoek en klinische praktijk. Een belangrijk doel voor onderzoek is het ontwikkelen van vragenlijsten die kleinere leeftijdscategorieën representeren. De reden hiervoor is, dat gezien de aard van chronische OM longitudinale studies noodzakelijk zijn, die het persisterende karakter van het ermee gepaard gaande gehoorverlies vaststellen, alvorens gevolgtrekkingen mogelijk zijn omtrent langdurige ontwikkelingseffecten. Het gebruik van kleinere leeftijdscategorieën betekent dat het mogelijk is om kortere vragenlijsten te ontwikkelen die goede psychometrische kwaliteiten combineren met gebruikersvriendelijkheid. Het integreren van vragenlijsten in de klinische praktijk zou het vaststellen individuele noden voor kinderen met chronische OM kunnen bevorderen. Dit zal niet mogelijk zijn zonder actieve betrokkenheid van de ouder, die wordt verondersteld sensitief te zijn voor mogelijke negatieve effecten van persisterend gehoorverlies op de FHS. Het aanbieden van informatie over 
chronische OM zou de identificatie kunnen bevorderen van risicofactoren, zodat vroegtijdige opsporing het kind tegen negatieve ontwikkelingseffecten zou kunnen beschermen. Een belangrijke taak voor toekomstig onderzoek is gelegen in de ontwikkeling van classificatie normen voor gevolgen van chronische OM gedurende de kindertijd. Naar verwachting wordt het op deze wijze gemakkelijker om te differentiëren tussen in de kleine groep kinderen met blijvende gevolgen, zodat 'het juiste kind de juiste operatie krijgt'. 
Dankwoord 

Het is nu eind augustus 2007, bijna 14 jaar na de eerste kennismaking met otitis media tijdens mijn studie gezondheidswetenschappen in 1993 en 10 jaar na de start van mijn promotie onderzoek in 1997. Hoewel steeds 'een rode draad' in mijn leven, heb ik ondertussen ook veel andere bezigheden gehad zoals het therapeutische werk. Ergens dringt het nog niet helemaal door dat met het schrijven van dit dankwoord mijn dissertatie echt bijna af is en ik afscheid ga nemen van het Audiologisch Centrum (azM) als werkplek. Ik ben dankbaar voor de kans die ik heb gekregen om dit onderzoek op te zetten als jonge, nog 'groene' student.

Dr. Cor Meesters, universitair docent bij de vakgroep Medische, Klinische en Experimentele Psychologie, is als eerste op mijn pad gekomen eind 1993. Tijdens een onderwijsgroep van het blok kinder en jeugdpsychopathologie kwam de vraag of iemand interesse zou hebben in een onderzoeksstage, gericht op het ontwikkelen van gedragsvragenlijsten voor het vaststellen van de gevolgen van otitis media (wat is dat, moet ik destijds hebben gedacht). Na enige gesprekken maak ik kennis met dr. Lucien Anteunis, klinisch fysicus-audioloog en momenteel hoofd van het Audiologisch Centrum, om de opzet van het onderzoek te bespreken. In februari 1995 is er het eerste resultaat van onze vruchtbare samenwerking geweest, een jaarwerkstuk getiteld: 'Het verband tussen otitis media met effusie en gedrag bij kinderen'. Vervolgens kan het echte afstudeeronderzoek van start gaan: (1) het ontwikkelen van twee vragenlijsten voor kinderen in de leeftijd 1224 en 24-36 maanden, (2) data verzameling bij ouders van kinderen met chronische otitis media op de polikliniek van de afdeling KNO en op het therapeutisch dagcentrum van het azM, waar trommelvliesbuisjes worden geplaatst. Toen ben ik geconfronteerd met een van de moeilijkste facetten van wetenschappelijk onderzoek: het verzamelen van data, mijn eerste oefening in geduld! Door een beleidsverandering in het ziekenhuis werden er minder kinderen geopereerd dan verwacht, zodat ik na 1,5 jaar moet afstuderen met $n=9$. Niet getreurd, in augustus 1997 werd ik doctorandus in de gezondheidswetenschappen met de volgende afstudeerscriptie: 'Otitis Media met effusie en gedrag: is er een verband? Een pilot: de ontwikkeling van een meetinstrument voor 'OME specifiek gedrag' bij kinderen van 12-36 maanden'. Hoe nu verder? Voor mezelf stel ik vast dat het onderzoek 'een soort kind' is geworden en dat ik er best verder mee zou willen gaan in het kader van een promotietraject. Er komt een parttime aanstelling bij de Stichting KNO vanaf oktober 1997. In die periode komt professor Hans Manni, hoogleraar van de afdeling KNO, voor het eerst in beeld. Al de volgende jaren heeft hij mijn vorderingen gevolgd, af en toe zie ik zijn hoofd om de hoek van de deur om belangstellend te vragen hoe de voortgang is. En, niet te vergeten de keren dat we naar elkaar zwaaien als professor Manni, net iets eerder naar huis gaat, als de afdeling al lang verlaten is! Een aantal kamerverhuizingen verder, worden er twee publicaties 'geboren' over de ontwikkelde vragenlijsten in 1999 en 2005! De 
samenwerking met Lucien Anteunis en Cor Meesters verloopt steeds prettig en leidt tot overleg met veel leuke en vaak ook humoristische wetenschappelijke discussies. Er volgt nog een publicatie in 2003 als Lucien Anteunis met een volgend nieuw idee komt om de OM- 6 vragenlijst van professor Richard Rosenfeld uit de USA te vertalen en te valideren voor het Nederlandstalige gebied.

$\mathrm{Na} 7$ jaar promotieonderzoek komt in 2004 mijn eerste serieuze dip, ik merk dat mijn geduld begint op te raken, zal vast ook met mijn hoge ambitieniveau te maken hebben. Mijn aanstelling wordt tijdelijk van 1 naar 2 dagen uitgebreid tot de afronding van mijn proefschrift. In die periode komen we in contact met professor Mark Haggard, uit Cambridge (UK), een gerenommeerd onderzoeker op het gebied van de gevolgen van chronische otitis media, via zijn nieuw ontwikkelde vragenlijst uit de TARGET trial, de OM8-30. Na consultatie met Mark Haggard (hij wil graag worden aangesproken met 'Mark') wordt besloten om deze vragenlijst eveneens te vertalen en te valideren. Dit zou betekenen dat er nog een aanvullend gevalideerd meetinstrument beschikbaar komt om de effecten van chronische otitis media op het dagelijkse functioneren van kinderen te meten. De OM-6 is namelijk zeer kort en bondig en het valideren van de door mij ontwikkelde gedragsvragenlijsten zou een veel langer onderzoekstraject gaan vergen. Zoals Lucien Anteunis stelt: 'we zijn door een Engelsman van rechts ingehaald...'. Er volgt een jarenlange samenwerking met Mark Haggard per e-mail en ik ontdek hoe communiceren via dit medium tot veel verwarring kan leiden. Aangezien je niet direct kunt navragen wat de ander bedoelt als je iets niet begrijpt, schep je een eigen denkkader, iets dat me vaak is overkomen, zodat het moeilijk is geweest om optimaal van zijn enorme deskundigheid en ervaring op dit onderzoeksgebied te profiteren. Mijn Engelse woordenschat verrijkt zich echter flink en ik leer me steeds vlotter in die taal uitdrukken, moet ik zeggen. In 2004 wordt een dataverzameling opgestart in samenwerking met Maruja Retana, aangesteld als onderzoeksassistente binnen de Stichting KNO. Haar enthousiaste aanpak leidt tot een aanzienlijke dataset, echter dan volgen de statistische analyses. Ik ben blij dat ik ondertussen een goed contact heb gekregen met drs. Mickey Chenault, statistisch analiste, zij staat me vasthoudend met 'raad en daad' terzijde. Dit geldt overigens ook voor mijn toenmalige kamergenote Annemie van der Heijden, maatschappelijk werkster van het Audiologisch Centrum die altijd belangstellend is. Ik besluit een eerste versie te schrijven van mijn vierde artikel over de OM8-30 en de kruisvalidatie met de Strengths and Difficulties Questionnaire (SDQ). Veel revisies verder volgt mijn tweede serieuze dip in de zomer van 2006, want ik merk hoe moeilijk ik het vind om binnen de soms ogenschijnlijk tegenstrijdige feedback van mijn begeleiders en Mark Haggard mijn eigen koers vast te houden. Ik ga twijfelen aan mijn onderzoeksvaardigheden en mijn schrijverspotentieel, maar vind toch dat ik zoveel jaar werk niet kan loslaten, dat zou pas 'een kater' betekenen. 
Hoe belangrijk deze leerervaring voor mij is, wordt pas duidelijk als ik eind 2006 in contact kom met een collega onderzoeker, dr. Renée Speyer, spraak en taalpathologe bij het Audiologisch Centrum. Zij heeft mij geholpen bij het zoeken van referenties voor een overzichtsartikel over ontwikkelde en gevalideerde vragenlijsten binnen dit onderzoeksgebied. Bij het vinden van bijna 1400 referenties, 'zakt mij de moed in de schoenen'. Ik bemerk bij Renée Speyer echter een rotsvast vertrouwen in mijn potentieel als zelfstandig wetenschappelijk onderzoeker. Het lukt me dan om binnen enige maanden dit artikel te schrijven, ik realiseer me opnieuw dat mijn promotie geen uitdaging meer is, maar me toenemend remt in mijn ontwikkeling. Het noodzaakt me om het proefschrift af te ronden als ik een baan tegenkom, waar ik op wil solliciteren.

Van april 2007 tot juli 2007 volgt er een periode waarin mijn leven alleen bestaat uit promoveren en lukt het me om mijn proefschrift volledig af te ronden en de laatste 3 van de 6 artikels naar een wetenschappelijk tijdschrift te sturen. (Dan merk ik hoe het is om je ergens volledig 'in te begraven', je wordt er wat wereldvreemd van...). Ik ben in die maanden erg blij geweest met de snelle feedback en correcties van mijn begeleiders Lucien Anteunis, Cor Meesters en professor Manni, zodat het mogelijk blijkt om door te werken naar de 'eindstreep'. Wat doet het schrijven van een proefschrift een appèl op je frustratietolerantie, zeg. Mijn partner Martijn is in die tijd mijn 'rots in de branding' geweest, zijn enorme begrip, incasseringsvermogen en steun, naast zijn hulp bij de lay-out van de vragenlijsten, maken me duidelijk hoe belangrijk hij voor me is!

Dan is er opeens de leegte... Het is toch een beetje rouwen, na al die jaren otitis media en samenwerking. We hebben het dan toch gered met elkaar, het proefschrift: 'How to describe the functional health status of children with otitis media' is er! Cor, bij jou heb ik vaak gedacht aan je aanstekelijke humor en je passie voor het onderzoek met kinderen. Lucien, ik heb veel gehad aan je scherpe inzichten, die mij weer op het juiste spoor konden zetten, ik waardeer je creatieve ideeën en gevleugelde uitspraken over de rol van ouders bij otitis media (...'zij komen met een klacht, niet het kind'...). Hans Manni, ik heb het gewaardeerd dat je me steeds je vertrouwen hebt gegeven, ook al blijf ik mogelijk 'een wat vreemde eend in de KNO bijt' ('je' zeggen blijft moeilijk, getuigt van mijn respect...).

Graag wil ik iedereen die 'betrokken' is geweest bij dit onderzoek bedanken en om niemand te vergeten, heb ik besloten om iedereen die ik dankbaar ben uit te nodigen tijdens de verdediging begin 2008 , om deze mijlpaal met mij en de paranimfen Ingrid Lendfers en Sharmila Rambaran, te vieren! 

Publications 


\section{Papers}

Timmerman AA, Anteunis LC, Meesters CMG. The initial development of an instrument for the description of 'Otitis Media with Effusion Specific Behavior' in young children. International Journal of Behavioral Medicine. 1999;6:255-267.

Joore MA, Potjewijd J, Timmerman AA, Anteunis UC. Response shift in the measurement of quality of life in hearing impaired adults after hearing aid fitting. Quality of Life Research. 2002;11:299-307.

Timmerman AA, Anteunis UC, Meesters CMG. Response-shift bias and parentreported quality of life in children with otitis media. Archives of OtolaryngologyHead and Neck Surgery. 2003;129:987-991.

Timmerman AA, Anteunis LC, Meesters CMG. Kwaliteit van leven bij kinderen met otitis media: de waarde van ouderrapportage bij diagnostiek en behandeling. Stem-, Spraak- en Taalpathologie. 2004:12:273-284.

Timmerman AA, Anteunis LC, Meesters CMG. First psychometric evaluation of a questionnaire for 'otitis media with effusion specific behavior in young children'. Psychological Reports. 2005;97:819-831.

Timmerman AA, Meesters CMG, Speyer R, Anteunis, UC. Psychometric qualities of questionnaires for the assessment of otitis media impact. Clinical Otolaryngology. 2007;32:1-11.

Timmerman AA, Meesters CMG, Anteunis LC, Chenault, MN. The level of psychosocial adaptation in young school children with otitis media. International Journal of Pediatric Otorhinolaryngology. 2007; in press.

\section{Abstracts}

Riley LCM, Timmerman AA, Meesters CMG, Anteunis UC. Gezocht: 'Otitis media met effusie-specifiek gedrag'. Nederlands Tijdschrift voor Keel-, Neus- en Oorheelkunde. 1997;3:173.

Riley LCM, Timmerman AA, Meesters CMG, Anteunis UC. Specifiek gedrag bij otitis media met effusie. Nederlands Tijdschrift voor Geneeskunde. 1998;142: 614-615. 


\section{Publications}

Timmerman AA, Anteunis LC, Meesters CMG. Parent reported otitis media with effusion-related behavior in children 12-36 months of age: development of an instrument. Proceedings of the Third Extraordinaty Symposium on Recent Advances in Otitis Media; June 1-5, 1997; Copenhagen, Denmark, Kugler.

Timmerman AA, Meesters CMG, Anteunis LC. Kwaliteit van leven bij kinderen met otitis media met effusie: validiteit van een meetinstrument. Nederlands Tijdschrift voor Geneeskunde. 2001;145:1095.

Timmerman AA, Anteunis UC, Meesters CMG. Quality of life in children with OME: validity of a survey. $4^{\text {th }}$ Extraordinary International Symposium on Recent Advances in Otitis Media; April 16-20, 2001; Sendai, Japan, Monduzzi.

Timmerman AA. Quality of life in Children with OME: Validity of a survey and the presence of response shift bias. $8^{\text {th }}$ International Congress of Paediatric Otorhinolaryngology (ESPO); September 11-14, 2002; Oxford, UK, BAPO.

Timmerman AA. Kwaliteit van leven bij kinderen met OME: onderzoek naar de validiteit van de OM- 6 en de aanwezigheid van response shift bias. Year conference of the Dutch association for Voice, Speech and Language Pathology; March 13, 2004; Rotterdam, the Netherlands.

Timmerman AA, Anteunis LC, Meesters CMG. The interrelationships between developmental risk factors, hearing levels and parental report in otitis media - $\mathrm{A}$ preliminary study with the OM8-30 questionnaire. $5^{\text {th }}$ Extraordinary International Symposium on Recent Advances in Otitis Media; April 24-27, 2005; Amsterdam, the Netherlands. 



\section{Questionnaires}

Paper versions of the Dutch questionnaires developed and/or validated in this thesis may be downloaded and subsequently photocopied without any charge by individuals or non-profit organisations from:

Questionnaire for 'OME Specific Behaviour' (OME-SBO 12-24):

http://www.azm.nl/5008/11862/5021/Vragenlijst_OME-specifiek_g1.pdf

Questionnaire for 'OME Specific Behaviour' (OME-SBQ 25-48):

http://www.azm.nl/5008/11862/5021/Vragenlijst_OME-specifiek_g2.pdf

OM6-I questionnaire:

http://www.azm.nl/5008/11862/5021/OM6-I.pdf

OM6-II-R questionnaire :

http://www.azm.nl/5008/11862/5021/OM6-IIR.pdf

OM8-30 questionnaire:

http://www.azm.nl/5008/11862/5021/Vragenlijst_kind_vocht_acht1.pdf

SDQ:

http://www.sdqinfo.com/d7.html 



\section{Curriculum vitae}

Angelique Timmerman was born on July $22^{\text {nd }} 1970$ in Maastricht, the Netherlands. In 1990 she graduated from secondary school (VWO) and started her study at the faculty of Health Sciences of the University of Limburg, followed by a specialisation in Mental Health in 1992. From March 1995 to April 1996 she conducted her research internship at the Ear, Nose and Throat (ENT) department of the University hospital Maastricht developing two behavioural questionnaires described in this thesis. After obtaining her master degree in September 1997 she continued the research that is described in this thesis (supervised by Prof. dr. J.J. Manni, dr. L.J.C. Anteunis and dr. C.M.G. Meesters) and worked parttime as a psychologist in a mental health institution. September 1998 she started her training to become a psychotherapist, which resulted in BIG registration in September 2002, followed by BIG registration as health psychologist in March 2003. In October 2004 she started her own practice treating individual clients, couples and families with mental health problems. From August 2005 she has been registered by the Dutch association for client-centred therapy (VCgP) as a client-centred therapist and in August 2006 by the Dutch association for marital and family therapy (NVRG) as a family therapist. The research carried out for this thesis was finished in July 2007 , followed by several publications of the chapters in the autumn of that year. 


\section{Sponsors}

The publication of this thesis has been financially supported by the following sponsors:

- Assurantiekantoor Bemelmans

- Beltone Netherlands B.V.

- Cochlear Benelux

- Der Kinderen Verzekeringen B.V.

- EMiD audiologische apparatuur

- GN Resound B.V.

- Schoonenberg Hoorcomfort

- Streukens Hooroplossingen B.V.

- TauRaConsult B.V.

- Veenhuis Medical Audio B.V. 